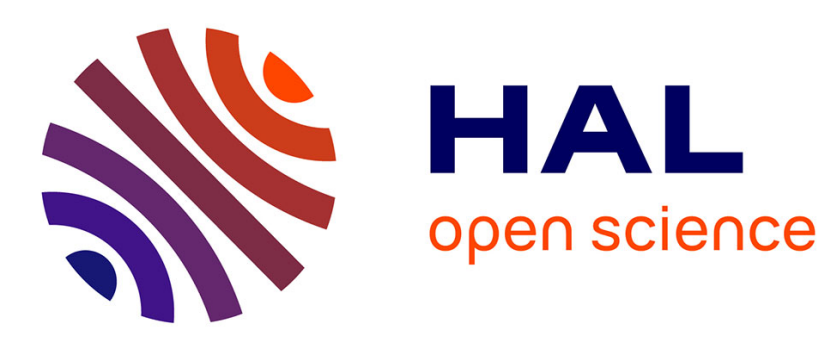

\title{
Évaluation de l'intérêt du test de fuite à l'eau pour le contrôle de fonctionnalité des conteneurs de stérilisation
}

Lucie Decarout

\section{To cite this version:}

Lucie Decarout. Évaluation de l'intérêt du test de fuite à l'eau pour le contrôle de fonctionnalité des conteneurs de stérilisation. Sciences pharmaceutiques. 2017. dumas-01512568

\section{HAL Id: dumas-01512568 https://dumas.ccsd.cnrs.fr/dumas-01512568}

Submitted on 24 Apr 2017

HAL is a multi-disciplinary open access archive for the deposit and dissemination of scientific research documents, whether they are published or not. The documents may come from teaching and research institutions in France or abroad, or from public or private research centers.
L'archive ouverte pluridisciplinaire HAL, est destinée au dépôt et à la diffusion de documents scientifiques de niveau recherche, publiés ou non, émanant des établissements d'enseignement et de recherche français ou étrangers, des laboratoires publics ou privés. 


\section{UFR de AI BIBLIOTHÈQUES Pharmacie UNIVERSITAIRES UNIVERSITÉ Grenoble Alpes \\ Grenoble Alpes

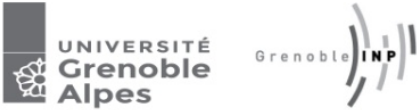

\section{AVERTISSEMENT}

Ce document est le fruit d'un long travail approuvé par le jury de soutenance et mis à disposition de l'ensemble de la communauté universitaire élargie.

Il n'a pas été réévalué depuis la date de soutenance.

Il est soumis à la propriété intellectuelle de l'auteur. Ceci implique une obligation de citation et de référencement lors de l'utilisation de ce document.

D'autre part, toute contrefaçon, plagiat, reproduction illicite encourt une poursuite pénale.

Contact au SID de Grenoble : bump-theses@univ-grenoble-alpes.fr

\section{LIENS}

Code de la Propriété Intellectuelle. articles L 122. 4

Code de la Propriété Intellectuelle. articles L 335.2- L 335.10

http://www.cfcopies.com/juridique/droit-auteur

http://www.culture.gouv.fr/culture/infos-pratiques/droits/protection.htm 
UNIVERSITÉ GRENOBLE ALPES

FACULTÉ DE PHARMACIE DE GRENOBLE

Année : 2017

EVALUATION DE L'INTERET DU TEST DE FUITE A L'EAU POUR LE CONTROLE DE FONCTIONNALITE DES CONTENEURS DE STERILISATION

MEMOIRE DU DIPLOME D'ETUDES SPECIALISEES DE PHARMACIE HOSPITALIEREPRATIQUE ET RECHERCHE

Conformément aux dispositions du décret № 90-810 du 10 septembre 1990, tient lieu de THESE

Lucie DECAROUT

[Données à caractère personnel]

MEMOIRE SOUTENU PUBLIQUEMENT À LA FACULTÉ DE PHARMACIE DE GRENOBLE Le 13/04/2017

DEVANT LE JURY COMPOSÉ DE

Président du jury :

Mme le Docteur Raphaële GERMI

Directeur de thèse : Mr le Docteur Christophe LAMBERT

Membres :

Mme le Docteur Catherine GUIMIER-PINGAULT

Mr le Docteur Christophe NAJEM

Mme le Professeur Valérie SAUTOU

La Faculté de Pharmacie de Grenoble n'entend donner aucune approbation ni improbation aux opinions émises dans les mémoires ; ces opinions sont considérées comme propres à leurs auteurs. 
Doyen de la Faculté : M. le Pr. Michel SEVE

Vice-doyen et Directrice des Etudes : Mme Christine DEMEILLIERS

Année 2016-2017

ENSEIGNANTS A L'UFR DE PHARMACIE

\begin{tabular}{|c|c|c|c|}
\hline STATUT & NOM & PRENOM & LABORATOIRE \\
\hline $\mathrm{MCU}$ & ALDEBERT & Delphine & LAPM - UMR CNRS 5163 \\
\hline PU-PH & ALLENET & Benoit & THEMAS TIMC-IMAG UMR CNRS 5525 \\
\hline PU & BAKRI & Aziz & TIMC-IMAG CNRS UMR 5525 \\
\hline ATER & BARDET & Jean-Didier & \\
\hline $\mathrm{MCU}$ & BATANDIER & Cécile & LBFA - INSERM U1055 \\
\hline MCU-PH & BEDOUCH & Pierrick & THEMAS TIMC-IMAG UMR CNRS 5525 \\
\hline $\mathrm{MCU}$ & BELAIDI-CORSAT & Elise & HP2 - INSERM U1042 \\
\hline MAST & BELLET & Béatrice & - \\
\hline ATER & BOUCHERLE & Benjamin & DPM \\
\hline DCE & BOULADE & Marine & SyMMES \\
\hline PU & BOUMENDJEL & Ahcène & DPM -UMR 5063 UJF CNRS \\
\hline DCE & BOURDIER & Guillaume & HP2 \\
\hline $\mathrm{MCU}$ & BOURGOIN & Sandrine & IAB - CRI INSERM UJF U823 \\
\hline DCE & BOUVET & Raphaël & HP2 \\
\hline $\mathrm{MCU}$ & BRETON & Jean & L.C.I.B. - UMR E3 CEA UJF \\
\hline $\mathrm{MCU}$ & BRIANCON-MARJOLLET & Anne & HP2 - INSERM U1042 \\
\hline DCE & BROCCO & Benjamin & ILL \\
\hline $\mathrm{MCU}$ & BUDAYOVA SPANO & Monika & IBS - UMR 5075 CEA CNRS UJF \\
\hline PU & BURMEISTER & Wim & UVHCI - UMI 3265 UJF EMBL CNRS \\
\hline MCU-PH & BUSSER & Benoit & IAB - CRI INSERM UJF U823 \\
\hline Professeur émérite & CALOP & Jean & - \\
\hline $\mathrm{MCU}$ & CAVAILLES & Pierre & LAPM - UMR 5163 CNRS UJF \\
\hline AHU & CHANOINE & Sébastien & THEMAS TIMC-IMAG UMR CNRS 5525 \\
\hline $\mathrm{MCU}$ & CHOISNARD & Luc & DPM-UMR 5063 UJF CNRS \\
\hline AHU & CHOVELON & Benoit & DPM-UMR 5063 UJF CNRS \\
\hline PU-PH & CORNET & Murielle & $\begin{array}{l}\text { THEREX - TIMC IMAG UMR } 5525 \text { CNRS } \\
\text { UJF }\end{array}$ \\
\hline $\mathrm{DCE}$ & COUCHET & Morgane & LBFA \\
\hline PU-PH & DANEL & Vincent & SMUR SAMU \\
\hline $\mathrm{PU}$ & DECOUT & Jean-Luc & DPM-UMR 5063 UJF CNRS \\
\hline $\mathrm{MCU}$ & DELETRAZ-DELPORTE & Martine & Equipe SIS -EAM 4128 UCB \\
\hline $\mathrm{MCU}$ & DEMEILLIERS & Christine & LBFA - INSERM U1055 \\
\hline $\mathrm{PU}$ & DROUET & Christian & AGIM - CNRS 3405 \\
\hline
\end{tabular}




\begin{tabular}{|c|c|c|c|}
\hline STATUT & NOM & PRENOM & LABORATOIRE \\
\hline $\mathrm{PU}$ & DROUET & Emmanuel & UVHCI - UMI 3265 UJF-EMBL- CNRS \\
\hline $\mathrm{MCU}$ & DURMORT - MEUNIER & Claire & I.B.S - UMR 5075 CEA UJF CNRS \\
\hline PU-PH & FAURE & Patrice & HP2- INSERM U1042 \\
\hline PRCE & FITE & Andrée & - \\
\hline $\mathrm{AHU}$ & GARNAUD & Cécile & $\begin{array}{c}\text { THEREX - TIMC IMAG UMR } 5525 \text { NCRS } \\
\text { UJF }\end{array}$ \\
\hline PRAG & GAUCHARD & Pierre-Alexis & - \\
\hline MCU-PH & GERMI & Raphaëlle & UVHCI, UMI 3265 UJF-EMBL-CNRS \\
\hline $\mathrm{MCU}$ & GEZE & Annabelle & DPM -UMR 5063 UJF CNRS \\
\hline $\mathrm{MCU}$ & GILLY & Catherine & DPM-UMR 5063 UJF CNRS \\
\hline $\mathrm{PU}$ & GODIN-RIBUOT & Diane & HP2- INSERM U1042 \\
\hline PRCE & GOUBIER MATHYS & Laurence & - \\
\hline Professeure émérite & GRILLOT & Renée & - \\
\hline $\mathrm{MCU}$ & GROSSET & Catherine & DPM -UMR 5063 UJF CNRS \\
\hline $\mathrm{MCU}$ & GUIEU & Valérie & DPM -UMR 5063 UJF CNRS \\
\hline $\mathrm{AHU}$ & HENNEBIQUE & Aurélie & sous réserve de création de poste \\
\hline $\mathrm{MCU}$ & HININGER-FAVIER & Isabelle & LBFA - Inserm U1055 \\
\hline $\mathrm{MCU}$ & JOYEUX-FAURE & Marie & HP2- INSERM U1042 \\
\hline $\mathrm{MCU}$ & KHALEF & Nawel & TIMC-IMAG CNRS UMR 5525 \\
\hline $\mathrm{MCU}$ & KRIVOBOK & Serge & LCBM, IRTSV CEA \\
\hline DCE & $\mathrm{LE}$ & Cong Anh Khanh & CERMAV \\
\hline $\mathrm{PU}$ & LENORMAND & Jean Luc & THEREX, TIMC-IMAG \\
\hline DCE & MARILLIER & Mathieu & HP2 \\
\hline PU & MARTIN & Donald & TIMC-IMAG, UMR 5525 UJF CNRS \\
\hline $\mathrm{AHU}$ & MAZET & Roseline & DPM -UMR 5063 UJF CNRS \\
\hline $\mathrm{MCU}$ & MELO DE LIMA & Christelle & L.E.C.A - UMR CNRS 5553 \\
\hline $\mathrm{PU}$ & MOINARD & Christophe & LBFA - Inserm U1055 \\
\hline DCE & MONTEMAGNO & Christopher & LRB \\
\hline ATER & MORAND & Jessica & HP2 \\
\hline PU-PH & MOSSUZ & Pascal & THEREX - TIMC-IMAG UMR 5525 CNRS \\
\hline $\mathrm{MCU}$ & MOUHAMADOU & Bello & L.E.C.A - UMR CNRS 5553 \\
\hline DCE & MOULIN & Sophie & HP2 \\
\hline DCE & NADER & Serge & LCBM \\
\hline DCE & NGUYEN & Kim-Anh & DPM \\
\hline $\mathrm{MCU}$ & NICOLLE & Edwige & DPM-UMR 5063 UJF CNRS \\
\hline $\mathrm{MCU}$ & OUKACINE & Farid & DPM -UMR 5063 UJF CNRS \\
\hline $\mathrm{MCU}$ & PERES & Basile & DPM- UJF/CNRS UMR 5063 \\
\hline DCE & PERONNE & Lauralie & IAB \\
\hline $\mathrm{MCU}$ & PEUCHMAUR & Marine & DPM -UMR 5063 UJF CNRS \\
\hline PU & PEYRIN & Éric & DPM-UMR 5063 UJF CNRS \\
\hline $\mathrm{MCU}$ & RACHIDI & Walid & L.C.I.B - UMR E3 CEA/UJF \\
\hline $\mathrm{MCU}$ & RAVELET & Corinne & DPM -UMR 5063 UJF CNRS \\
\hline PU & RIBUOT & Christophe & HP2- INSERM U1042 \\
\hline
\end{tabular}




\begin{tabular}{|c|c|c|c|}
\hline STATUT & NOM & PRENOM & LABORATOIRE \\
\hline PAST & RIEU & Isabelle & - \\
\hline Professeure émérite & ROUSSEL & Anne -Marie & Michel \\
\hline PU-PH & SEVE & Florence & DPM -UMR 5063 UJF CNRS \\
\hline MCU & SOUARD & Raleb & IBS \\
\hline DCE & TAHER & Faezeh & TIMC-IM2AG \\
\hline ATER & TAHMASEBI & Nicolas & UVHCI, UMR 3265 UJF-EMBL- CNRS \\
\hline MCU & TARBOURIECH & Zlatomir & BCI \\
\hline DCE & TODOROV & Patrice & CRI-GIN \\
\hline PAST & TROUILLER & Yvan & CRI-IAB \\
\hline DCE & VACHEZ & Cécile & DPM -UMR 5063 UJF CNRS \\
\hline MCU & VANHAVERBEKE & Céline & UVHCI \\
\hline DCE & VERNET & Charles & DPM -UMR 5063 UJF CNRS \\
\hline DCE & VRAGNIAU & Denis & \\
\hline PU & WOUESSIDJEWE & & \\
\hline & &
\end{tabular}

ATER : Attachés Temporaires d'Enseignement et de Recherches

BCI : Biologie du Cancer et de l'Infection

CHU : Centre Hospitalier Universitaire

CIB : Centre d'Innovation en Biologie

CRI : Centre de Recherche INSERM

CNRS : Centre National de Recherche Scientifique

DCE : Doctorants Contractuels Enseignement

DPM : Département de Pharmacochimie Moléculaire et

de Cognition et Ontogenese "

HP2 : Hypoxie Physiopathologie Respiratoire et Cardiovasculaire

IAB : Institut Albert Bonniot,

IBS : Institut de Biologie Structurale

JR : Jean Roget

LAPM : Laboratoire Adaptation et Pathogenèse des Microorganismes

LBFA : Laboratoire Bioénergétique Fondamentale et Appliquée

LCBM : Laboratoire Chimie et Biologie des Métaux

LCIB : Laboratoire de Chimie Inorganique et Biologie

LECA : Laboratoire d'Ecologie Alpine

LR : Laboratoire des Radio pharmaceutiques

MCU : Maitre de Conférences des Universités

MCU-PH : Maître de Conférences des Universités et Praticiens

Hospitaliers

PAST : Professeur Associé à Temps Partiel

PRAG : Professeur Agrégé

PRCE : Professeur certifie affecté dans l'enseignement

PU : Professeur des Université

PU-PH : Professeur des Universités et Praticiens Hospitaliers

TIMC-IMAG : Laboratoire Technique de l'Imagerie, de la Modelisation

UMR: Unité Mixte de Recherche

UVHCI: Unit of Virus Host Cell Interactions 
TABLE DES MATIERES

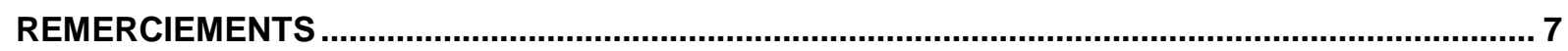

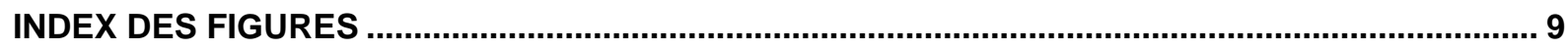

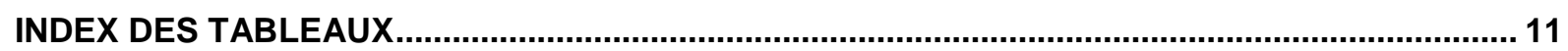

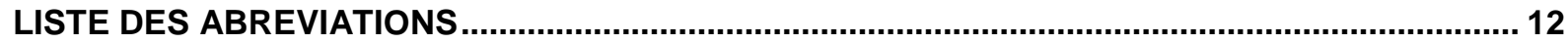

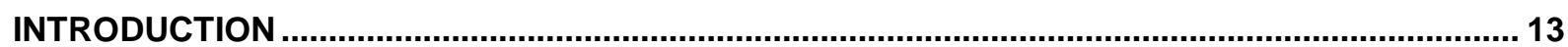

PARTIE I : LE CONDITIONNEMENT ET LES CONTRÔLES DE FONCTIONNALITÉ EN STERILISATION

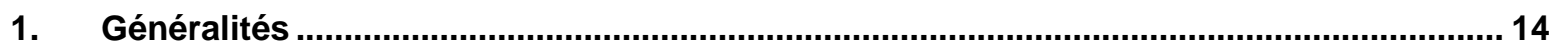

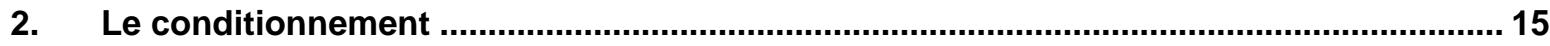

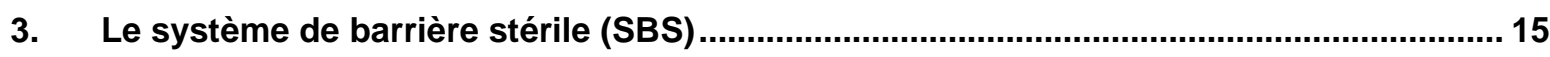

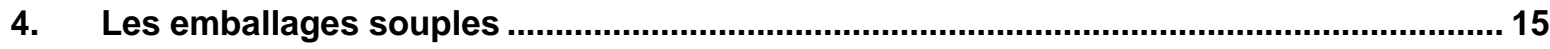

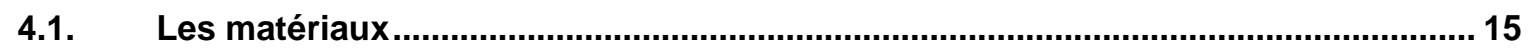

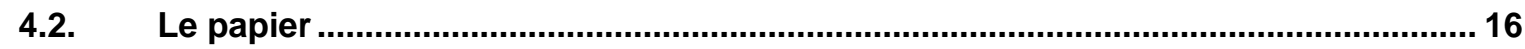

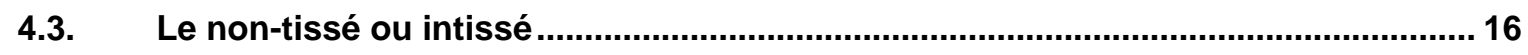

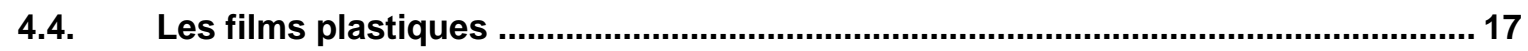

4.5. Les différents types de conditionnements souples .............................................. 17

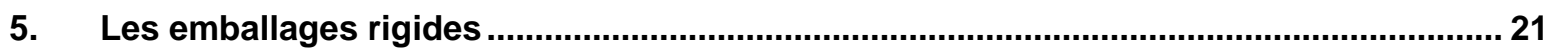

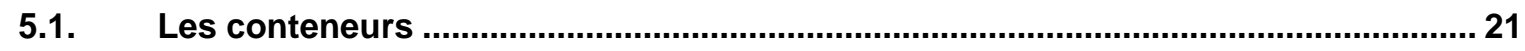

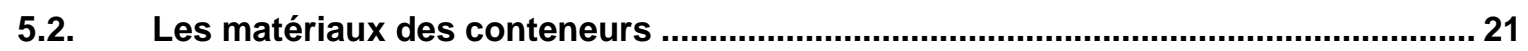

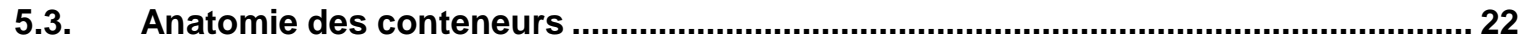

5.4. Avantages et inconvénients des conteneurs .......................................................... 23

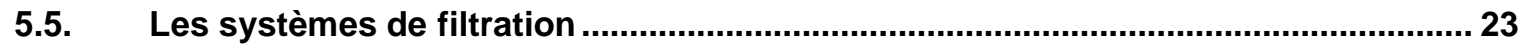

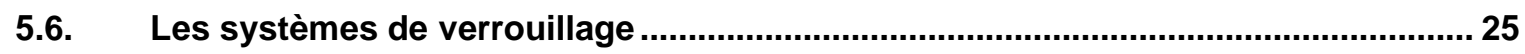

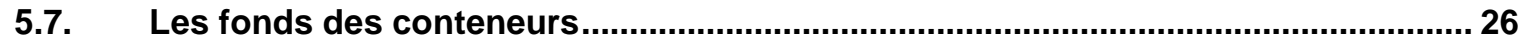

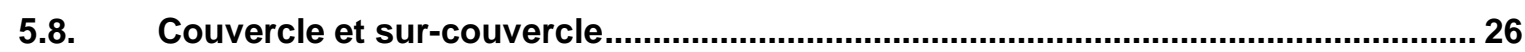

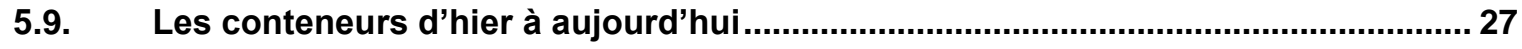

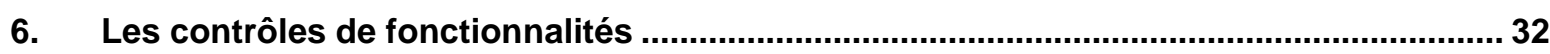

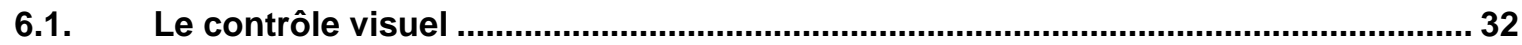




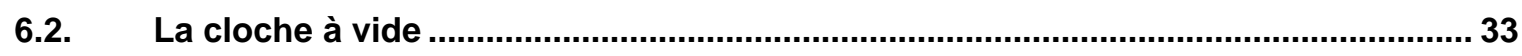

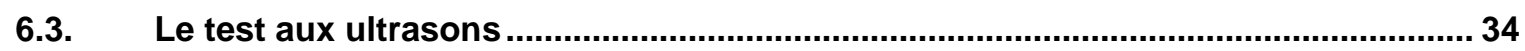

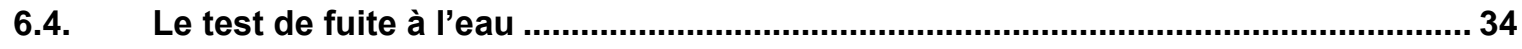

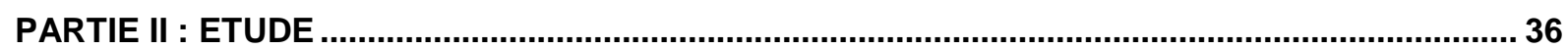

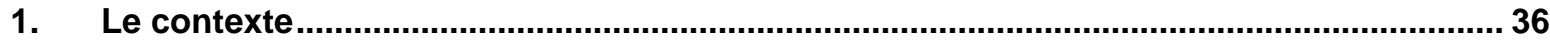

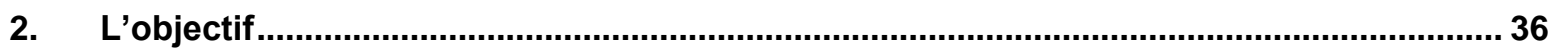

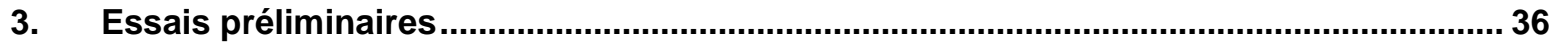

3.1. Détermination du délai de refroidissement à la sortie des autoclaves.................... 37

3.2. Détermination du volume d'air entrant dans les compositions en sortie

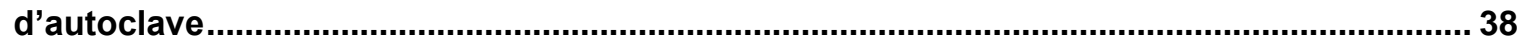

3.3. Détermination des variations de pression en conditions réelles lors du stockage et

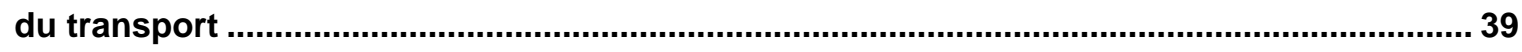

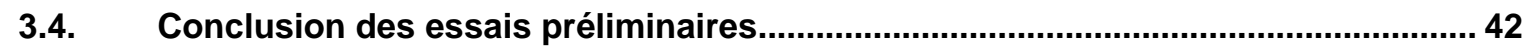

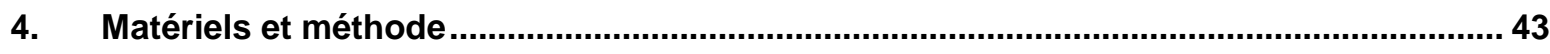

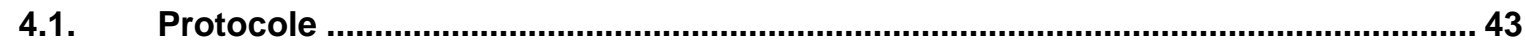

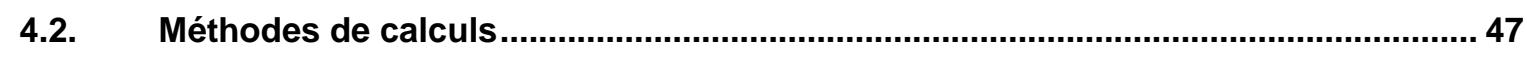

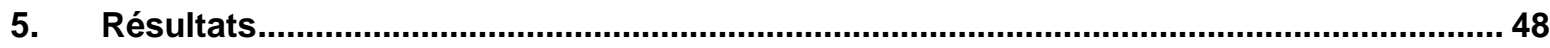

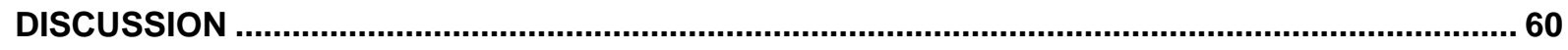

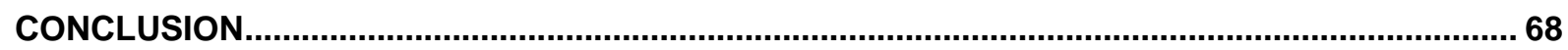

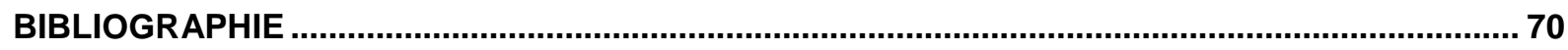

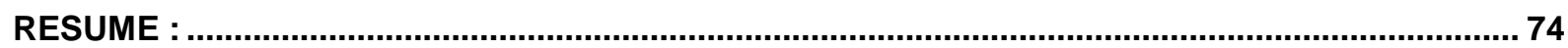




\section{REMERCIEMENTS}

A Raphaële Germi, je vous remercie d'avoir accepté de présider le jury de thèse.

A Valérie Sautou, je vous remercie d'avoir accepté de faire partie du jury et de juger mon travail.

A Catherine Guimier-Pingault, je vous remercie de faire partie de mes juges dans cette thèse qui est aussi dans votre domaine : la stérilisation.

A Christophe Lambert, je te remercie de m'avoir donné ce sujet de thèse et de m'avoir fait confiance pour ce travail. Merci pour ton implication majeur et ta pertinence scientifique.

A Christophe Najem, je suis ravie que tu ais accepté de participer à mon jury de thèse. Je te remercie de m'avoir aussi facilement intégré sur Mayotte.

A Luc Choisnard, maître de conférences appartenant à l'équipe NOVA (Nouveaux Outils de Vectorisation et d'Analyse), je vous remercie d'avoir contribué aux résultats statistiques de mon travail.

A Clément Andonian et l'équipe d'hygiène d'Aix les Bains pour avoir collaboré à cette thèse par la lecture de mes géloses. A Camille Fayard, pour avoir contribué à cette thèse. Je remercie aussi l'équipe de bactériologie de Chambéry pour nous avoir prêté leurs hottes. Un gros merci à l'équipe de la sté qui égayait ma journée et répondait toujours à mes multiples questions ! Nathalie, Maryline, Arnaud, Andréa, Yannick, et tous les autres.

A ma Famille, mes parents toujours présents depuis ma naissance. Merci maman d'avoir toujours été là pour me réconforter durant mes nombreux doutes et d'avoir eu confiance en moi. Au meilleur des papas, qui m'a initié dans tant d'activités sportives. A Juliette, ma grande sœur chérie, toi la sagesse, moi la fougueuse ; toi la littéraire, moi la scientifique ; toi la casanière, moi la baroudeuse... malgré nos différences, je sais que je peux compter sur toi... A Seb' pour tes bons plans. A mon petit Malo chéri. A mes chères et tendres grandsmères : de Paris et de Morlaix. Je vous remercie de m'avoir appris vos astuces pour le quotidien et surtout de m'avoir raconté vos souvenirs. A mes cousins de Panam et de Bretagne.

A mes amis de fac: Johanne \& Agnès je vous remercie d'avoir été là et de me suivre dans mes idées. Ma coloc d'enfer Sofia, je te remercie d'avoir supporté ma folie pendant un an et de toujours être là dans nos moments de partage. Mon petit monkey Margaux que j'ai découvert tardivement durant ces années de fac mais mieux vaut tard que jamais. 
Clémence, ma tutrice de maths préférée, je te remercie pour tes conseils assidus durant mes études.

A tous mes co-internes, amis et collègues que j'ai rencontrés durant mes semestres à Clermont-Ferrand, Annecy, Chambéry, Mayotte et Grenoble. Une attention particulière pour l'équipe des «bonnasses » qui s'est constituée (Audrey, Aurélie et Marine) : on en a gravi des montagnes ensemble ! Un clin d'œil à ma co-interne, Lucie 1 ou 2 : tu as rendu mon semestre dynamique! Orgalulus est dans la place. Merci aux filles « Inès et Julie » que j'adorais retrouver pour un petit repas après le travail. A mes nouveaux colocs Juliette et Greg.

A Antoine, merci d'être à mes côtés depuis plusieurs mois. Nous voilà partis sur la même vague. 


\section{INDEX DES FIGURES}

Figure 1 : Les différentes étapes du cycle de retraitement des DMR ......................................... 14

Figure 2 : évolution des terminologies sur le conditionnement (5) …..................................... 15

Figure 3 : Les fibres du non tissé en cellulose en microscopie d'après Arjowiggings ............... 16

Figure 4 : Les fibres du tisssu en microscopie d'après Arjowiggings ....................................... 16

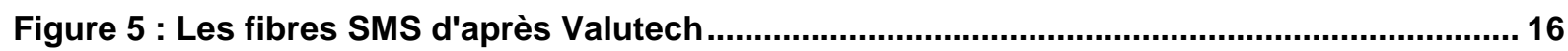

Figure 6 : feuille de NT pliée lors du conditionnement .......................................................... 18

Figure 7 : Wrap dry ${ }^{\circledR}$

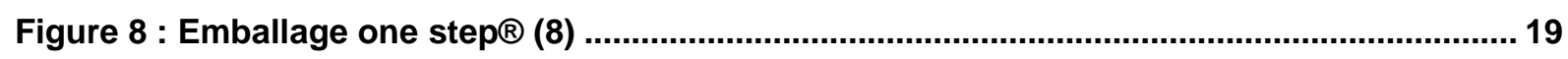

Figure 9 : Pliage type enveloppe (10) Figure 10 : Pliage type Pasteur (5)................. 19

Figure 11 : Caractéristiques présentes sur les sachets de stérilisation ................................... 21

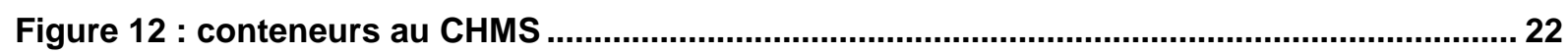

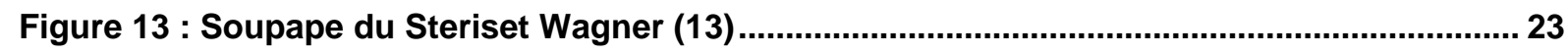

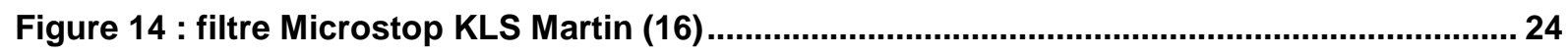

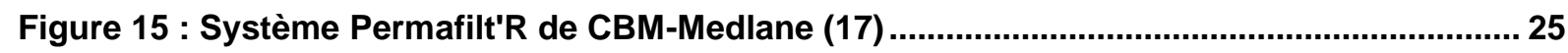

Figure 16: système ThermoLoc ${ }^{\circledR}$ de Landanger : Steriset Wagner (13)..................................... 25

Figure 17 : Ecoulement du purgeur thermique quand celui-ci s'ouvre de Landanger : Steriset

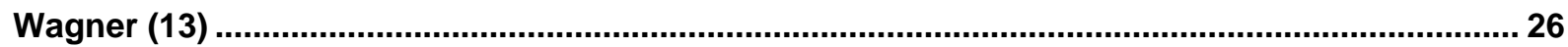

Figure 18 : Conteneur version PRIMELINE de la marque AESCULAP (18) ................................. 27

Figure 19 : Stérilisateur à vapeur conçu par Curt Schimmelbusch pour la stérilisation des

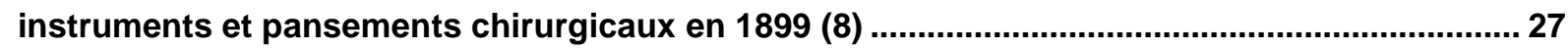

Figure 20 : Stérilisation à vapeur de Schimmelbusch dans le catalogue AESCULAP de 1904 (10)

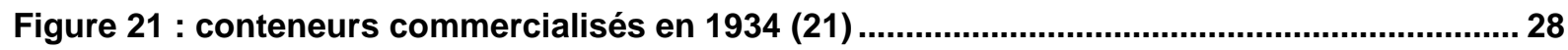

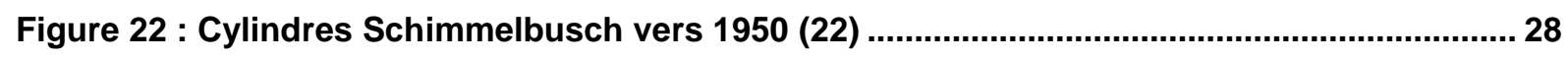

Figure 23 : Triple conteneur, composé d'éléments de fond, de cadre et de couvercle à partir de 1971 (22)

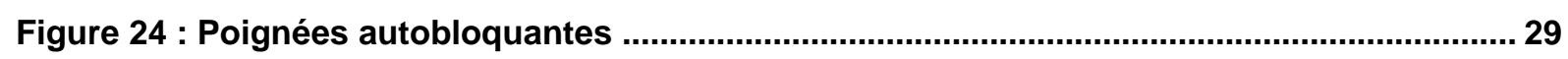

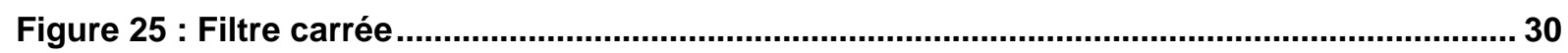

Figure 26 : Conteneur avec un système de verrouillage avec un plomb ................................... 30

Figure 27 : Conteneur AESCULAP de génération 3 ............................................................... 30 
Figure 28 : Couvercle avec un filtre rond avec un joint sur le porte filtre

Figure 29 : Filtre rond avec un joint sur le porte filtre

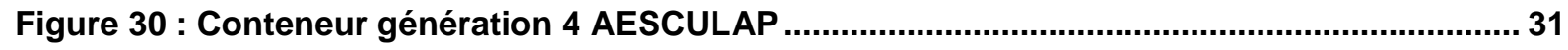

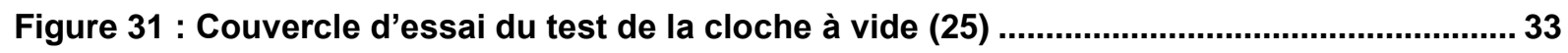

Figure 32: Protocole de suivi des conteneurs au Centre Hospitalier Métropole Savoie (3)........ 34

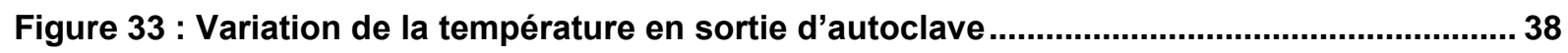

Figure 34 : Variation de la pression et du volume .................................................................. 40

Figure 35 : Variation de la pression atmosphérique selon l'altitude d'après Météo-France ${ }^{\circledR}$... 40

Figure 36 : variation de la pression (mbar) pendant l'entrée et la sortie d'une salle de bloc

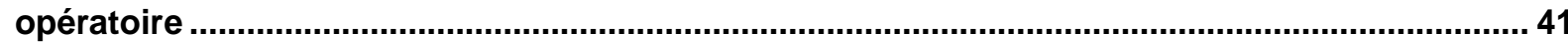

Figure 37 : variation de la pression entre les différents étage du CHMS (mbar)........................ 42

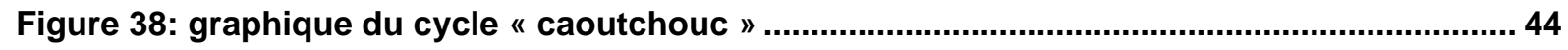

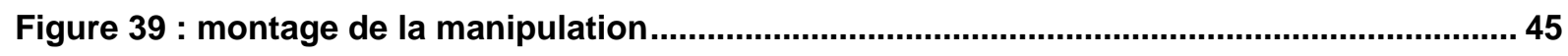

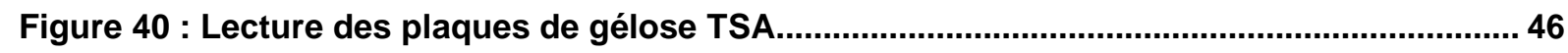

Figure 41 : Répartition du nombre d'UFC par conteneur à une pression de 25 mbar ...............51

Figure 42 : Répartition du nombre d'UFC par conteneur à une pression de 50 mbar ................ 52

Figure 43 : Répartition du nombre d'UFC par conteneur à une pression de 75 mbar .................53

Figure 44 : Représentation graphique des données.............................................................. 56

Figure 45 : Analyse de la variance entre les groupes (conteneurs) ........................................ 57

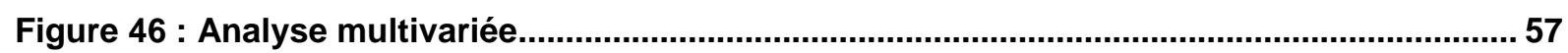

Figure 47 : Analyse de variance à deux facteurs - modèle linéaire général : LRV en fonction de Pression ; Conteneurs ..................................................................................................................5 58

Figure 48 : Analyse Post-hoc des moyennes différentes - comparaisons multiples de Dunnett avec un contrôle $:$ réponse $=\mathrm{LRV}$, terme $=$ Conteneurs

Figure 49 : Comparaisons multiples de Dunnett avec un contrôle : réponse = LRV, terme = Conteneurs 


\section{INDEX DES TABLEAUX}

Tableau I : Avantages et inconvénients des feuilles de stérilisation

Tableau II : Avantages et inconvénients des sachets et gaines de papier/plastique stérilisation (5)

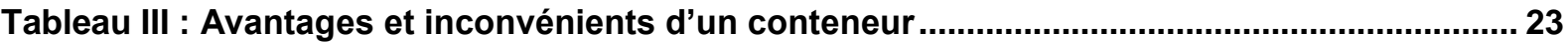

Tableau IV: Résultats des tests à l'eau effectués dans deux pays ............................................ 35

Tableau V : Détermination des poids composant les quatre emballages secondaires............... 37

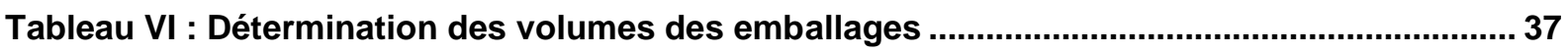

Tableau VII : Détermination des volumes d'air entrant lors du refroidissement ..........................39

Tableau VIII : variation du volume à l'intérieur des conteneurs pendant le transport ................ 41

Tableau IX : données des 15 séries à la pression de 25 mbar.................................................... 48

Tableau $X$ : données des 15 séries à la pression de 50 mbar.................................................... 49

Tableau XI : données des 15 séries à la pression de 75 mbar..................................................50

Tableau XII : données utilisées pour les tests statistiques ............................................................ 55 


\section{LISTE DES ABREVIATIONS}

AFNOR : Association Française de Normalisation

BPPH : Bonnes Pratiques de Pharmacie Hospitalière

CHMS : Centre Hospitalier Métropole Savoie

DM : Dispositifs Médicaux

DMR : Dispositifs Médicaux Réutilisables

LRV : Log Reduction Value

NT : Non-Tissé

PP : Polypropylène

$\mathbf{P} / \mathbf{T}^{\circ}$ : pression/température

PTFE : Polytétrafluoroéthylène

PUI : Pharmacie à Usage Intérieur

SBS : Système de Barrière Stérile

SE : Système d'Emballage

SF2S : Société Française de Stérilisation

TSA : Trypto-caséine soja

UFC : Unité Formant Colonies 


\section{INTRODUCTION}

Le processus de retraitement des dispositifs médicaux réutilisables est un procédé spécial nécessitant une maîtrise et un contrôle des différentes étapes de préparation. D'après les Bonnes pratiques de pharmacie hospitalière, "L'emballage est compatible avec le procédé de stérilisation, assure le maintien de la stérilité jusqu'à l'utilisation et permet l'extraction aseptique du dispositif »(1). L'état stérile d'un dispositif médical ne peut être maintenu que lorsque l'emballage est intègre. Dans le cas des emballages souples (sachets, gaines ou pliages) les déchirures ou perforations compromettant la stérilité sont facilement identifiables. Dans le cas des conteneurs réutilisables, l'intégrité de l'emballage est plus difficile à contrôler et notamment juste avant l'utilisation au bloc opératoire. Pour cette raison des tests de fonctionnalités sont effectués préalablement au conditionnement afin de contrôler le maintien des performances de ces emballages avant stérilisation. Lorsque ces contrôles se révèlent négatifs, les conteneurs sont retirés du circuit de production et devront faire l'objet d'une maintenance avant réutilisation. En France, une méthode d'essai pour évaluer l'étanchéité de la fermeture cuve/couvercle des conteneurs est décrite dans un document normatif (2). Ce test de fuite à l'eau pratiqué dans certains établissements de santé (3) est actuellement non reconnu par les fabricants de conteneurs. Cet essai de performance a-t-il véritablement un caractère prédictif de la rupture d'étanchéité de la barrière stérile?

L'objectif de ce travail est de vérifier le maintien de l'intégrité du système de barrière stérile de conteneurs présentant un test de fuite à l'eau positif, en prenant en compte les variations de pression observées pendant le transport et le stockage de ces dispositifs. Estce que l'effet de la pression peut-être une porte d'entrée de contaminants ?

Dans la première partie de ce travail, nous rappellerons l'importance du conditionnement qui s'intègre dans le processus global de stérilisation, les différents tests de fonctionnalités et le rôle du Système de Barrière Stérile (SBS).

Dans un second temps, nous débuterons par le contexte de notre étude, établirons les essais préliminaires indispensables à la rédaction de notre protocole de recherche. Enfin nous présenterons les résultats de notre étude évaluant l'intérêt du test de fuite à l'eau pour le contrôle de fonctionnalité des conteneurs. 


\section{PARTIE I : LE CONDITIONNEMENT ET LES CONTRÔLES DE FONCTIONNALITÉ EN STERILISATION}

\section{Généralités}

La stérilisation des dispositifs médicaux est une activité optionnelle de la PUI soumise à autorisation préfectorale. Cette activité est exercée sous la responsabilité du pharmacien gérant de la PUI ou d'un autre pharmacien responsable après délégation de celle-ci (4).

La stérilisation est un procédé spécial nécessitant une maîtrise de toutes les étapes du processus car il est impossible de vérifier l'état stérile du produit final sans altérer son intégrité. II est donc nécessaire de disposer d'opérateurs qualifiés et d'un système d'assurance qualité afin d'atteindre l'objectif final. Les différentes étapes du processus de stérilisation sont décrites dans la figure suivante. Chacune d'entre-elles fait l'objet d'exigences et de contrôles qui lui sont rattachés. Nous décrirons plus spécifiquement les éléments participant à la maitrise du conditionnement.

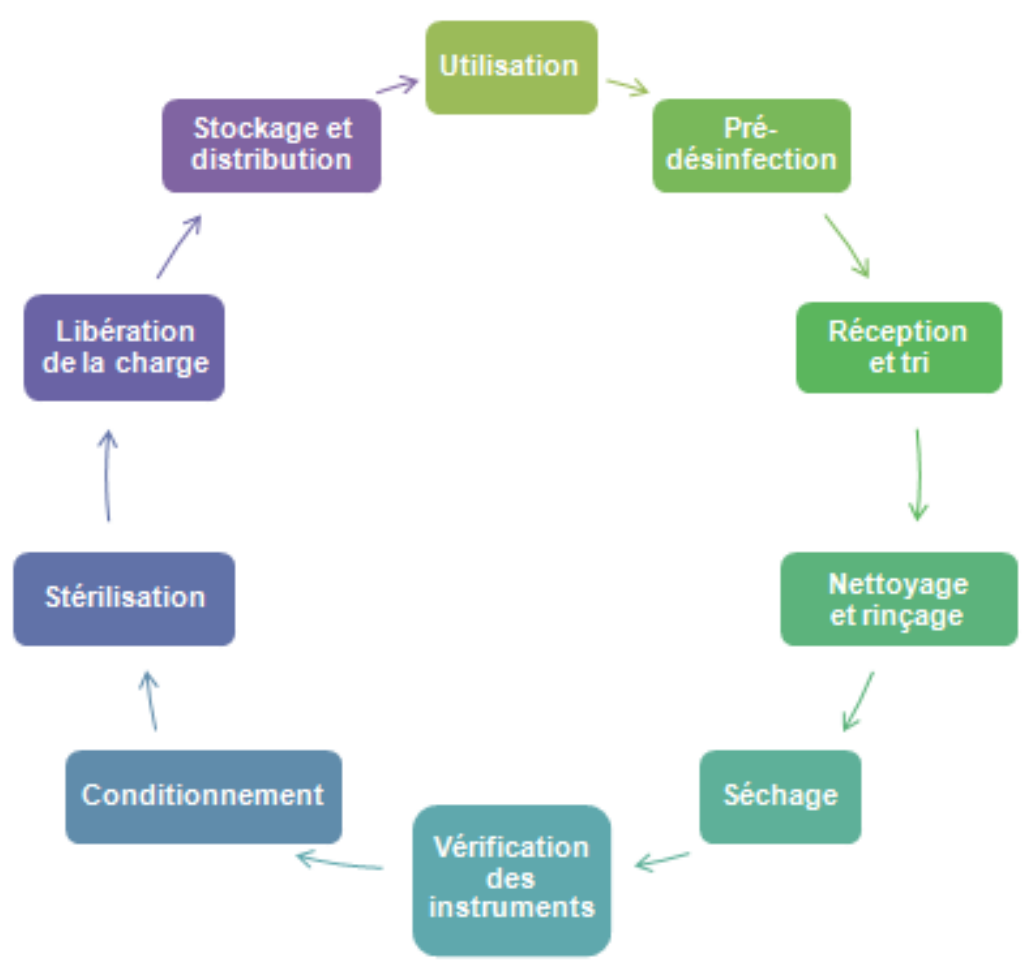

Figure 1 : Les différentes étapes du cycle de retraitement des DMR 


\section{Le conditionnement}

Après l'étape de nettoyage, l'étape de recomposition qui lui succède consiste à contrôler et assembler les différents instruments d'une même composition selon un listing défini et validé. Après recomposition, les dispositifs et articles seront conditionnés dans un emballage qui permettra de garantir le maintien de leur stérilité jusqu'au moment de son utilisation.

\section{Le système de barrière stérile (SBS)}

Les emballages utilisés lors du conditionnement sont de type à usage unique ou réutilisable. Le choix du type d'emballage pour un dispositif médical dépend notamment de leur configuration et de leur masse, mais également des conditions de stockage et de transport, du coût, du mode de stérilisation et du mode d'ouverture attendu par les utilisateurs (présentation aseptique).

Selon la norme ISO 11607-1(7), le système de barrière stérile (SBS) est "l'emballage placé directement en contact avec le dispositif et constitue une barrière imperméable aux micro-organismes ».

«Le système de barrière stérile préformé est un système de barrière stérile qui est fourni partiellement assemblé pour remplissage et fermeture finale ou scellage ». Le conteneur réutilisable répond à la définition du SBS préformé.

L'emballage de protection est défini par une « configuration de matériaux conçue pour éviter tout dommage au système de barrière stérile et à son contenu depuis leur assemblage jusqu'au point d'utilisation ».

L'association d'un SBS et d'un emballage de protection constitue le système d'emballage.

\begin{tabular}{|lll|}
\hline Pharmacopée & NF EN 868-1 & NF EN ISO 11607-1 \\
\hline Protecteur individuel de stérilité (PIS) & Emballage primaire & Système de barrière stérile (SBS) \\
\hline Emballage de protection & Emballage secondaire & Emballage de protection \\
\hline Unité protégée & Emballage final & Système d'emballage \\
\hline
\end{tabular}

Figure 2 : évolution des terminologies sur le conditionnement (5)

\section{Les emballages souples}

\subsection{Les matériaux}

Les matériaux utilisés dans la confection des emballages souples doivent permettre la pénétration de l'agent stérilisant, en procurant une résistance mécanique et en assurant un rôle barrière aux micro-organismes. 


\subsection{Le papier}

Celui-ci est fabriqué à base de fibres de cellulose blanchie, non recyclées, enrichies d'additifs permettant l'amélioration des performances. La norme NF EN 868-3 (6) spécifie les exigences auxquelles doivent répondre les papiers.

\subsection{Le non-tissé ou intissé}

Le non-tissé (NT) est défini comme « une feuille manufacturée, constituée de voile ou de nappe de fibres, qu'elles soient orientées directionnellement ou par hasard, liées par friction et/ou cohésion et/ou adhésion" (7). II est constitué de fibres naturelles hydrophiles (cellulose) ou synthétiques hydrophobes (polyéthylène, polypropylène, polyester). L'absence de structure géométrique organisée le différencie du papier. II existe une grande variété de non tissés selon le procédé de fabrication, de la nature des fibres et des adjuvants utilisés.

La présence d'un liant entre les fibres du NT, créant un enchevêtrement des fibres, augmente la résistance mécanique et améliore les performances de barrière microbienne.

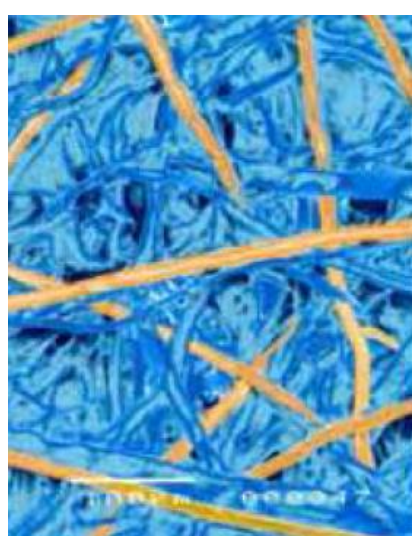

Figure 3 : Les fibres du non tissé en cellulose en microscopie d'après Arjowiggings

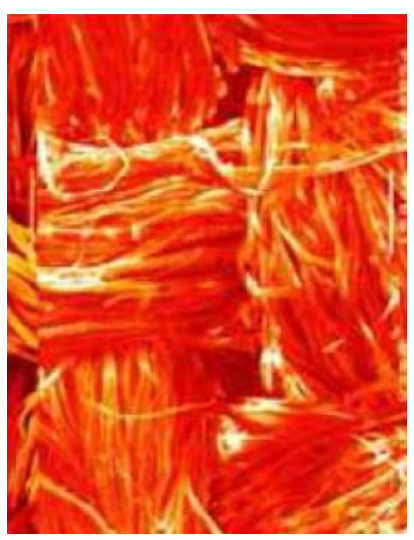

Figure 4 : Les fibres du tisssu en microscopie d'après Arjowiggings

Le non-tissé SMS est formé de trois couches de fibres : Spunbond-Meltblown-Spunbond. Le Meltblown est un réseau de fibres denses permettant la filtration des micro-organismes. Les couches Spunbond apportent de la résistance.

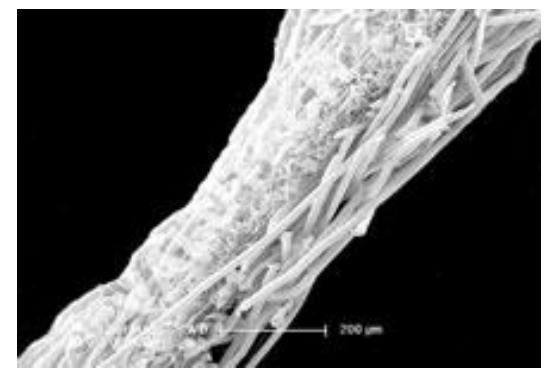

Figure 5 : Les fibres SMS d'après Valutech 


\subsection{Les films plastiques}

Ne permettant pas le passage de l'agent stérilisant, les films plastiques sont utilisés en association avec le papier ou le NT qui eux seuls permettent le passage de la vapeur d'eau. Généralement le polyéthylène est associé au polyester et au polyamide. Le plus souvent il s'agit d'un complexe associant deux films dont l'un est utilisé pour le scellage par thermofusion et l'autre comme support. L'association de deux films co-extrudés renforce la résistance mécanique et la sécurité vis-à-vis du risque de perforations.

4.5. Les différents types de conditionnements souples

a) Les feuilles de stérilisation

Elles sont constituées de papier crêpé simple ou renforcé ou de NT simple ou double. Les feuilles de stérilisation utilisées sont à usage unique et définies dans la norme EN 868-3.

\begin{tabular}{|c|c|c|}
\hline & Avantages & Inconvénients \\
\hline crêpé & Absorption & $\begin{array}{l}\text { Grande mémoire de forme } \\
\text { Très faible résistance mécanique }\end{array}$ \\
\hline Crêpé renforcé & Absorption & $\begin{array}{l}\text { Mémoire de forme } \\
\text { Faible résistance mécanique }\end{array}$ \\
\hline Non-tissé & $\begin{array}{l}\text { Résistance mécanique importante } \\
\text { Peu de mémoire de forme }\end{array}$ & Risque d'humidité résiduelle \\
\hline Non-tissé SMS & $\begin{array}{l}\text { Résistance mécanique importante } \\
\text { Pas de mémoire de forme }\end{array}$ & Risque d'humidité résiduelle \\
\hline
\end{tabular}

Tableau I : Avantages et inconvénients des feuilles de stérilisation 


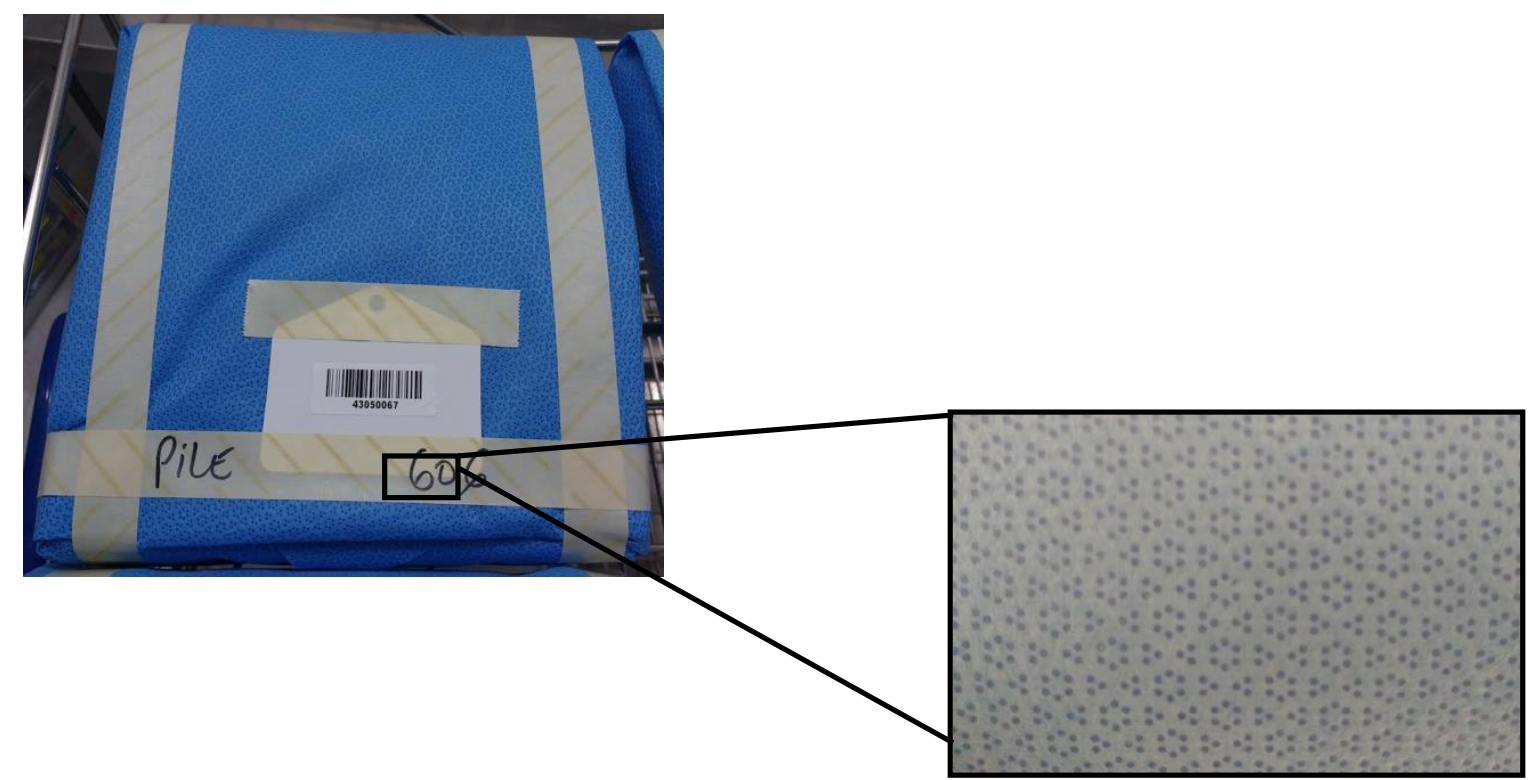

Figure 6 : feuille de NT pliée lors du conditionnement

L'emballage Wrap Dry® signifie emballage sec. La feuille violette constituée de polypropylène et d'une couche hydrophile favorise la diffusion et la vaporisation des excès de condensats pendant la phase de stérilisation. Elle doit toujours être associée à un SBS car elle ne constitue qu'un emballage de protection.

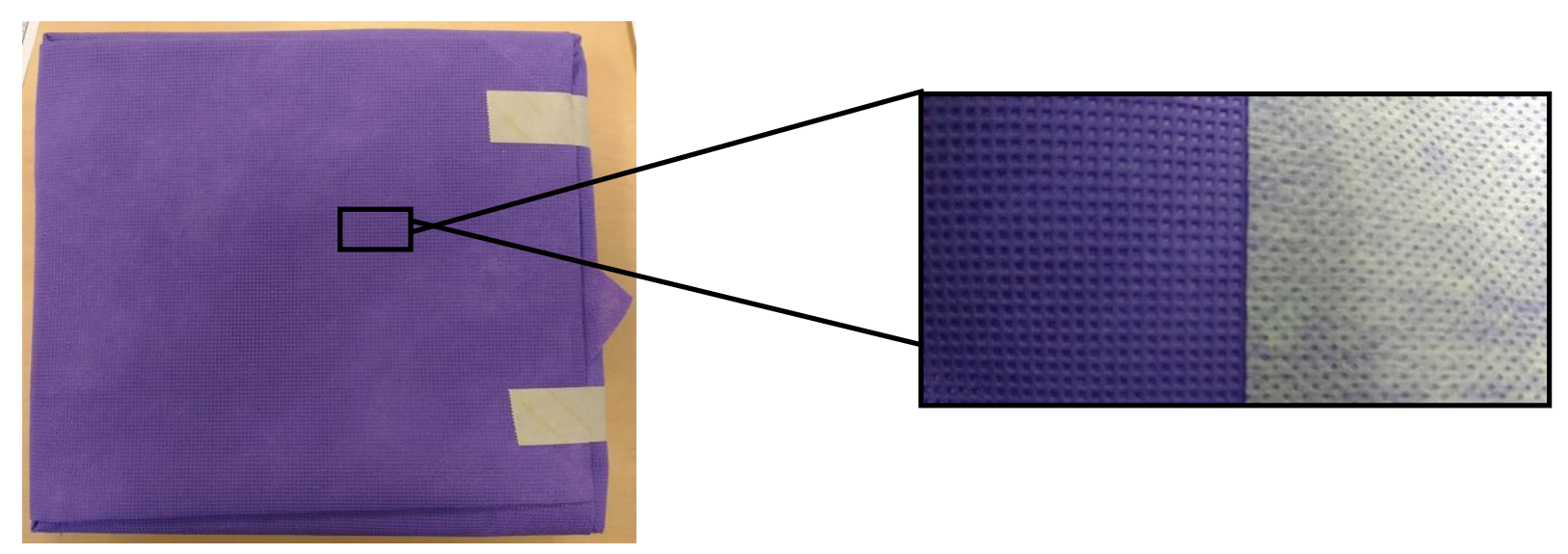

Figure 7 : Wrap dry®

L'emballage Kimguard one step®est constituée de deux feuilles de NT (polypropylène) soudées sur les 2 bords. L'avantage énoncé par le fabricant est la réalisation d'un emballage double feuille en un seul temps de pliage, ce qui réduirait le temps agent consacré au pliage. 


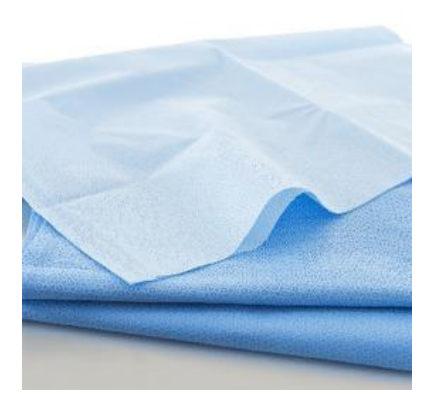

Figure 8 : Emballage one $\operatorname{step}^{\circledR}(8)$

On appelle pliage le terme définissant le conditionnement réalisé à l'aide de feuilles de stérilisation. L'utilisation de deux feuilles, anciennement appelé double emballage, permet une ouverture en deux temps au moment de l'utilisation. L'emballage externe, plus exposé aux contaminants environnementaux serait ôté à l'extérieur de la salle opératoire. Dans un second temps, l'emballage interne (actuellement SBS) serait enlevé dans la salle d'intervention juste avant l'utilisation du DM stérile.

Les feuilles pour emballage peuvent être de couleurs différentes facilitant ainsi la détection d'éventuelles déchirures ou perforations. Il existe plusieurs types de pliages (9) : le pliage enveloppe ou le pliage pasteur. Le pliage enveloppe serait à favoriser car le nombre de plis formés permettent une meilleure barrière contre les microorganismes. La fermeture est ensuite réalisée par un ruban adhésif comportant un indicateur de passage.

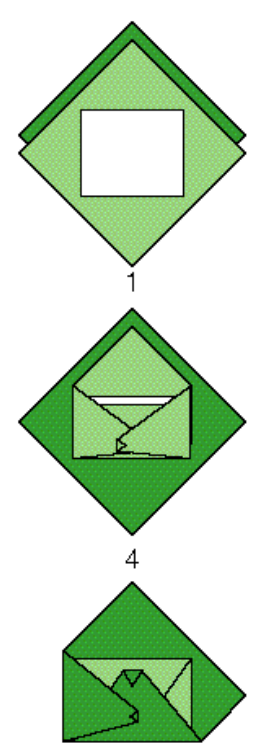

7

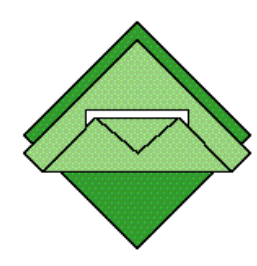

2

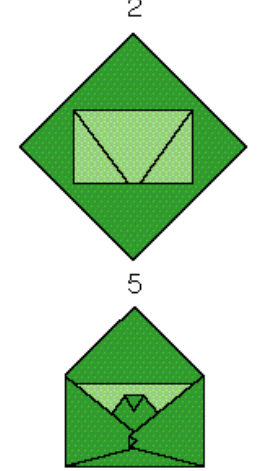

8
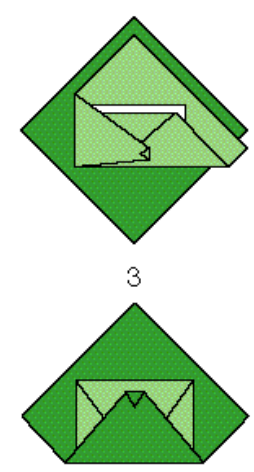

6

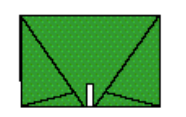

9

Figure 9 : Pliage type enveloppe (10)

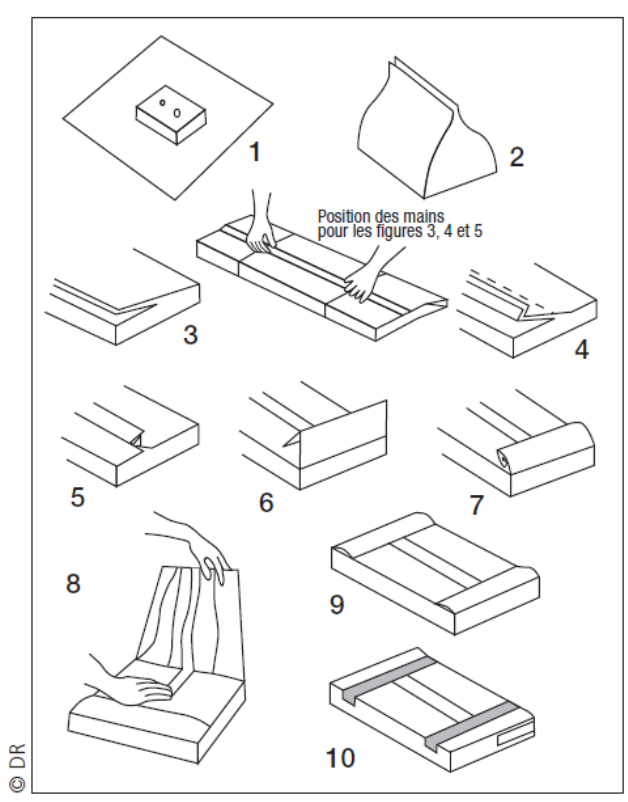

Figure 10 : Pliage type Pasteur (5) 
b) Les sachets et les gaines de stérilisation

Les sachets et les gaines de stérilisation répondent à la définition des « systèmes de barrière stérile préformés 》.

Plusieurs types existent :

- Les sachets entièrement papier

- Les sachets avec une face papier et une face plastique

- Les sachets avec une face en NT et une face plastique

En général, les trois côtés du sachet sont scellés par le fournisseur tandis que la fermeture finale est effectuée par l'utilisateur par thermoscellage. II existe des gaines dont seuls les côtés longitudinaux sont scellés par le fournisseur permettant l'adaptation aux différentes tailles des instruments.

Les exigences spécifiques pour les sachets et gaines thermoscellables sont indiquées dans la norme EN 868-5 (11)

Le système de barrière stérile “ULTRA®» présente l'avantage d'avoir une excellente pelabilité grâce au matériau employé. II ne présente pas de défibration ou d'émission de particules lors de l'ouverture qu'il soit réalisé sur l'un ou l'autre côté de la soudure par l'utilisateur (12).

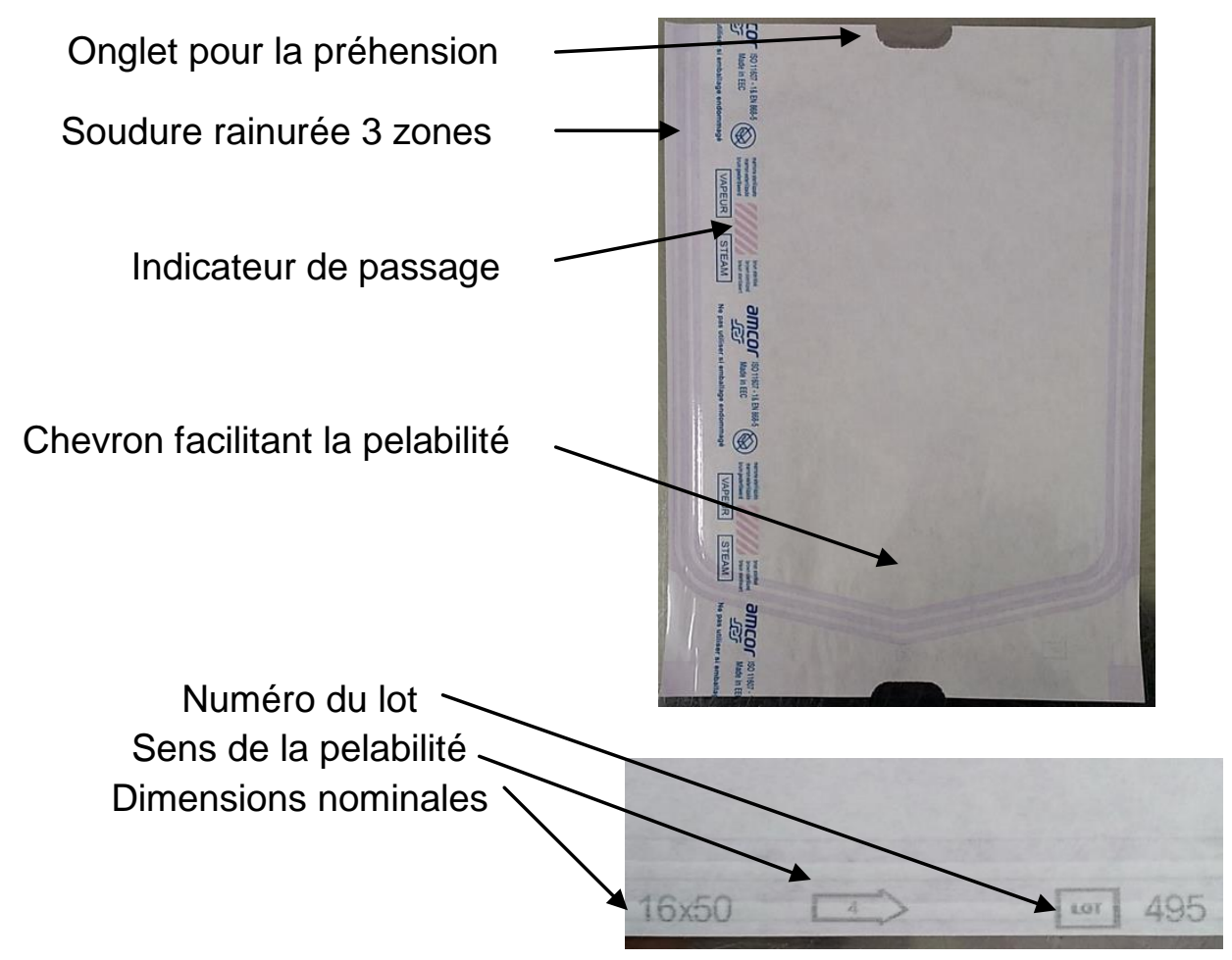




\section{Figure 11 : Caractéristiques présentes sur les sachets de stérilisation}

\begin{tabular}{|c|c|c|}
\hline & Avantages & Inconvénients \\
\hline $\begin{array}{c}\text { Sachet } \\
\text { papier/plastique }\end{array}$ & $\begin{array}{c}\text { Facile à souder } \\
\text { Face transparente qui permet de voir } \\
\text { le DM } \\
\text { Pelabilité totale }\end{array}$ & $\begin{array}{c}\text { Difficulté de conditionner les DM } \\
\text { lourds et volumineux } \\
\text { Défibration lors de l'ouverture }\end{array}$ \\
\hline $\begin{array}{c}\text { Sachet } \\
\text { papier/plastique } \\
\text { avec soufflet }\end{array}$ & $\begin{array}{l}\text { Face transparente qui permet de voir } \\
\text { le DM } \\
\text { Pelabilité totale } \\
\text { Très pratique pour les DM volumineux }\end{array}$ & $\begin{array}{l}\text { Difficulté pour le scellage } \\
\text { Risque de défibration }\end{array}$ \\
\hline $\begin{array}{l}\text { Sachet non- } \\
\text { tissé/plastique }\end{array}$ & $\begin{array}{c}\text { Face transparente qui permet de voir } \\
\text { le DM } \\
\text { Pelabilité totale } \\
\text { Pratique pour les DM lourds et } \\
\text { volumineux } \\
\text { Résistance mécanique intermédiaire }\end{array}$ & Risque d'humidité résiduelle \\
\hline $\begin{array}{c}\text { Sachet } \\
\text { papier/papier }\end{array}$ & $\begin{array}{c}\text { Echange de vapeur sur la surface } \\
\text { totale du sac }\end{array}$ & $\begin{array}{l}\text { Visualisation impossible du } \\
\text { contenu } \\
\text { Ouverture par déchirement } \\
\text { (particules et risque de faute } \\
\text { d'asepsie) }\end{array}$ \\
\hline $\begin{array}{c}\text { Gaine } \\
\text { papier/plastique }\end{array}$ & $\begin{array}{c}\text { Facilité de scellage } \\
\text { Bonne adaptation à la dimension du } \\
\text { DM } \\
\text { Face transparente qui permet de voir } \\
\text { le DM }\end{array}$ & $\begin{array}{l}\text { Absence de chevrons facilitant la } \\
\text { pelabilité }\end{array}$ \\
\hline
\end{tabular}

Tableau II : Avantages et inconvénients des sachets et gaines de papier/plastique stérilisation (5)

\section{Les emballages rigides}

\subsection{Les conteneurs}

Le conteneur est un «système de barrière stérile rigide conçu pour être utilisé de manière répétée » (7). II appartient au groupe des « systèmes de barrière stérile préformé ».

\subsection{Les matériaux des conteneurs}

Ils sont conçus en acier inoxydable, en aluminium anodisé ou en matériau synthétique. L'aluminium anodisé offre une légèreté supérieure à celle de l'acier inoxydable mais sa résistance aux chocs et à la déformation est plus faible. L'aluminium possède des 
propriétés physiques d'accumulation thermique et de conductibilité thermique élevées apportant en parallèle des résultats de séchage intéressants.

\subsection{Anatomie des conteneurs}

Les conteneurs sont de forme carré ou parallélépipédique. Ils sont constitués d'une cuve pouvant recevoir des paniers internes ou directement des instruments placés sur le fond. Ils disposent d'un couvercle permettant la fermeture du conteneur et parfois d'un surcouvercle selon les générations, La cuve comporte un porte-étiquette pour identifier la composition et deux poignées afin de faciliter le portage. Les conteneurs ont un système permettant le passage de la vapeur d'eau et celui-ci se situe dans la plupart des cas au niveau du couvercle.

Tous les éléments sont inscrits sur la figure ci-dessous.

Coins internes arrondis facilitant le nettoyage

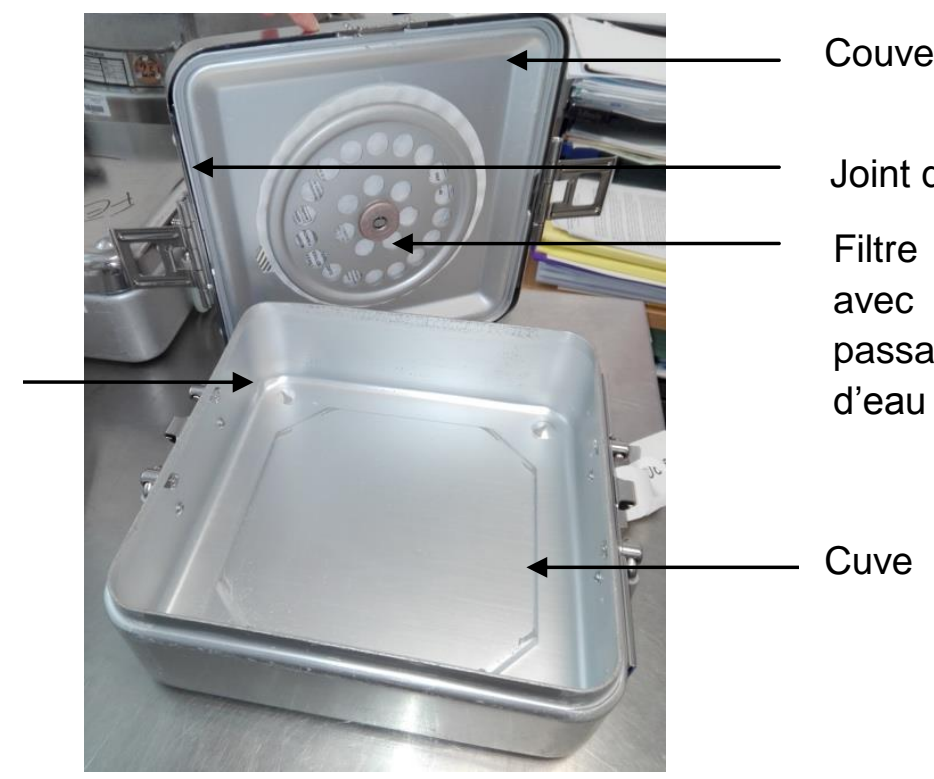

Couvercle

Joint d'étanchéité

Filtre à usage unique avec témoin de passage de la vapeur d'eau

\section{Cuve}

Système de fermeture Poignée

Figure 12 : conteneurs au CHMS 


\begin{tabular}{|c|c|}
\hline Avantages & Inconvénients \\
\hline $\begin{array}{c}\text { Dimension normalisée permettant un } \\
\text { stockage ordonné } \\
\text { Conditionnement adapté à des instruments } \\
\text { lourds } \\
\text { Bonne résistance mécanique lors du } \\
\text { transport et du stockage } \\
\text { Identification simple avec l'étiquetage } \\
\text { Evite les déchets et les coûts d'élimination } \\
\text { engendrés par les emballages à usage } \\
\text { unique }\end{array}$ & $\begin{array}{c}\text { Coût à l'achat } \\
\text { Maintenance régulière coûteuse } \\
\text { Obligation de les désassembler lors du } \\
\text { lavage } \\
\text { Contrôle rigoureux avant chaque réutilisation } \\
\text { Poids } \\
\text { Difficulté d'appréciation des détériorations } \\
\text { possibles }\end{array}$ \\
\hline
\end{tabular}

Tableau III : Avantages et inconvénients d'un conteneur

\subsection{Les systèmes de filtration}

A. Filtre de papier crêpé à usage unique. Ils répondent aux mêmes exigences que les feuilles de crêpes décrites dans la norme EN 868-3. Ils sont préférentiellement équipés d'un indicateur de passage et sont tenus en place par le porte-filtre. Ils sont remplacés lors de chaque recomposition.

B. Filtre mécanique :

a) Soupape (pression/dépression)

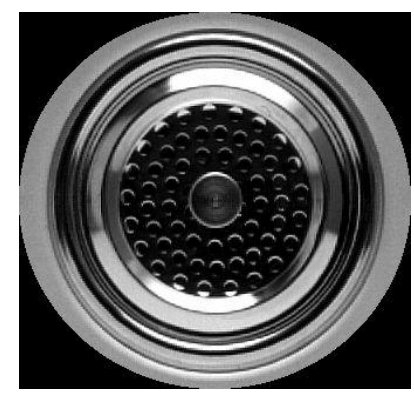

Figure 13 : Soupape du Steriset Wagner (13) 
Les soupapes réagissent différemment selon les différences de pression au cours du cycle de stérilisation :

- Pendant les phases de pression sub atmosphérique : la soupape s'ouvre en laissant pénétrer la vapeur d'eau.

- Pendant les phases de vide : la soupape s'ouvre en sens opposé, l'air et la vapeur s'échappe en dehors du conteneur

En dehors du cycle de stérilisation c'est-à-dire pendant le stockage et le transport : la soupape est fermée, et constitue une barrière à la pénétration des micro-organismes. Le principal avantage du système soupape est qu'il n'utilise pas de consommable. Son principal inconvénient réside dans la difficulté d'exécuter un contrôle de fonctionnalité des soupapes en routine. Les soupapes sont localisées soit dans le couvercle ou dans le fond de la cuve du conteneur.

\section{b) Système MicroStop® KLS MARTIN :}

Le système Microstop est constitué d'un disque en matière plastique indéformable, placé sur la face interne du couvercle et formant une barrière infranchissable pour les germes. Ce filtre est indiqué pour 500 cycles ou une année d'utilisation (14). Selon le principe d'inhibition de flux décrit par Pasteur, il impose un chemin tortueux aux gaz, retenant ainsi les particules et les germes. Ce système revendique une efficacité à $99.99999 \%$ de la barrière microbienne bien que le dossier scientifique repose sur un échantillon de 2 conteneurs testés 3 fois. Les performances de stérilisation et de l'aptitude au stockage ont été réalisées sur 5 conteneurs(15).
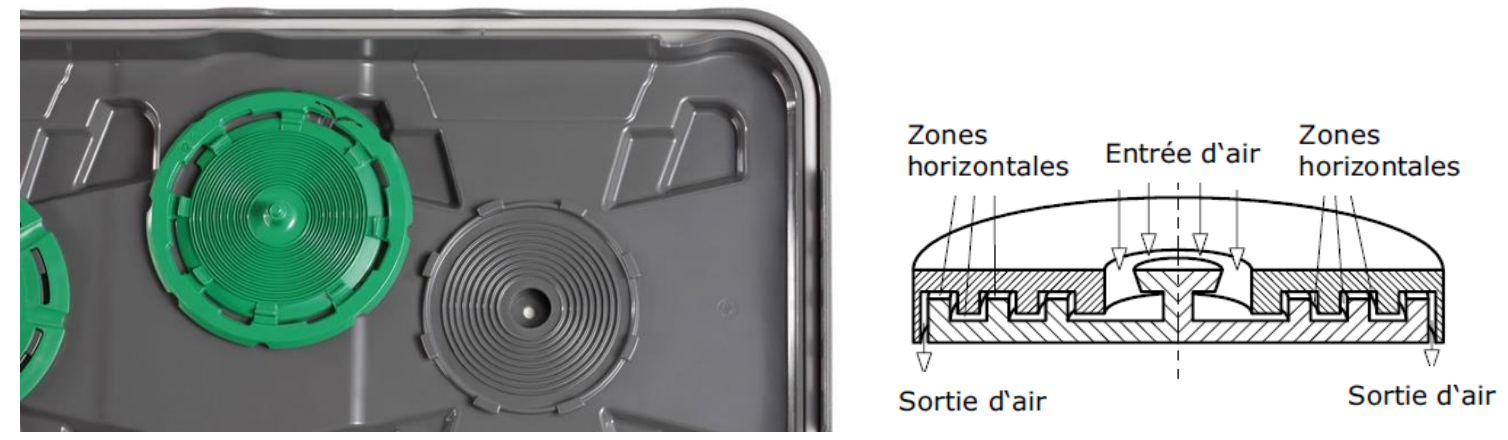

Figure 14 : filtre Microstop KLS Martin (16)

C. Filtres de tissus : utilisés pour 200 cycles ou trois mois d'utilisation.

D. Autres filtres permanents/réutilisables (membrane en PTFE testé pour 5000 cycles) : 
a) Système PRIMELINE® AESCULAP : le filtre PTFE est validé pour 5000 cycles de stérilisation, il s'agit d'une barrière microbienne à action permanente. Ce dernier est intégré au couvercle en polysulfones.

b) Système Permafilt'R® CBM-Medlane : c'est une bi-filtration en PTFE placée sur les parois latérales de la cuve. II est validé pour 2000 cycles de stérilisation.

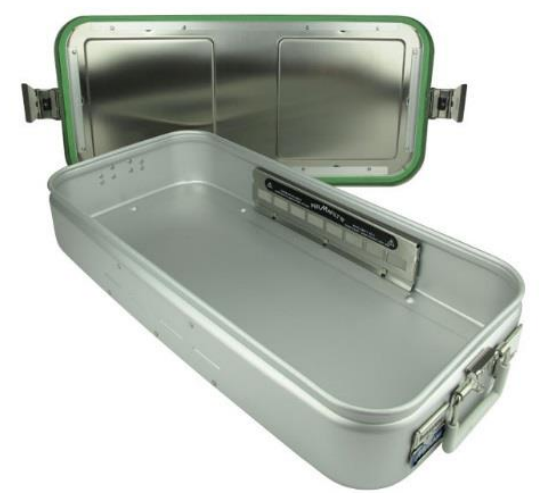

\section{Figure 15 : Système Permafilt'R de CBM-Medlane (17)}

5.6. Les systèmes de verrouillage

A. Verrouillage automatique par le système ThermoLoc® : sous l'action de la chaleur pendant le cycle de stérilisation, le verrou coulisse vers le bas bloquant ainsi la fermeture jusqu'à l'ouverture volontaire du conteneur.

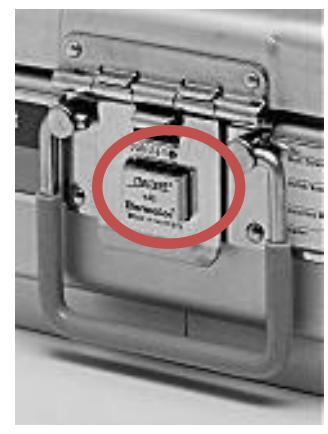

Figure 16: système ThermoLoc ${ }^{\circledR}$ de Landanger : Steriset Wagner (13)

B. Verrouillage avec scellés : les scellés ou plombs sont des systèmes de verrouillage en matériau synthétique disposés avant le cycle de stérilisation. Ils peuvent comporter un indicateur de procédé et seront rompus et enlevés avant l'utilisation du contenu du conteneur en salle d'intervention. L'absence ou la rupture de scellé témoigne d'une ouverture possible du couvercle du conteneur. 


\subsection{Les fonds des conteneurs}

A. Fond standard

B. Fond avec filtre : principe identique au filtre de couvercle

C. Fond avec purgeur: il permet de sécher les charges lourdes contenant des instruments. Ce principe n'est pas adapté pour le conditionnement et la stérilisation des textiles. Le liquide provenant de la condensation peut s'écouler hors du conteneur lorsque la température dépasse un certain seuil $\left(130^{\circ} \mathrm{C}\right.$ pour les conteneurs SteriSet®).

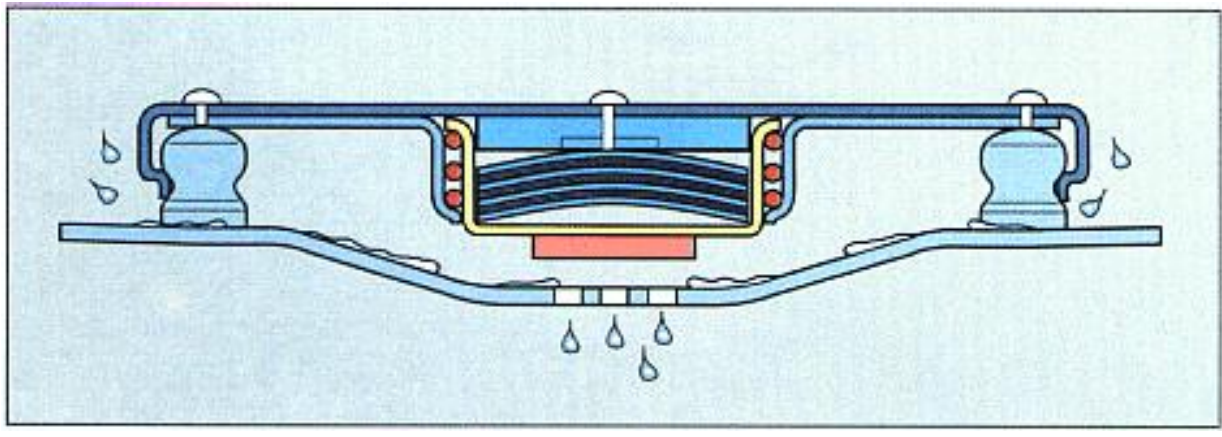

Figure 17 : Ecoulement du purgeur thermique quand celui-ci s'ouvre de Landanger :

\section{Steriset Wagner (13)}

\subsection{Couvercle et sur-couvercle}

A. Couvercle rigide en acier inoxydable ou en aluminium

B. Couvercle en PolyPhényISUlfone (PPSU)

Système PRIMELINE® AESCULAP : le couvercle est en matériau synthétique et la cuve en aluminium. Contrairement aux couvercles en aluminium, ce dernier est plus résistant aux chocs et déformations mais il présente une interaction avec les produits de lavage ou de rinçage. II existe une incompatibilité entre les tensio-actifs contenus dans ces agents chimiques et les polysulfones non recuits présents dans le matériau entraînant sa fragilité et sa rupture. Cela s'appelle le stress-cracking dont le résultat est l'apparition de microfissures. II est nécessaire d'utiliser un programme de lavage différent ou un produit parfaitement adapté à ces couvercles pour éviter ce phénomène. 


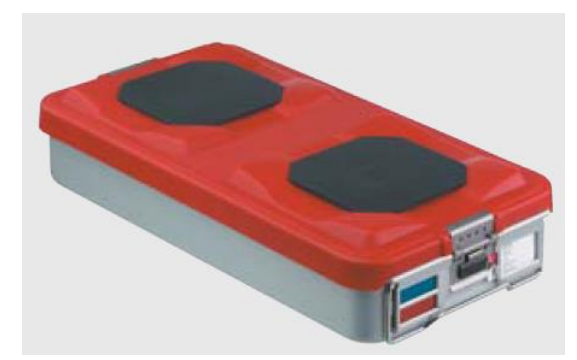

Figure 18 : Conteneur version PRIMELINE de la marque AESCULAP (18)

C. Sur-couvercle : en inox ou en aluminium anodisé

5.9. Les conteneurs d'hier à aujourd'hui

* Curt Theodor Schimmelbusch (1860-1895) est un physicien et médecin allemand. Vers 1890 (19), il propose une stérilisation quotidienne des pansements médicaux conditionnés et stockés dans la même boîte jusqu'à leur utilisation pendant l'intervention chirurgicale. Pour cela il modifie les dessins du stérilisateur et invente les boîtes de stérilisation cylindriques. II s'agit d'un tambour métallique avec un couvercle refermable et des orifices de ventilation latéraux refermables. Le tambour est recouvert d'une doublure de coton épais. II est également destiné à contenir les instruments chirurgicaux. Celui-ci étant fermé, il est transporté jusqu'au lieu de l'opération sans contamination. (20)

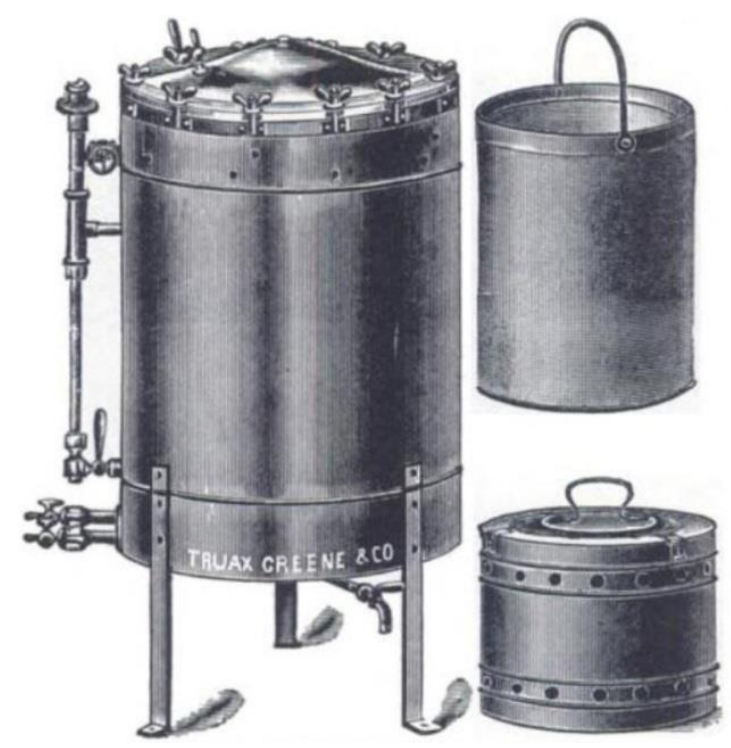

Figure 19 : Stérilisateur à vapeur conçu par Curt Schimmelbusch pour la stérilisation des instruments et pansements chirurgicaux en 1899 (8)

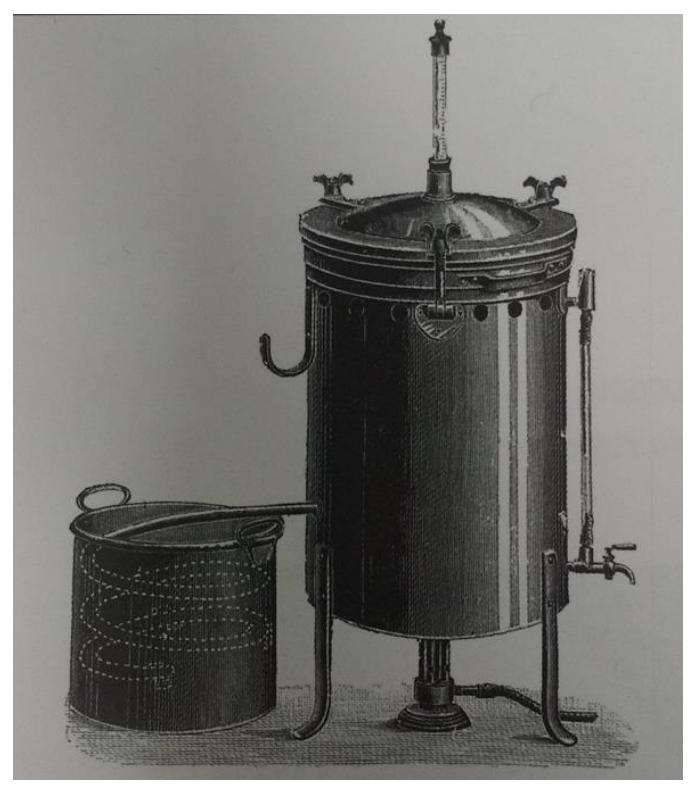

Figure 20 : Stérilisation à vapeur de Schimmelbusch dans le catalogue AESCULAP de 1904 (10) 


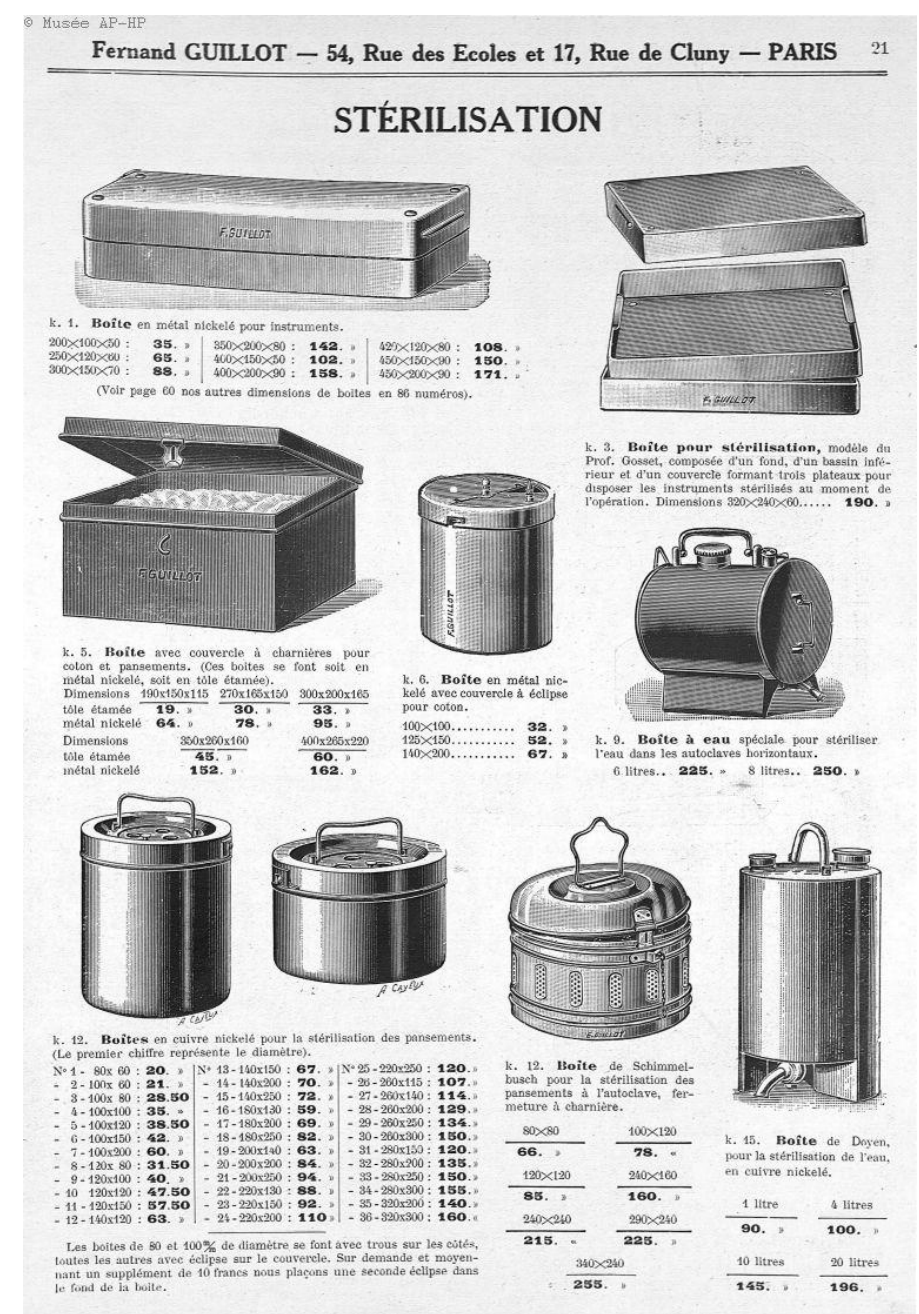

Figure 21 : conteneurs commercialisés en 1934 (21)

* 1950 : cylindres Schimmelbusch

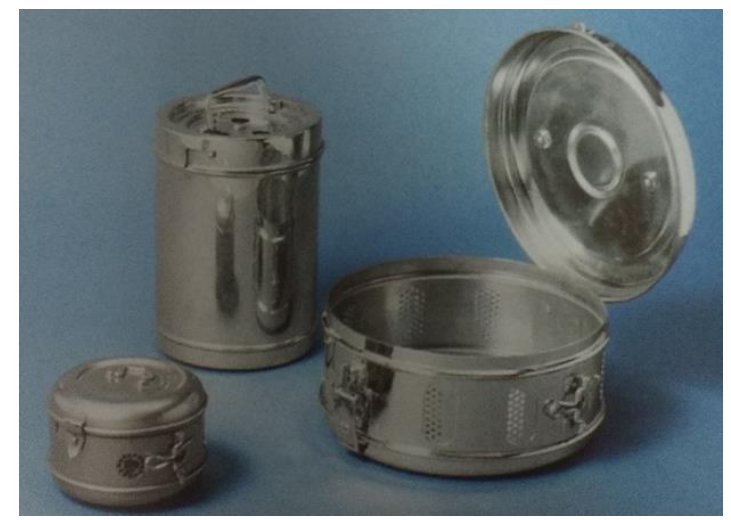

Figure 22 : Cylindres Schimmelbusch vers 1950 (22)

* «Dans les années 70 s'imposa une nouvelle méthode de mise à disposition du matériel stérile: le système du set. Son principe de base: l'instrumentation, les champs et les compresses destinés à une opération étaient préparés dans un set. 
Les instruments faisant partie d'un set étaient définis et par conséquent standardisés. Après l'opération, le set pouvait ainsi être évacué dans son ensemble et retraité. Le patient suivant était opéré au moyen d'un nouveau set. »(22)

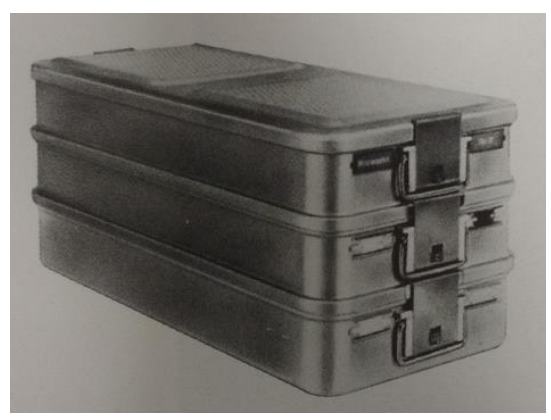

Figure 23 : Triple conteneur, composé d'éléments de fond, de cadre et de couvercle à partir de $1971(22)$

* 1972-1984 : génération 1 - AESCULAP(23)

- Petites poignées autobloquantes $90^{\circ}$

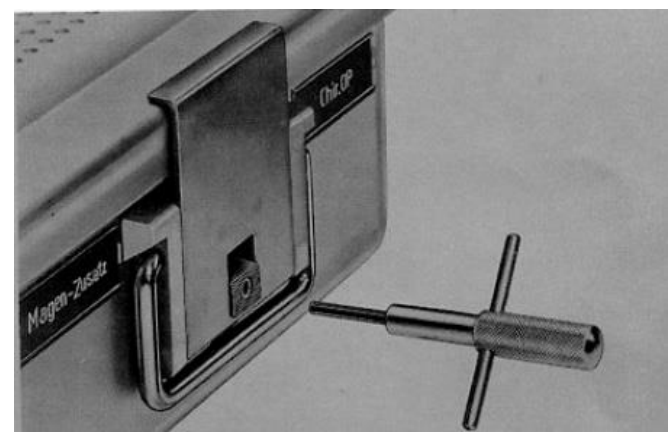

Figure 24 : Poignées autobloquantes

- Plaquettes d'identification de chaque côté

- Plaques de fermeture sur la cuve

- Filtre carré, sans joint sur le porte filtre

- Clé de verrouillage 


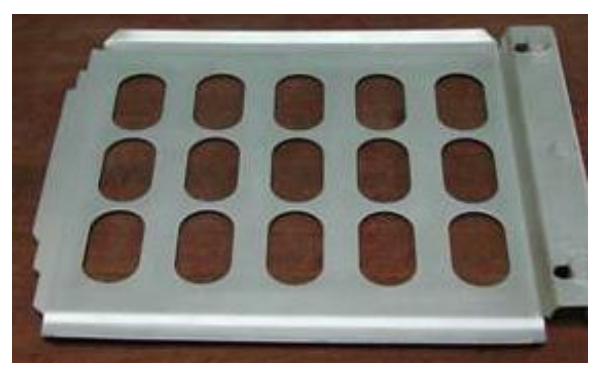

Figure 25 : Filtre carrée

* 1984-1987 : génération 2 - AESCULAP(23)

- Petites poignées autobloquantes $90^{\circ}$

- 2 plaquettes d'identification à gauche et étiquette de passage à droite

- Plaques de fermeture sur la cuve

- Filtre carré, sans joint sur le porte filtre

- Système de verrouillage avec un plomb

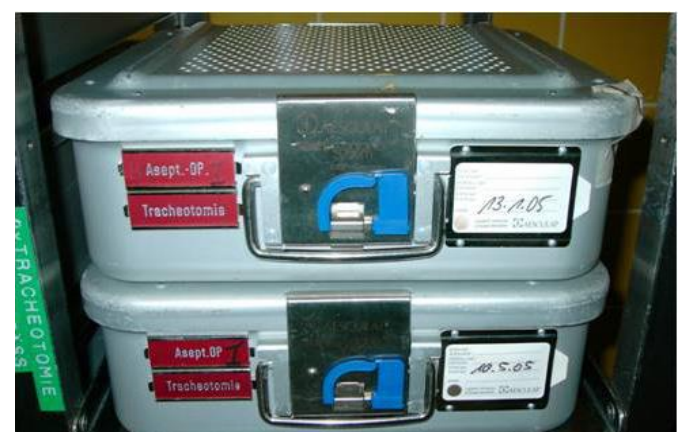

Figure 26 : Conteneur avec un système de verrouillage avec un plomb

* 1987-1994 : génération 3 - AESCULAP(23)

- Petites poignées autobloquantes $90^{\circ}$

- 2 plaquettes d'identification à gauche et étiquette de passage à droite

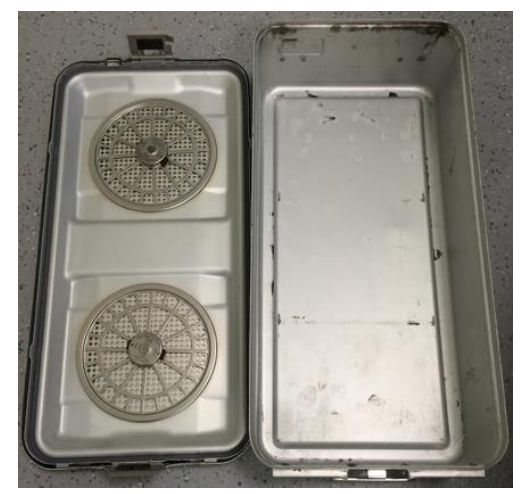

Figure 27 : Conteneur AESCULAP de génération 3 
- Plaques de fermeture sur le couvercle avec ressort intégré

- Filtre rond avec un joint sur le porte filtre

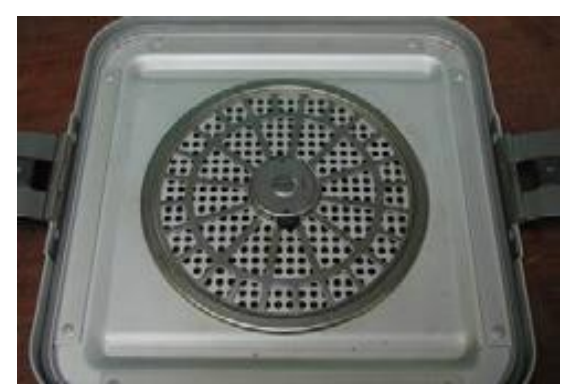

Figure 28 : Couvercle avec un filtre rond avec un joint sur le porte filtre

- Système de verrouillage avec un plomb

* 1994 à aujourd'hui : génération 4 : AESCULAP(23)

- Larges poignées autobloquantes $90^{\circ}$

- 2 plaquettes d'identification à gauche et étiquette de passage à droite

- Plaques de fermeture sur le couvercle avec ressort intégré

- Filtre rond avec un joint sur le porte filtre

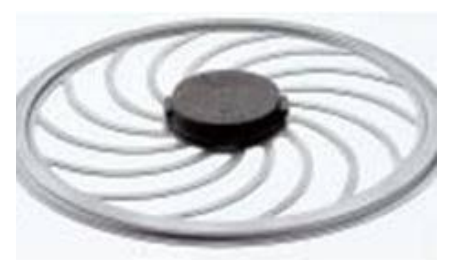

Figure 29 : Filtre rond avec un joint sur le porte filtre

- Système de verrouillage avec un plomb

- Système de sur-couvercle

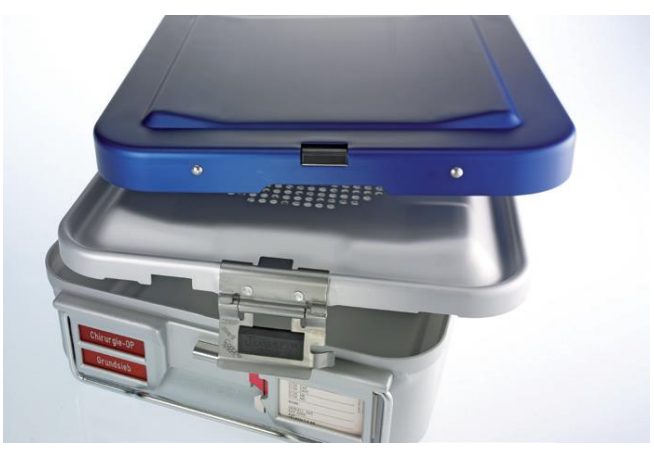

Figure 30 : Conteneur génération 4 AESCULAP 


\section{Les contrôles de fonctionnalités}

Selon les BPPH publiées en 2001, "Avant stérilisation, chaque conteneur réutilisable fait l'objet d'un contrôle visuel, et son aptitude au fonctionnement est vérifiée selon les recommandations du fabricant. [...] Un plan de maintenance des conteneurs est établi et mis en œuvre, et le remplacement de tout élément est enregistré. » (1).

Nous allons présenter ci-après les différents tests de fonctionnalités permettant de contrôler les performances d'un conteneur. Actuellement et seulement depuis peu de temps , en dehors du fabricant AESCULAP® (24), peu de fabricants fournissent les recommandations nécessaires à l'exécution des contrôles de fonctionnalité des conteneurs avant réutilisation. Par conséquent, ces tests de fonctionnalité, indispensables avant chaque réutilisation d'un emballage réutilisable sont rédigés en interne dans les établissements de santé.

\subsection{Le contrôle visuel}

Au Centre Hospitalier Métropole Savoie (CHMS), avant chaque utilisation, les conteneurs ou emballages réutilisables rigides font l'objet d'une vérification visuelle de leur fonctionnalité. Toutes les parties du conteneur sont contrôlés selon la procédure interne :

a. Cuve et couvercle : vérifier l'absence de déformation sur le pourtour supérieur de la cuve et sur le couvercle

b. Poignées et portes-étiquettes : vérifier la présence des rivets et des vis de serrage au niveau des portes-poignées et des portes-étiquettes

c. Guide-joint du couvercle : vérifier le bon positionnement et l'immobilité des rails du guide-joint

d. Joint du couvercle: vérifier l'état du joint, l'absence de coupures, fissures, décollement, écrasement, sortie de gorge

e. Joint du porte filtre : vérifier l'absence de décollement, de fissure ou de coupure du joint

f. Système de verrouillage du porte-filtre : vérifier l'absence de déformation du portefiltre et l'efficacité de son système de verrouillage

g. Soupape : vérifier l'absence d'enfoncement ou de déformation des platines 
h. Système de verrouillage : vérifier le bon fonctionnement

Chaque contrôle est enregistré sur un document de traçabilité.

\subsection{La cloche à vide}

Ce test est décrit dans la norme EN 868-8 de juillet 1997. Le test de la cloche à vide évalue l'imperméabilité des scellages qui ne sont formés ni par fusion ni par adhésion. Cette méthode est destinée au conteneur rigide et détermine «la capacité des scellages à préserver une pression inférieure à la pression atmosphérique pendant au moins 10 minutes, lorsque le conteneur est soumis à une pression extérieure dépassant les limites élastiques ». II s'effectue en plusieurs étapes grâce au couvercle d'essai. La première étape consiste à définir le point de dépression à partir duquel apparait une déformation sur un conteneur d'essai. La deuxième étape s'exerce sur deux conteneurs de dimensions identiques. L'essai est validé si les deux conteneurs maintiennent une dépression. Ce test difficilement réalisable en pratique quotidienne n'est plus décrit dans la dernière version de la norme EN 868-8.

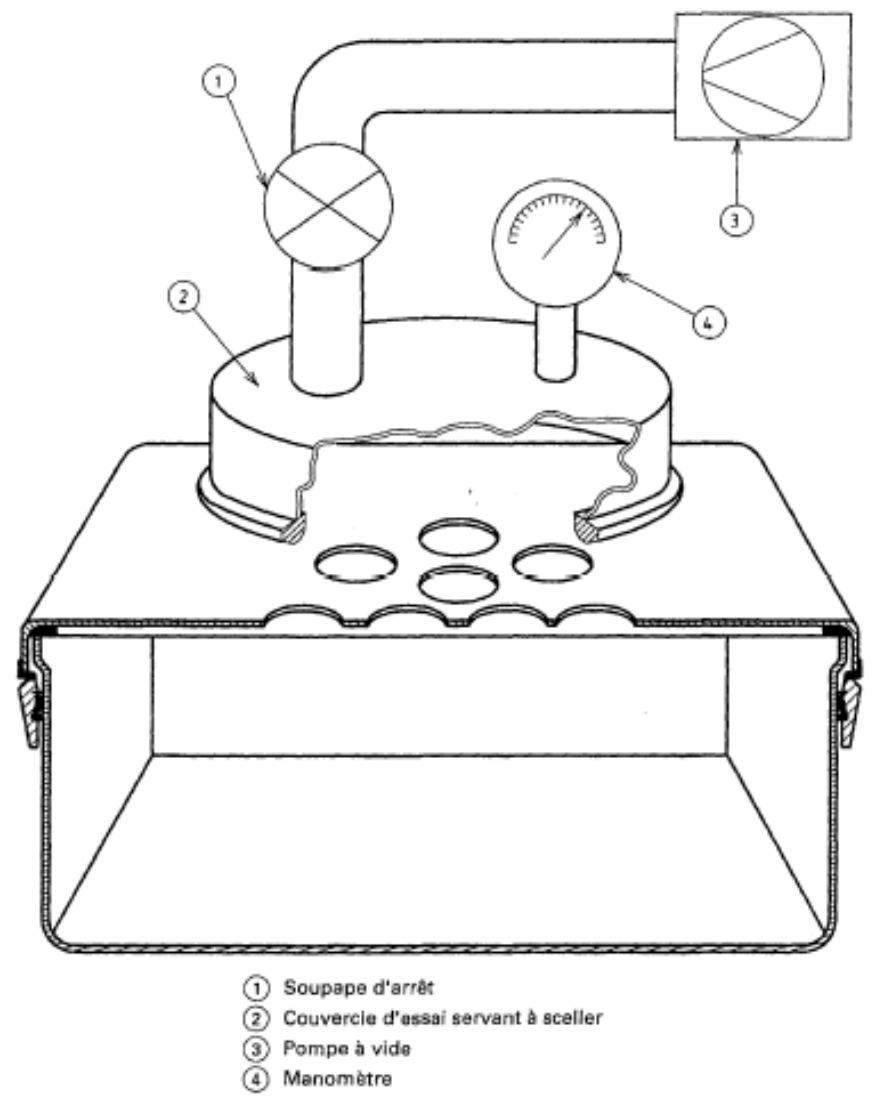

Figure 31 : Couvercle d'essai du test de la cloche à vide (25) 


\subsection{Le test aux ultrasons}

Ce test développé en partenariat avec un établissement hospitalier utilise le principe des ultrasons. Le détecteur ultrasons DE 120/EX est composé d'un émetteur placé à l'intérieur du conteneur et d'un récepteur à l'extérieur du conteneur. II convient de déplacer la sonde réceptrice sur le pourtour du conteneur afin de détecter une éventuelle fuite. En effet, la fuite crée une turbulence générant des sons à haute fréquence aussi appelés ultrasons. Cette méthode nécessite d'effectuer un étalonnage sur un conteneur neuf.(3)

\subsection{Le test de fuite à l'eau}

Le test de fuite à l'eau est aussi appelé « test par rotation sur la tranche ». Le principe du test à l'eau (2) évalue l'étanchéité de la fermeture cuve/couvercle des conteneurs. C'est un test simple et utilisé en routine au CHMS. Après contrôle visuel des fonctionnalités des conteneurs, chaque conteneur présentant un défaut fait l'objet d'un test à l'eau avant son départ en réparation. A son retour après maintenance le test est à nouveau pratiqué pour vérifier la qualité de cette opération.

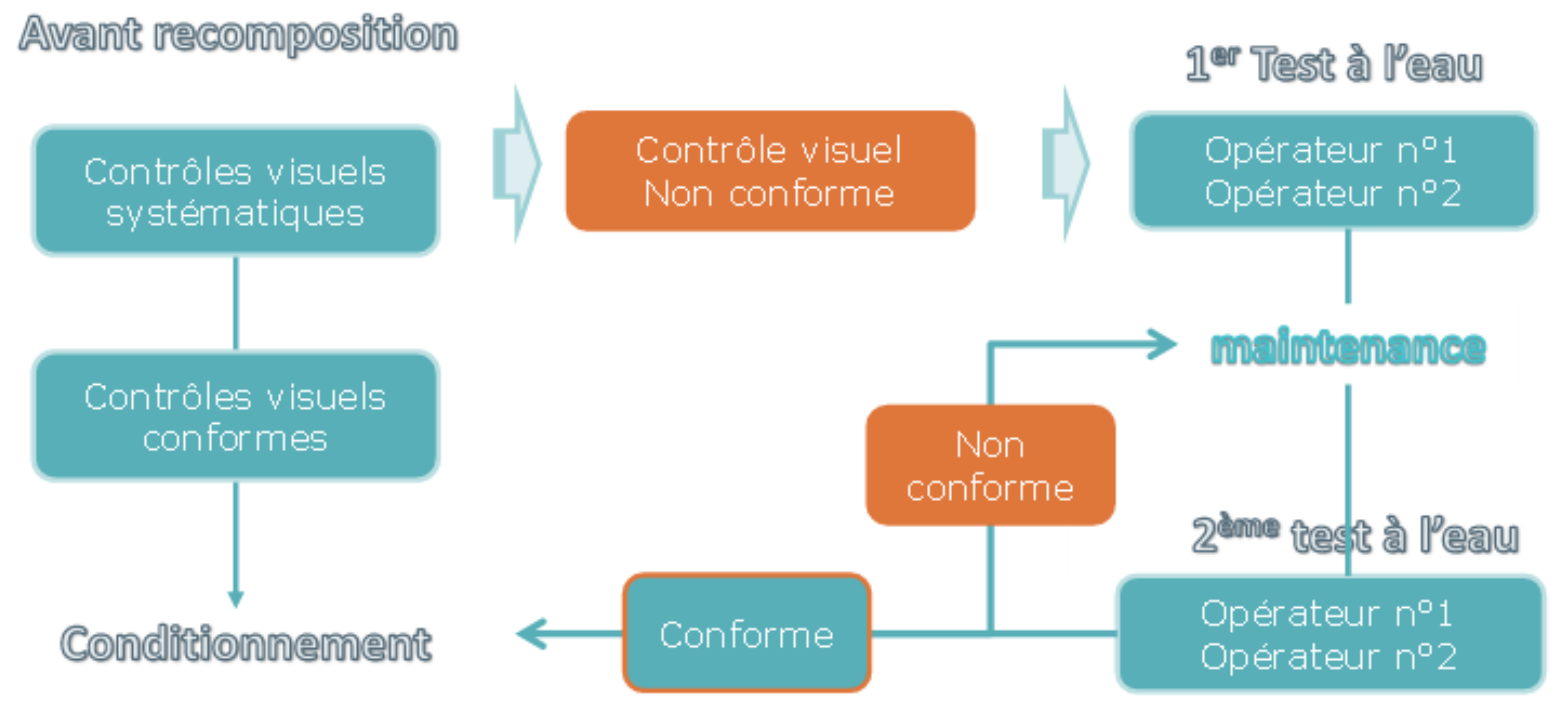

Figure 32: Protocole de suivi des conteneurs au Centre Hospitalier Métropole Savoie

(3)

Les différentes étapes du test de fuite à l'eau sont de :

a. Mettre de l'eau au fond de la cuve pour arriver à une hauteur d'environ $5 \mathrm{~mm}$

b. Remettre en place le couvercle grâce à son système de fermeture. 
c. Se placer au-dessus d'un champ permettant une meilleure visualisation des fuites d'eau.

d. Basculer avec précaution le conteneur sur la tranche afin de ne pas déborder sur le système de filtration.

e. Observer pendant 20 secondes d'éventuelles fuites.

f. Renouveler l'opération sur chacun des 4 côtés du conteneur.

Le test à l'eau est défini positif lorsque des fuites apparaissent sur au minimum l'un des côtés du conteneur testé. Le résultat est négatif en l'absence de fuites.

Ce test a fait l'objet d'une étude nationale auprès de 7 établissements de santé. Après élaboration d'un protocole commun, les 7 établissements participants ont obtenu les résultats suivants :

Tableau IV: Résultats des tests à l'eau effectués dans deux pays France (3) Suisse (26)

\begin{tabular}{ccc}
\hline Nombre d'établissements de santé & 7 & 4 \\
Nombre de conteneurs testés & 257 & 1024 \\
$\%$ de test à l'eau positif & 29 & 17
\end{tabular}

Suite aux enquêtes démontrant un nombre conséquent de conteneurs présentant une mauvaise étanchéité, AFNOR a rédigé un protocole harmonisé : FD S98-053 Juillet 2014 Protocole d'essais à effectuer sur les systèmes de barrière stérile réutilisables (conteneurs) afin d'évaluer l'étanchéité de la fermeture Cuve/Couvercle (2). 


\section{PARTIE II : ETUDE}

\section{Le contexte}

Suite aux résultats d'une l'enquête nationale montrant que $29 \%$ des conteneurs présents dans les établissements de santé présentait un résultat positif au test de fuite à l'eau (3), la question de savoir si la présence de fuites de la jonction cuve/couvercle était potentiellement corrélée au risque de perte du maintien de la stérilité dans un conteneur de stérilisation s'est naturellement imposée.

\section{L'objectif}

L'objectif de notre étude est d'évaluer le maintien de la stérilité dans les conteneurs présentant un test de fuite à l'eau positif. Un conteneur positif au test constitue-t-il toujours un système de barrière stérile ? Pour répondre à ces questions, nous allons dans un premier temps effectuer des essais préliminaires afin de déterminer les facteurs susceptibles de provoquer la pénétration de microorganismes durant le stockage et le transport entre deux établissements. Dans un second temps, nous procéderons à l'étude du maintien de l'étanchéité de la jonction cuve/couvercle des conteneurs en les exposant à un aérosol bactérien dans une chambre étanche.

\section{Essais préliminaires}

Selon différents auteurs (27)(28) l'efficacité de la barrière peut être influencée par des changements de pression. Lors d'essais préliminaires évaluant l'impact des variations de pression au cours du stockage et transport, 2 types d'emballage ont été utilisés : panier emballé sous feuille non-tissé et conteneur. Dans chacun des conditionnements ont été placées quatre sondes d'enregistrement de pression et de température (TECHNOSOFT®) avant stérilisation. Au cours de l'essai, les données sont enregistrées toutes les minutes avec une sensibilité de +/- 15 mbar et une résolution de 2 mbar et pendant une durée de 10 jours. Les quatre compositions contenaient toutes des instruments.

Les tableaux $\mathrm{V}$ et $\mathrm{VI}$ expriment le poids et le volume des compositions. Ces données seront exploitées pour le calcul du volume entrant. 


\begin{tabular}{cccccc}
\hline Type & $\begin{array}{c}\text { Poids } \\
\text { des } \\
\text { paniers } \\
\text { vides }(\mathrm{g})\end{array}$ & $\begin{array}{c}\text { Poids du } \\
\text { conteneur } \\
\text { brut }(\mathrm{g})\end{array}$ & $\begin{array}{c}\text { Poids net des } \\
\text { instruments }(\mathrm{g})\end{array}$ & $\begin{array}{c}\text { Poids } \\
\text { total } \\
(\mathrm{g})\end{array}$ & $\begin{array}{c}\text { Volume des instruments }(\mathrm{L}) \\
\text { avec d=m/V et } \\
\text { Densité (acier inoxydable) }= \\
8 \mathrm{~kg} / \mathrm{L}\end{array}$ \\
\hline Panier A & 1376 & 2190 & 3566 & 0.45 \\
Panier B & 1395 & & 2418 & 3813 & 0.48 \\
Conteneur C & 1384 & 4231 & 2847 & 7798 & 0.53 \\
Conteneur D & 1010 & 4792 & 3782 & 8310 & 0.60 \\
\hline
\end{tabular}

Tableau V : Détermination des poids composant les quatre emballages secondaires.

\begin{tabular}{cccc}
\hline Type & $\begin{array}{c}\text { Volume des instruments }(\mathrm{L}) \\
\text { avec } \mathrm{d}=\mathrm{m} / \mathrm{V} \text { et Densité } \\
\text { (acier inoxydable })=8 \mathrm{~kg} / \mathrm{L}\end{array}$ & $\begin{array}{c}\text { Volume } \\
\text { total }(\mathrm{L})\end{array}$ & $\begin{array}{c}\text { Volume disponible } \\
(\mathrm{L})=\mathrm{V} \text { total }-\mathrm{V} \\
\text { instruments }\end{array}$ \\
\hline $\begin{array}{c}\text { Conteneur } \\
\text { dimensions } 56 \times 27 \times 12 \mathrm{~cm}\end{array}$ & 0.56 & 18.14 & 17.58 \\
$\begin{array}{c}\text { Panier } \\
\text { dimensions } 51 \times 25 \times 5 \mathrm{~cm}\end{array}$ & 0.45 & 6.38 & 5.92 \\
\hline
\end{tabular}

\section{Tableau VI : Détermination des volumes des emballages}

3.1. Détermination du délai de refroidissement à la sortie des autoclaves

Afin de déterminer le délai de refroidissement à la sortie des autoclaves, des essais ont été réalisés avec quatre sondes de $\mathrm{P} / \mathrm{T}^{\circ}$ placées dans deux types d'emballages : paniers emballés sous double feuille non-tissé et des conteneurs. Les emballages contenaient tous des instruments. Toutes les compositions ont été stérilisées ensemble dans le même stérilisateur à $134^{\circ} \mathrm{C}$ pendant $18 \mathrm{~min}$. minimum. Les résultats sont présentés dans la figure 33. 


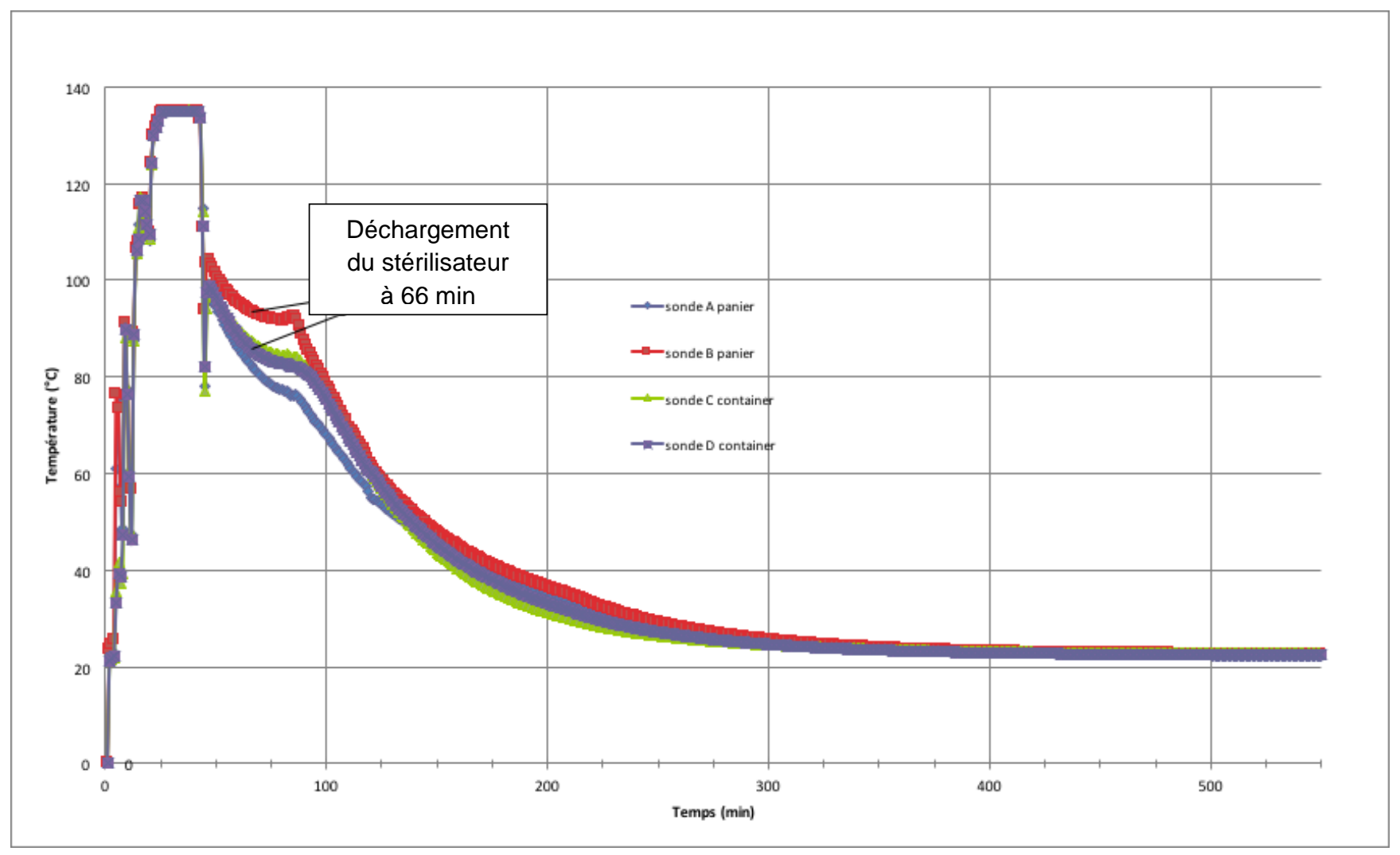

Figure 33 : Variation de la température en sortie d'autoclave

Après stérilisation et lors du déchargement, la température moyenne à l'intérieur des compositions en sortie d'autoclave est de $83,5^{\circ} \mathrm{C}$. II faut environ 120 minutes après la sortie d'autoclave pour atteindre une température de $37^{\circ} \mathrm{C}$ à l'intérieur des emballages et environ 5 heures et 30 minutes pour retourner à la température ambiante de l'arsenal soit $23^{\circ} \mathrm{C}$. II n'existe pas de différence de la vitesse de refroidissement entre les emballages souples et les conteneurs.

3.2. Détermination du volume d'air entrant dans les compositions en sortie d'autoclave

A l'issue du cycle de stérilisation et lors du refroidissement, il se produit une entrée d'air vers l'intérieur des compositions du fait du phénomène de contraction des gaz. Grâce à nos sondes de $\mathrm{P} / \mathrm{T}^{\circ}$ et en appliquant la loi des gaz parfaits [ ( pression $\times$ volume ) / température = constante ], il est possible de déterminer ce volume d'air entrant. Dans les conditions de refroidissement de la charge, la pression atmosphérique étant constante, nous pouvons utiliser cette formule

$$
\mathrm{V}_{1} / \mathrm{T}_{1}=\mathrm{V}_{2} / \mathrm{T}_{2}
$$


$T_{1}(K)$ : température moyenne mesurée des compositions en sortie d'autoclave

$\mathrm{T}_{2}(\mathrm{~K})$ : température moyenne mesurée des compositions minimums atteint après complet refroidissement

$V_{1}(L)$ : volume d'air théorique à l'intérieur des compositions en sortie d'autoclave

$V_{2}(L)$ : Volume d'air théorique à l'intérieur des compositions après refroidissement

$V_{1}-V_{2}(L)=$ volume possible de l'appel d'air extérieur

Remarque : les deux conteneurs étant de mêmes dimensions, de même pour les paniers, un seul volume est calculé.

\begin{tabular}{cccccc}
\hline Type & $\mathrm{V}_{1}(\mathrm{~L})$ & $\mathrm{T}_{1}(\mathrm{~K})$ & $\mathrm{T}_{2}(\mathrm{~K})$ & $\mathrm{V}_{2}(\mathrm{~L})$ & $\mathrm{V}_{1}-\mathrm{V}_{2}(\mathrm{~L})$ \\
\hline Conteneur & 17,02 & 356.5 & 295.5 & 14.57 & 2,45 \\
Panier & 5.63 & 356.5 & 295.5 & 4.91 & 0,72 \\
\hline
\end{tabular}

Tableau VII : Détermination des volumes d'air entrant lors du refroidissement

Le tableau VII montre qu'au cours du refroidissement, 2,45 litres d'air extérieur vont pénétrer à l'intérieur des conteneurs contre 0,72 litre dans le cas des paniers emballés.

En conditions normales, l'air pénètre au travers des filtres des conteneurs ou des emballages non-tissé ce qui n'a pas d'impact sur le maintien de l'état stérile du fait de leurs propriétés de barrière filtrante. Cependant si l'emballage non-tissé est endommagé ou si le conteneur n'est plus hermétique, l'air peut alors pénétrer en dehors du système filtrant.

3.3. Détermination des variations de pression en conditions réelles lors du stockage et du transport

Lors du transport, la variation d'altitude fait varier la pression atmosphérique. Lorsque l'altitude augmente, la pression diminue et inversement. 

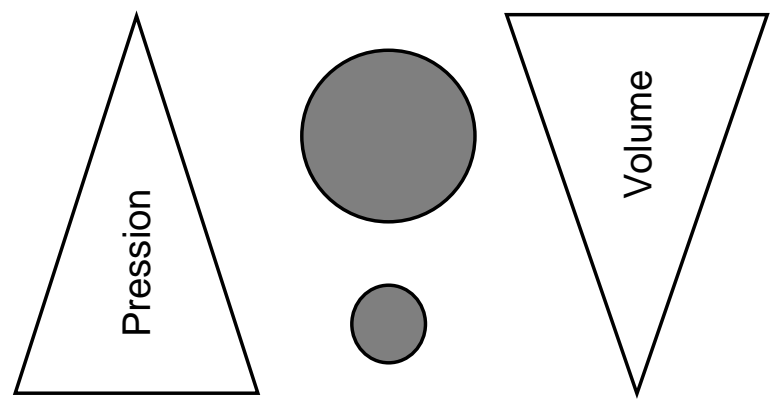

Figure 34 : Variation de la pression et du volume

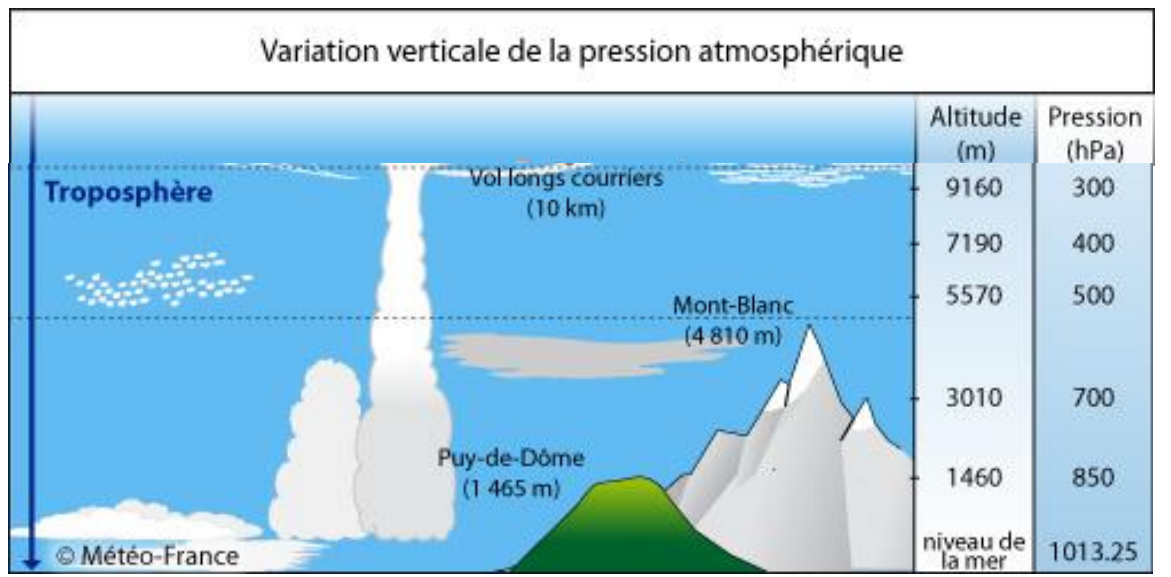

Figure 35 : Variation de la pression atmosphérique selon l'altitude d'après Météo-France ${ }^{\circledR}$

Dans un premier temps nous pouvons vérifier que la pression contenue dans les conteneurs varie de la même façon que la pression atmosphérique théorique en utilisant la formule suivante :

$$
\begin{gathered}
P(z)=P_{0}\left(1-\left(0,0065^{\star} z\right) / 288,15\right)^{5,255} \\
\text { avec } z \text { (mètre) : altitude } \\
P_{0} \text { (mbar) : pression atmosphérique } \\
P(z) \text { (mbar) : pression théorique à une altitude donnée }
\end{gathered}
$$

A partir des enregistrements des sondes de pression $/ \mathrm{T}^{\circ}$ et de la formule des gaz parfaits [ ( pression $\mathrm{x}$ volume ) / température = constante ] il est possible de déterminer le volume d'air entrant dans chaque emballage. Dans les conditions de refroidissement de la charge, la température de la zone de déchargement étant constante, nous pouvons utiliser la loi de Mariotte : 


$$
P_{1} \cdot V_{1}=P_{2} \cdot V_{2}
$$

$P_{1}$ (bar) : pression mesurée au Centre Hospitalier Métropole Savoie 0,962 bar

$\mathrm{P}_{2}$ (bar) : pression mesurée à la destination finale $\mathrm{V}_{1}(\mathrm{~L})$ : volume d'air théorique à l'intérieur des compositions au CHMS

$V_{2}(L)$ : volume d'air théorique à l'intérieur des compositions à la destination finale

Nous avons réalisé des essais en entrant nos compositions dans deux salles de bloc opératoire affichant une surpression de $25 \mathrm{~Pa}$ soit 0.25 mbar. Les variations observées à l'intérieur des emballages ne sont pas significatives étant donnée la sensibilité de la sonde à 2 mbar.

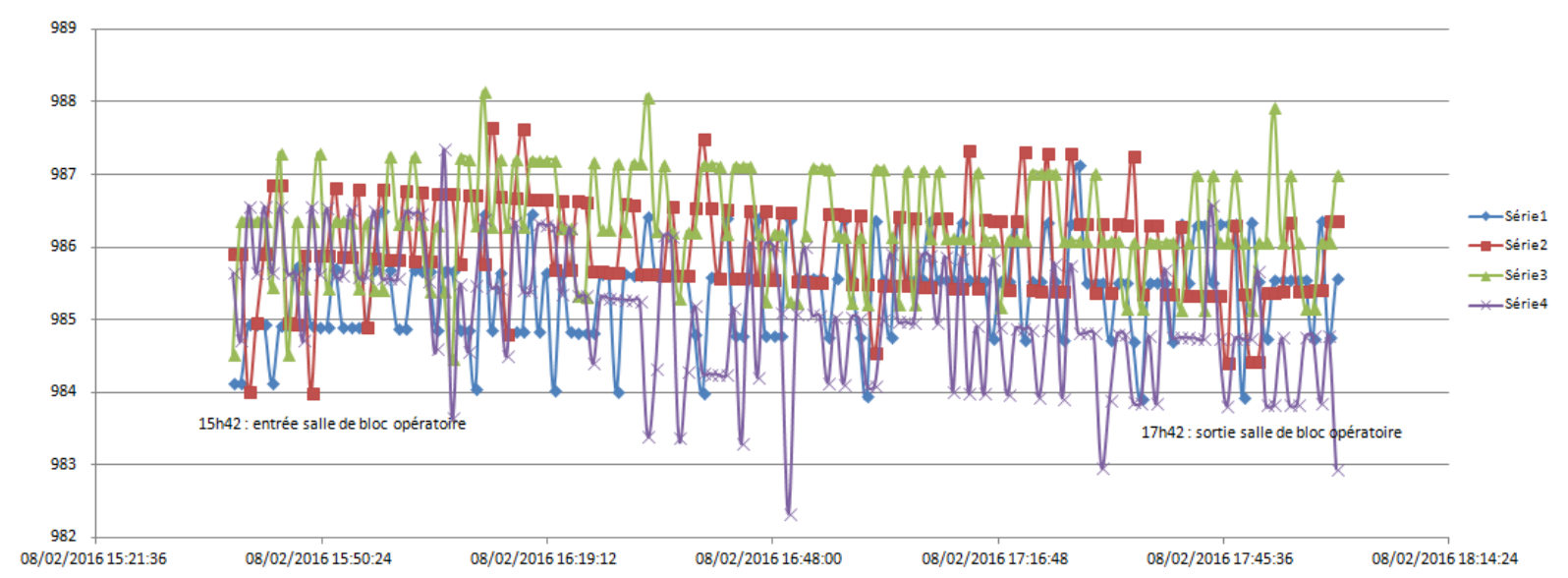

Figure 36 : variation de la pression (mbar) pendant l'entrée et la sortie d'une salle de bloc opératoire

Dans le cas d'une salle de bloc opératoire maintenue en surpression par rapport aux couloirs, nous pouvons déterminer le volume d'air entrant sous contrainte dans nos emballages (tableau VIII).

Variation par rapport au CHMS

(281 m d'altitude)
Variation entre arsenal et bloc opératoire (281 m d'latitude)

\begin{tabular}{ccccc}
\hline Altitude $(\mathrm{m})$ & 580 & 1325 & 238 & 281 \\
$\Delta \mathrm{P}(\mathrm{mbar})$ & 32 & 115 & 4 & 0,25 \\
$\mathrm{~V}_{1}-\mathrm{V}_{2}(\mathrm{~L})$ conteneur & 0,61 & 2,39 & 0,07 & 0 \\
$\mathrm{~V}_{1}-\mathrm{V}_{2}(\mathrm{~L})$ panier & 0,21 & 0,83 & 0,03 & 0 \\
\hline
\end{tabular}

$\Delta P=$ variation de pression et $V 1-V 2=$ variation de volume

Tableau VIII : variation du volume à l'intérieur des conteneurs selon la variation de pression pendant le transport 
On observe d'après le tableau VIII que la différence de pression entre la salle de bloc opératoire et le couloir ne provoque pas de variation de volume.

De la même façon, nous avons étudié les variations de pression lors du transport en ascenseur entre les étages -2 et +4 (figure 37 ).

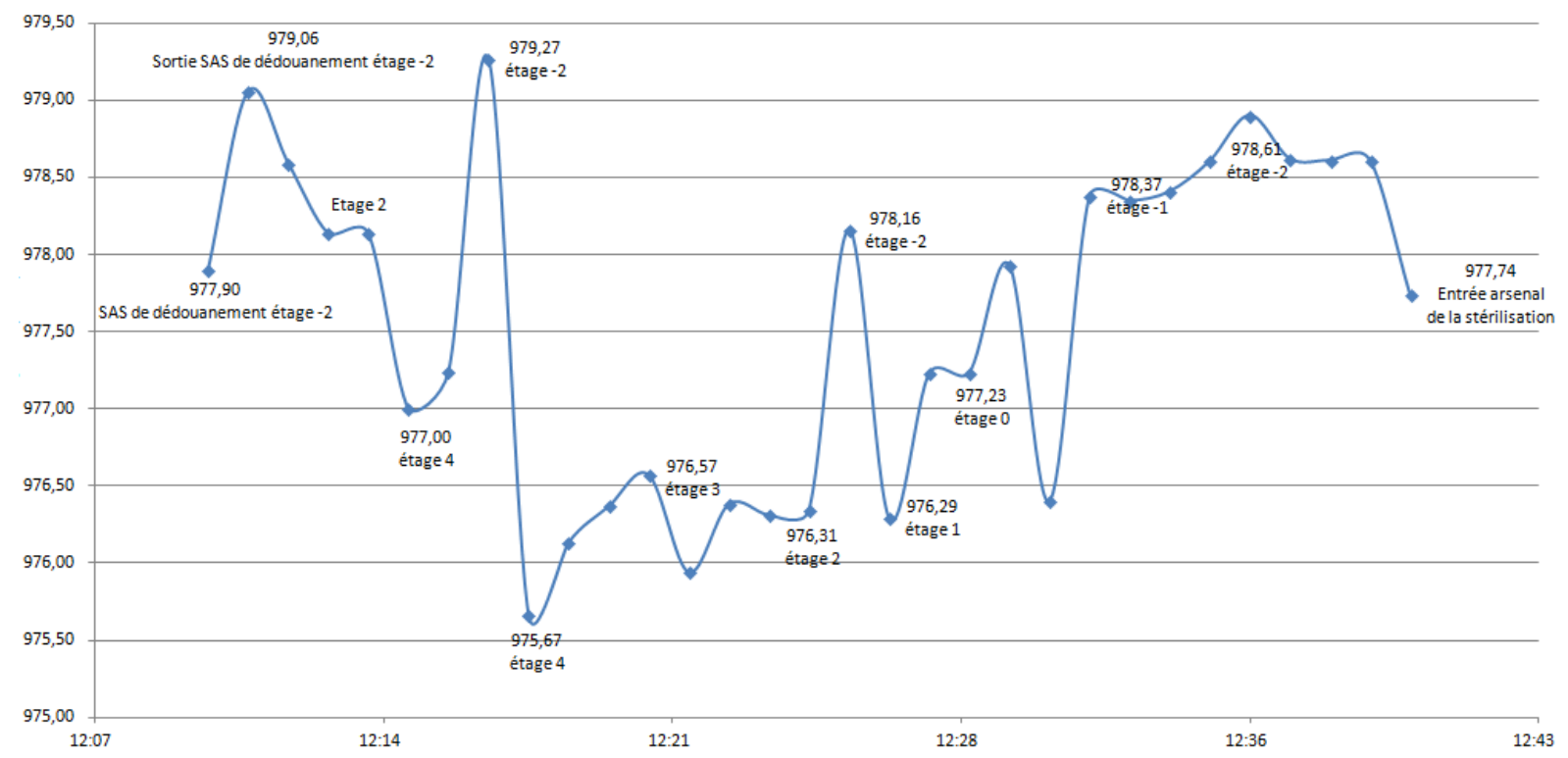

Figure 37 : variation de la pression entre les différents étage du CHMS (mbar)

Malgré la faible sensibilité des sondes employées, ce graphique nous permet d'observer les variations de la pression selon les étages de l'établissement. L'étage le plus bas (Niveau -2) présente la plus grande pression dans les emballages.

\subsection{Conclusion des essais préliminaires}

Les résultats de nos essais préliminaires montrent que lors du stockage dans les arsenaux stériles, l'entrée dans les salles opératoires ou lors des déplacements en ascenseur, les variations de pression sont trop faibles pour engendrer une pénétration d'air à l'intérieur des emballages. Ce phénomène d'entrée d'air est cependant bien marqué lors du refroidissement des compositions au déchargement du stérilisateur et lors du transport entre 2 établissements de santé situés à une altitude différente. 


\section{Matériels et méthode}

\subsection{Protocole}

Choix du microorganisme: Micrococcus luteus, comparable en taille avec Staphylococcus aureus est un coccus Gram positif aérobie avec un diamètre de taille de 1.0 à $1.8 \mu \mathrm{m}(27)$.

1. Sélection des conteneurs

A partir des conteneurs présents dans le circuit de production, et après exécution des contrôles de fonctionnalité, effectuer le test de fuite à l'eau afin de sélectionner les échantillons :

Composition d'une série de 3 conteneurs avec surcouvercle :

- F- : conteneur avec test de fuite à l'eau négatif et présence d'un filtre (= témoin négatif)

- $F+$ : conteneur avec test de fuite à l'eau positif et présence d'un filtre

- $\quad T+$ : conteneur sans filtre (= témoin positif)

Les conteneurs utilisés sont les mêmes d'une série à une autre. Ils sont identifiés tels que : $F$ - de 1 à $5 ; F+$ de 1 à 5 et $T+$ de 1 à 5

Réalisation de 15 séries de 3 conteneurs pour chaque surpression.

2. Préparer des géloses de Trypticase soja $(B D \AA)$ sur des plateaux en polypropylène de dimension $12.5 \mathrm{~cm}$ sur $22 \mathrm{~cm}$. Mettre en suspension $40 \mathrm{~g}$ de poudre dans 1 litre d'eau stérile, bien mélanger puis chauffer sous agitation fréquente et laisser bouillir pendant 1 minute de façon à dissoudre entièrement la poudre. (2 litres pour 15 plaques).

Laver puis stériliser les plateaux de PP avant chaque remplissage. Disposer 1 plateau contenant le milieu TSA dans chaque conteneur.

Composition par litre de produit :

- 15 g de digestion pancréatique de caséine

- $5 \mathrm{~g}$ de digestion papaïnique de soja

- $5 \mathrm{~g}$ de chlorure de sodium

- 15 g de gélose 
3. Stériliser les conteneurs au cours d'un même cycle à $125^{\circ} \mathrm{C}$ pendant 20 min.

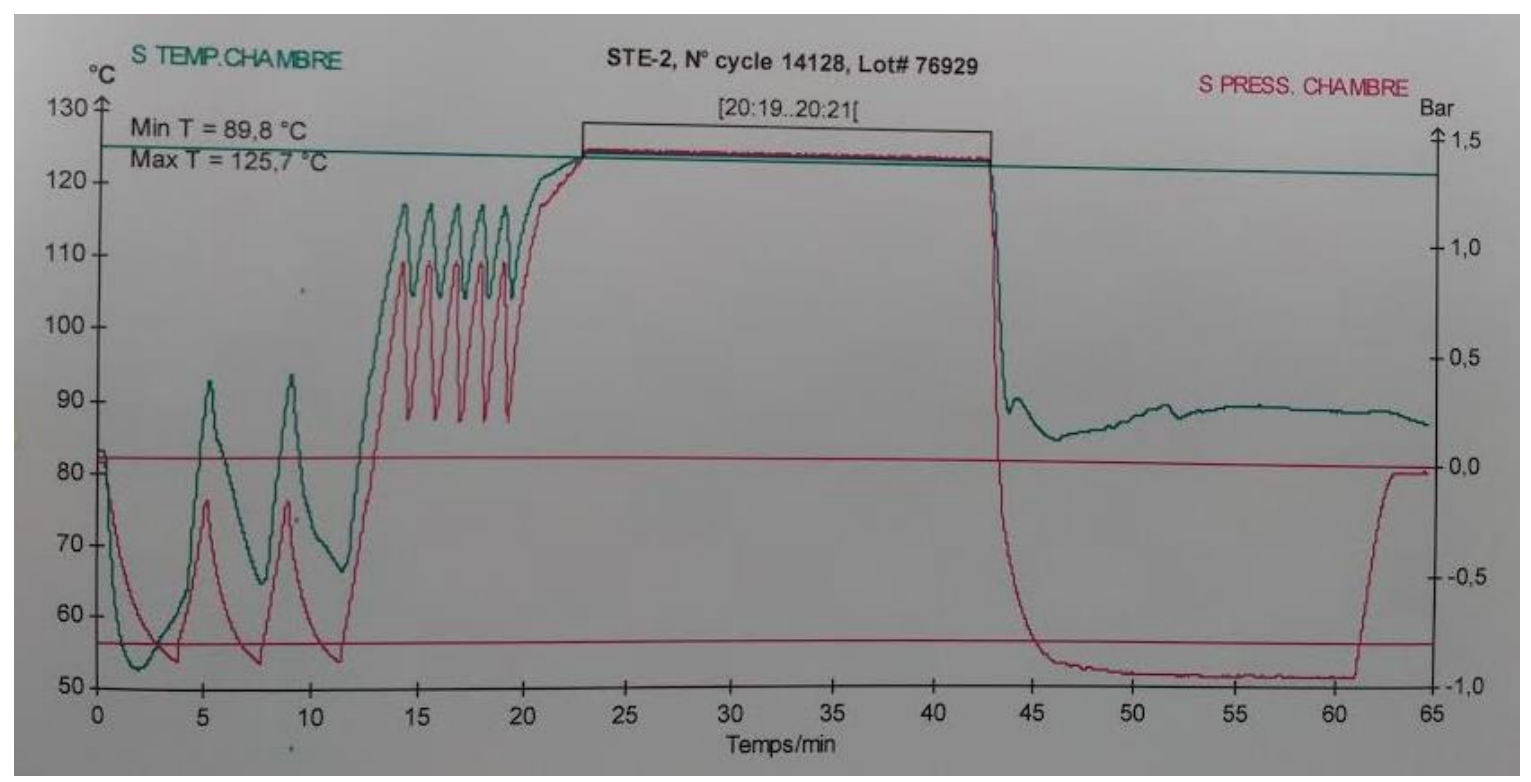

Figure 38: graphique du cycle « caoutchouc »

4. Après déchargement des conteneurs, laisser refroidir pendant $2 \mathrm{~h} 30$ (selon les essais préliminaires) dans la zone de déchargement

5. Protéger par un emballage de protection pour le transport jusqu'à la salle de manipulation

6. Préparer une série de 3 conteneurs

a. Pression utilisée : surpression de 25, 50 ou 75 mbar.

b. Aérosol biodynamique: utilisation d'un aérosol et d'une suspension de Micrococcus luteus à la concentration de $5.10^{8}$ UFC pour $1 \mathrm{ml}$. Décongélation par friction à température ambiante des aliquots de Micrococcus luteus. Dans la fiole contenant $1 \mathrm{ml}$ de solution de Micrococcus luteus, $4 \mathrm{ml}$ d'eau stérile (eau ppi) sont ajoutés avec une seringue stérile à usage unique pour un volume final de $5 \mathrm{ml}$ et une concentration finale de $10^{8} \mathrm{UFC} / \mathrm{ml}$.

c. Les conteneurs sont empilés dans la chambre d'aérosolisation d'un volume total de $0,11 \mathrm{~m}^{3}$ selon un ordre défini (voir figure 39: montage de la manipulation)

d. Nébulisation de $5.10^{8}$ UFC de Micrococcus luteus pendant 20 min avec nébuliseur EKS Pro Ultrasonic Silent Jet 0201®. 
e. Ajout de la surpression dans la chambre grâce à une pompe à air à pied.

f. Surveillance de la pression à l'intérieur de la chambre grâce au manomètre manuel externe.

g. La chambre étanche reste fermée pendant 60 minutes.

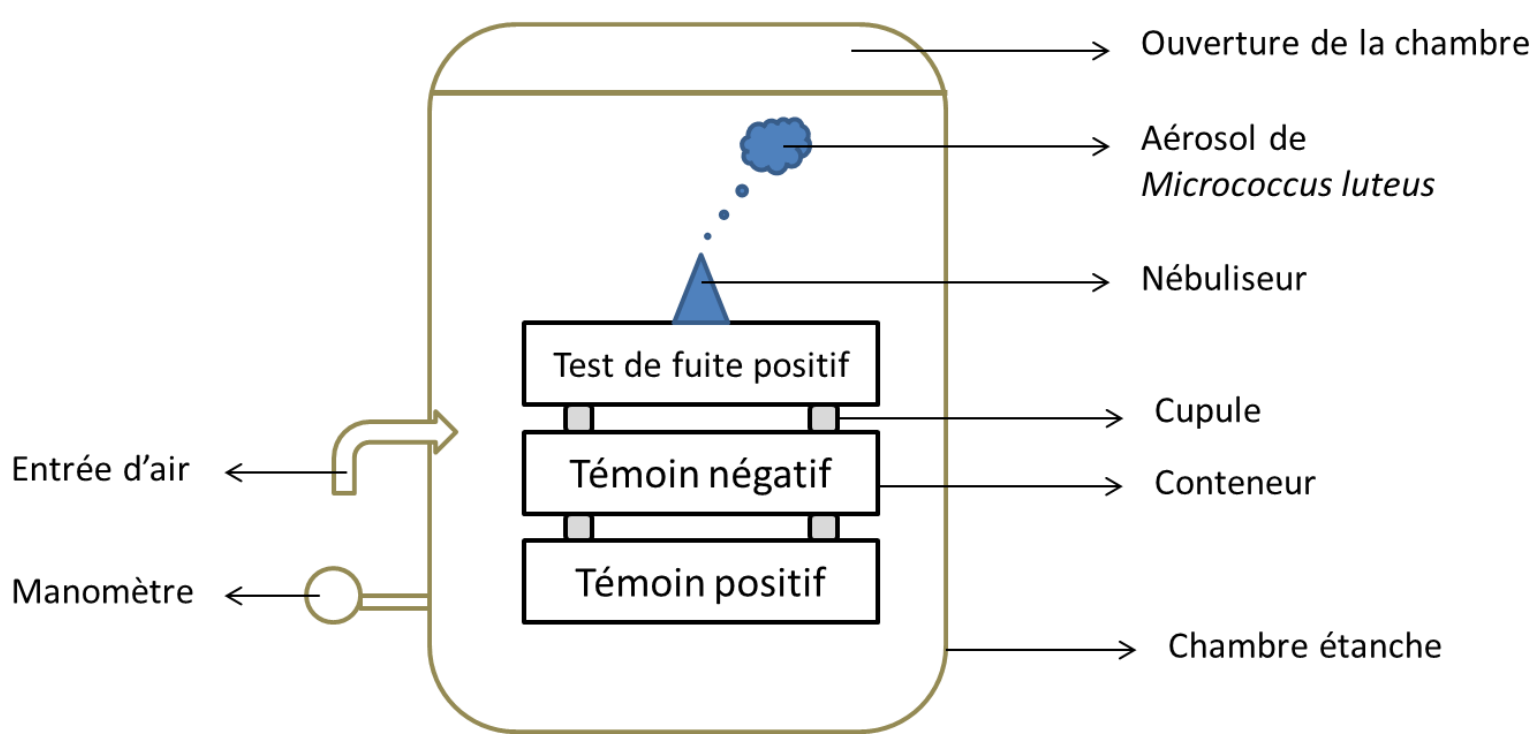

Figure 39 : montage de la manipulation

7. Retirer les conteneurs de la chambre. Désinfecter la surface grâce à une lingette BACTINYL®

8. Emballer à nouveau chaque conteneur dans un emballage de protection pour le transport jusqu'au laboratoire de bactériologie

9. Manipulation sous hotte à flux laminaire. Les conteneurs sont préalablement nettoyés avec une lingette BACTINYL®. L'aide opérateur ouvre le conteneur et le présente à l'opérateur installé sous la hotte à flux laminaire. L'opérateur attrape de façon aseptique la plaque de PP et la glisse dans un sachet de stérilisation préalablement stérilisé. Les manipulations sont réalisées avec des gants stériles sur un champ stérile.

Matériel nécessaire pour chaque manipulation :

- 2 cagoules,

- 2 masques,

- 2 casaques stériles,

- 2 paires de gants stériles, 
- 1 champ de table stérile $70 \times 90 \mathrm{~cm}$,

- 1 marqueur stérile (identification des plaques),

- Gel hydro-alcoolique,

- Lingettes BACTINYL®.

- 1 soudeuse

- 15 sachets papier/plastique préalablement stérilisés

10. La fermeture des sachets par soudure est réalisée directement sous la hotte à flux laminaire.

11. Après fermeture des emballages, les plaques sont disposées dans une étuve à $37^{\circ} \mathrm{C}$.

12. Une lecture des plaques est réalisée au $5^{\text {ème }}$ jour. Les plaques positives sont identifiées et quantifiées en UFC.

13. Chaque série de 3 conteneurs est réalisée 5 fois à la même pression
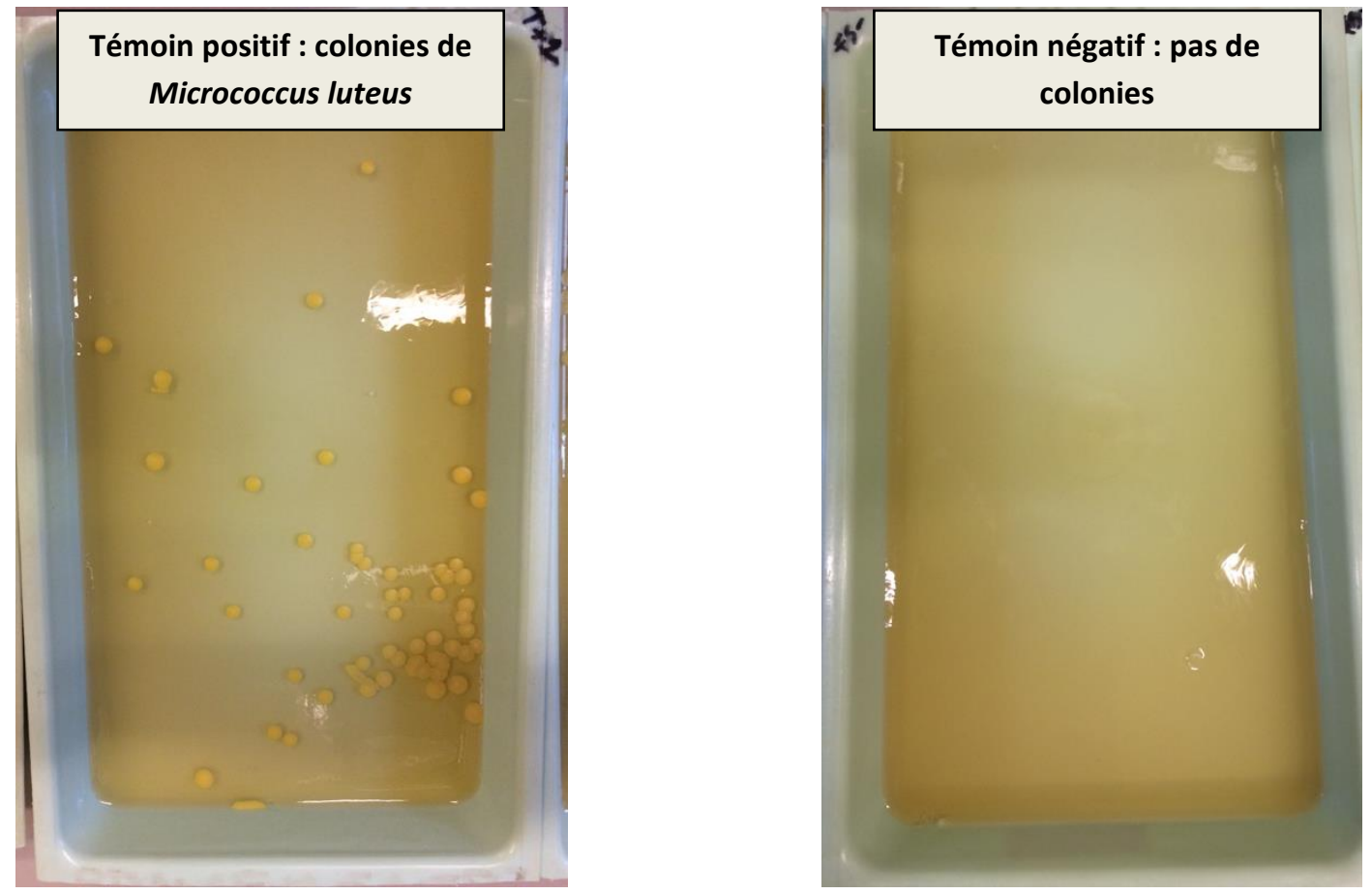

Figure 40 : Lecture des plaques de gélose TSA 


\subsection{Méthodes de calculs}

Détermination du volume entrant dans les conteneurs

Comme PV = constante, nous pouvons déterminer le volume d'arrivée dans les conteneurs grâce à la formule suivante :

$$
\mathrm{V}_{\text {arrivée }}=\left(\mathrm{P}_{\text {atmosphérique }} \cdot \mathrm{V}_{\text {départ }}\right) /\left(\mathrm{P}_{\text {atmosphérique+surpression }}\right)
$$

avec $V_{\text {départ du conteneur }}=L^{*} I^{*} h(L=$ longueur, $l=$ largeur et $h=$ hauteur).

soit $\mathrm{V}_{\text {entrant }}=\mathrm{V}_{\text {départ }}-\mathrm{V}_{\text {arrivée }}$

\section{Détermination du nombre théorique d'UFC entrant dans les conteneurs}

Sachant que $5.10^{8}$ UFC ont été nébulisées dans une chambre d'un volume de $0.11 \mathrm{~m}^{3}$, nous pouvons ainsi calculer le nombre de UFC par $\mathrm{m}^{3}$ puis déterminer avec la formule suivante le nombre d'UFC entrant dans les conteneurs en théorie :

$$
\mathrm{UFC}_{\text {entrant en théorie }}=\mathrm{UFC}_{0}=\left[\mathrm{UFC} / \mathrm{m}^{3}\right] \cdot \mathrm{V}_{\text {entrant }}
$$

Détermination du Log Reduction Value (LRV) : valeur de réduction logarithmique

$$
\mathrm{LRV}=\log \mathrm{UFC}_{0}-\log \mathrm{UFC}_{1}
$$

$\mathrm{UFC}_{0}$ : nombre total théorique de bactéries présentes dans le volume d'air et pénétrant dans les conteneurs

UFC $_{1}$ : nombre de bactéries présente sur les plaques de géloses après incubation.

Un LRV supérieur ou égale à 6 peut être considéré suffisant et permet d'obtenir le 10-6 correspondant à la définition de l'état stérile. Le Niveau d'Assurance Stérilité est obtenu lorsque le LRV est supérieur ou égale à 6.(28)

Détermination du pourcentage de la barrière filtrante

$$
\text { Barrière filtrante }(\%)=100-\left(\mathrm{UFC}_{1} .100\right) / \mathrm{UFC}_{0}
$$

\section{$\underline{\text { Particularité des calculs }}$}

Les UFC sont déterminées en quantités strictes lorsque les colonies sont visibles. Si celles-ci sont absentes UFC $<1$ ou lorsque celles-ci sont présentes en grandes quantités (UFC>300) alors :

- $\quad$ Si UFC>300 nous prenons par défaut UFC $=300$

- $\quad$ Si UFC $<1$ nous prenons par défaut UFC $=0.1$ pour le LRV car log 0 impossible et $\mathrm{UFC}=0$ pour la barrière filtrante. 


\section{Résultats}

Les résultats des essais effectués à chacune des pressions 25, 50 et 75 mbar sont présentés respectivement dans les tableaux IX, $\mathrm{X}$ et $\mathrm{XI}$.

\begin{tabular}{|c|c|c|c|c|c|c|c|}
\hline \multicolumn{2}{|c|}{$\begin{array}{l}\text { Série avec } \\
\mathrm{P}=25 \mathrm{mBar}\end{array}$} & \multirow{2}{*}{$\begin{array}{c}\begin{array}{c}\text { UFC par } \\
\text { plaque }\end{array} \\
>300\end{array}$} & \multirow{2}{*}{\begin{tabular}{|c|} 
Micrococcus luteus \\
$>300$
\end{tabular}} & \multirow{2}{*}{$\begin{array}{c}\text { Autres bactéries } \\
\text { 1 Staphylococcus cohnii }\end{array}$} & \multirow{2}{*}{$\frac{\log \text { UFC }_{0}}{5,74}$} & \multirow{2}{*}{\begin{tabular}{|c|}
$\begin{array}{c}\text { LRV }=\log \text { UFC }_{0}- \\
\log \text { UFC }_{1}\end{array}$ \\
3,26 \\
\end{tabular}} & \multirow{2}{*}{$\begin{array}{c}\begin{array}{c}\text { Barrière } \\
\text { filtrante (\%) }\end{array} \\
99,945653\end{array}$} \\
\hline & $\mathrm{T} 1+$ & & & & & & \\
\hline 1 & $\mathrm{~F} 1+$ & 250 & 250 & & 5,82 & 3,42 & 99,962013 \\
\hline & F1- & $<1$ & & & 5,82 & 6,82 & 100 \\
\hline \multirow{3}{*}{2} & $\mathrm{~T} 2+$ & $>300$ & $>300$ & & 5,74 & 3,26 & 99,945653 \\
\hline & \begin{tabular}{|l|}
$\mathrm{F} 2+$ \\
\end{tabular} & 125 & 125 & & 5,92 & 3,83 & 99,985136 \\
\hline & F2- & 23 & 23 & & 5,81 & 4,45 & 99,996426 \\
\hline \multirow{3}{*}{3} & $\mathrm{~T} 3+$ & $>300$ & $>300$ & & 5,85 & 3,37 & 99,957730 \\
\hline & F3+ & 10 & 10 & & 5,98 & 4,98 & 99,998948 \\
\hline & F3- & $<1$ & & & 5,79 & 6,79 & 100 \\
\hline \multirow{3}{*}{4} & $\mathrm{~T} 4+$ & $>300$ & $>300$ & 1 Staphylococcus cohnii, 1 bactérie non identifiable & 5,74 & 3,26 & 99,945653 \\
\hline & $\mathrm{F} 4+$ & $>300$ & & & 5,81 & 3,33 & 99,953382 \\
\hline & F4- & 1 & 1 & & 5,82 & 5,82 & 99,999848 \\
\hline \multirow{3}{*}{5} & T5+ & $>300$ & $>300$ & & 5,85 & 3,37 & 99,957730 \\
\hline & $\mathrm{F} 5+$ & 118 & 118 & & 5,98 & 3,91 & 99,987775 \\
\hline & F5- & 3 & 3 & & 5,82 & 5,34 & 99,999544 \\
\hline \multirow{3}{*}{6} & $\mathrm{~T} 1+$ & 70 & 70 & & 5,74 & 3,90 & 99,987319 \\
\hline & $\mathrm{F} 1+$ & 1 & 1 & & 5,82 & 5,82 & 99,999848 \\
\hline & F1- & $<1$ & & & 5,82 & 6,82 & 100 \\
\hline \multirow{3}{*}{7} & $\mathrm{~T} 2+$ & 61 & 60 & 1 Staphylococcus haemolyticus & 5,74 & 3,96 & 99,988949 \\
\hline & $\mathrm{F} 2+$ & $<1$ & & & 5,92 & 6,92 & 100 \\
\hline & F2- & $<1$ & & & 5,81 & 6,81 & 100 \\
\hline \multirow{3}{*}{8} & $\mathrm{~T} 3+$ & 41 & 40 & 1 Staphylococcus warmeri & 5,85 & 4,24 & 99,994223 \\
\hline & $\mathrm{F} 3+$ & $<1$ & & & 5,98 & 6,98 & 100 \\
\hline & F3- & $<1$ & & & 5,79 & 6,79 & 100 \\
\hline \multirow{3}{*}{9} & $\mathrm{~T} 4+$ & 71 & 53 & 18 bactéries non identifiées & 5,74 & 3,89 & 99,987138 \\
\hline & $\mathrm{F} 4+$ & $<1$ & & & 5,81 & 6,81 & 100 \\
\hline & F4- & $<1$ & & & 5,82 & 6,82 & 100 \\
\hline \multirow{3}{*}{10} & T5+ & $>300$ & $>300$ & & 5,85 & 3,37 & 99,957730 \\
\hline & \begin{tabular}{|l|}
$\mathrm{F} 5+$ \\
\end{tabular} & 2 & 2 & & 5,98 & 5,68 & 99,999793 \\
\hline & F5- & $<1$ & & & 5,82 & 6,82 & 100 \\
\hline \multirow{3}{*}{11} & $\mathrm{~T} 1+$ & $>300$ & $>300$ & & 5,74 & 3,26 & 99,945653 \\
\hline & $\mathrm{F} 1+$ & $<1$ & & & 5,82 & 6,82 & 100 \\
\hline & F1- & $<1$ & & & 5,82 & 6,82 & 100 \\
\hline \multirow{3}{*}{12} & $\mathrm{~T} 2+$ & $>300$ & $>300$ & & 5,74 & 3,26 & 99,945653 \\
\hline & $\mathrm{F} 2+$ & 14 & 14 & & 5,92 & 4,78 & 99,998335 \\
\hline & F2- & 3 & 2 & 1 Staphylococcus pettenkoferi & 5,81 & 5,33 & 99,999534 \\
\hline \multirow{3}{*}{13} & $\mathrm{~T} 3+$ & $>300$ & $>300$ & & 5,85 & 3,37 & 99,957730 \\
\hline & $\mathrm{F} 3+$ & 3 & 3 & & 5,98 & 5,50 & 99,999684 \\
\hline & F3- & $<1$ & & & 5,79 & 6,79 & 100 \\
\hline \multirow{3}{*}{14} & $\mathrm{~T} 4+$ & $>300$ & $>300$ & 1 Staphylococcus epidermidis & 5,74 & 3,26 & 99,945653 \\
\hline & \begin{tabular}{|l|}
$\mathrm{F} 4+$ \\
\end{tabular} & 38 & 38 & & 5,81 & 4,23 & 99,994095 \\
\hline & F4- & $<1$ & & & 5,82 & 6,82 & 100 \\
\hline \multirow{3}{*}{15} & $\mathrm{~T} 5+$ & $>300$ & $>300$ & & 5,85 & 3,37 & 99,957730 \\
\hline & \begin{tabular}{|l|}
$5+$ \\
\end{tabular} & 1 & 1 & & 5,98 & 3,91 & 99,999896 \\
\hline & F5- & $<1$ & & & 5,82 & 6,82 & 100 \\
\hline
\end{tabular}

$\mathrm{T}_{+}=$témoins positifs $; \mathrm{F}+=$ conteneurs positifs au test à l'eau ; F- = conteneurs négatifs au test à l'eau

Tableau IX : données des 15 séries à la pression de 25 mbar 


\begin{tabular}{|c|c|c|c|c|c|c|c|}
\hline \multicolumn{2}{|c|}{$\begin{array}{c}\text { Série avec } \mathrm{P}=50 \\
\mathrm{mBar}\end{array}$} & \multirow{2}{*}{$\begin{array}{c}\begin{array}{c}\text { UFC par } \\
\text { plaque }\end{array} \\
215 \\
\end{array}$} & \multirow{2}{*}{$\begin{array}{c}\begin{array}{c}\text { Micrococcus } \\
\text { luteus }\end{array} \\
213 \\
\end{array}$} & \multirow{2}{*}{$\begin{array}{c}\text { Autres bactéries } \\
1 \text { acinetobacter, } 1 \text { non identifié }\end{array}$} & \multirow{2}{*}{$\frac{\log \mathrm{UFC}_{0}}{6,03}$} & \multirow{2}{*}{$\begin{array}{c}\begin{array}{c}\mathrm{LRV}=\log \mathrm{UFC}_{0^{*}} \\
\log \mathrm{UFC}_{1}\end{array} \\
3,70\end{array}$} & \multirow{2}{*}{$\begin{array}{c}\begin{array}{c}\text { Barrière filtrante } \\
(\%)\end{array} \\
99,980057 \\
\end{array}$} \\
\hline & $\mathrm{T} 1+$ & & & & & & \\
\hline 1 & $\mathrm{~F} 1+$ & 7 & 7 & & 6,11 & 5,26 & 99,999455 \\
\hline & F1- & 5 & 5 & & 6,11 & 5,41 & 99,999611 \\
\hline \multirow{3}{*}{2} & $\mathrm{~T} 2+$ & 300 & 299 & 1 Staphylococcus hominis & 6,03 & 3,56 & 99,972173 \\
\hline & $\mathrm{F} 2+$ & 4 & 4 & & 6,22 & 5,61 & 99,999756 \\
\hline & F2- & $<1$ & & & 6,10 & 7,10 & 100 \\
\hline \multirow{3}{*}{3} & $\mathrm{~T} 3+$ & 181 & 179 & 2 Staphylococcus hominis & 6,14 & 3,88 & 99,986942 \\
\hline & $\mathrm{F} 3+$ & 1 & 1 & & 6,27 & 6,27 & 99,999946 \\
\hline & F3- & $<1$ & & & 6,08 & 7,08 & 100 \\
\hline \multirow{3}{*}{4} & $\mathrm{~T} 4+$ & 90 & 88 & 1 Staphylococcus epidermidis, 1 Staphylococcus capitis & 6,03 & 4,08 & 99,991652 \\
\hline & $\mathrm{F} 4+$ & 1 & 1 & & 6,10 & 6,10 & 99,999920 \\
\hline & F4- & 1 & & Staphylococcus haemolyticus & 6,11 & 6,11 & 99,999922 \\
\hline \multirow{3}{*}{5} & T5+ & 44 & 44 & & 6,14 & 4,50 & 99,996826 \\
\hline & $\mathrm{F} 5+$ & $<1$ & & & 6,28 & 7,28 & 100 \\
\hline & F5- & $<1$ & & & 6,11 & 7,11 & 100 \\
\hline \multirow{3}{*}{6} & $\mathrm{~T} 1+$ & 1 & 1 & & 6,03 & 6,03 & 99,999907 \\
\hline & $\mathrm{F} 1+$ & $<1$ & & & 6,11 & 7,11 & 100 \\
\hline & F1- & $<1$ & & & 6,11 & 7,11 & 100 \\
\hline \multirow{3}{*}{7} & $\mathrm{~T} 2+$ & 11 & 10 & 1 Staphylococcus coagulase négative & 6,03 & 4,99 & 99,998980 \\
\hline & $\mathrm{F} 2+$ & $<1$ & & & 6,22 & 7,22 & 100 \\
\hline & F2- & $<1$ & & & 6,10 & 7,10 & 100 \\
\hline \multirow{3}{*}{8} & $\mathrm{~T} 3+$ & 23 & 22 & 1 non identifié & 6,14 & 4,78 & 99,998341 \\
\hline & $\mathrm{F} 3+$ & $<1$ & 1 & & 6,27 & 7,27 & 100 \\
\hline & F3- & $<1$ & & & 6,08 & 7,08 & 100 \\
\hline \multirow{3}{*}{9} & $\mathrm{~T} 4+$ & 10 & 9 & 1 Staphylococcus coagulase négative & 6,03 & 5,03 & 99,999072 \\
\hline & $\mathrm{F} 4+$ & $<1$ & 1 & & 6,10 & 7,10 & 100 \\
\hline & F4- & $<1$ & & & 6,11 & 7,11 & 100 \\
\hline \multirow{3}{*}{10} & T5+ & 1 & 1 & & 6,14 & 6,14 & 99,999928 \\
\hline & $\mathrm{F} 5+$ & $<1$ & & & 6,28 & 7,28 & 100 \\
\hline & F5- & $<1$ & & & 6,11 & 7,11 & 100 \\
\hline \multirow{3}{*}{11} & $\mathrm{~T} 1+$ & 39 & 36 & 1 bacillus, 1 Staphylococcus coagulase négative, 1 non identifié & 6,03 & 4,44 & 99,996383 \\
\hline & $\mathrm{F} 1+$ & $<1$ & & & 6,11 & 7,11 & 100 \\
\hline & F1- & $<1$ & & & 6,11 & 7,11 & 100 \\
\hline \multirow{3}{*}{12} & $\mathrm{~T} 2+$ & 113 & 112 & 1 pantoea sp. & 6,03 & 3,98 & 99,989519 \\
\hline & $\mathrm{F} 2+$ & 9 & 9 & & 6,22 & 5,26 & 99,999452 \\
\hline & F2- & 7 & 7 & & 6,10 & 5,25 & 99,999443 \\
\hline \multirow{3}{*}{13} & $\mathrm{~T} 3+$ & 85 & 85 & & 6,14 & 4,21 & 99,993868 \\
\hline & $\mathrm{F} 3+$ & 3 & 3 & & 6,27 & 5,79 & 99,999838 \\
\hline & F3- & 2 & 1 & 1 Staphylococcus coagulase négative & 6,08 & 5,78 & 99,999835 \\
\hline \multirow{3}{*}{14} & $\mathrm{~T} 4+$ & 68 & 67 & 1 champignon & 6,03 & 4,20 & 99,993693 \\
\hline & $\mathrm{F} 4+$ & 9 & 9 & & 6,10 & 5,15 & 99,999284 \\
\hline & F4- & $<1$ & & & 6,11 & 7,11 & 100 \\
\hline \multirow{3}{*}{15} & T5+ & 102 & 100 & 2 Staphylococcus coagulase négative & 6,14 & 4,13 & 99,992641 \\
\hline & $\mathrm{F} 5+$ & 1 & 1 & & 6,28 & 6,28 & 99,999947 \\
\hline & F5- & $<1$ & & & 6,11 & 7,11 & 100 \\
\hline
\end{tabular}

$\mathrm{T}_{+}=$témoins positifs ; F+ = conteneurs positifs au test à l'eau ; F- = conteneurs négatifs au test à l'eau

Tableau $X$ : données des 15 séries à la pression de 50 mbar 


\begin{tabular}{|c|c|c|c|c|c|c|c|}
\hline \multicolumn{2}{|c|}{$\begin{array}{l}\text { Série avec } \\
\mathrm{P}=75 \mathrm{mBar}\end{array}$} & \multirow{2}{*}{$\begin{array}{c}\begin{array}{c}\text { UFC par } \\
\text { plaque }\end{array} \\
96 \\
\end{array}$} & \multirow{2}{*}{$\begin{array}{l}\text { Micrococcus luteus } \\
\text { nombreuses colonies }\end{array}$} & \multirow[t]{2}{*}{ Autres bactéries } & \multirow{2}{*}{$\frac{\log \mathrm{UFC}_{0}}{6,20}$} & \multirow{2}{*}{$\begin{array}{c}\begin{array}{c}\mathrm{LRV}=\log \text { UFC }_{0} \\
\log \mathrm{UFC}_{1}\end{array} \\
4,22\end{array}$} & \multirow{2}{*}{$\begin{array}{c}\begin{array}{c}\text { Barrière } \\
\text { filtrante (\%) }\end{array} \\
99,993924 \\
\end{array}$} \\
\hline \multirow{3}{*}{1} & $\mathrm{~T} 1+$ & & & & & & \\
\hline & $\mathrm{F} 1+$ & $<1$ & & & 6,28 & 7,28 & 100 \\
\hline & F1- & 1 & kocuria sp & & 6,28 & 6,28 & 99,999947 \\
\hline \multirow{3}{*}{2} & $\mathrm{~T} 2+$ & 57 & nombreuses colonies & & 6,20 & 4,44 & 99,996393 \\
\hline & $\mathrm{F} 2+$ & $<1$ & & & 6,38 & 7,38 & 100 \\
\hline & F2- & $<1$ & & & 6,27 & 7,27 & 100 \\
\hline \multirow{3}{*}{3} & $\mathrm{~T} 3+$ & 201 & nombreuses colonies & 1 colonie Staphylococcus haemolyticus & 6,31 & 4,00 & 99,990106 \\
\hline & $\mathrm{F} 3+$ & $<1$ & & & 6,43 & 7,43 & 100 \\
\hline & F3- & $<1$ & & & 6,25 & 7,25 & 100 \\
\hline \multirow{3}{*}{4} & $\mathrm{~T} 4+$ & 134 & très nombreuses colonies & 3 colonies staphylococcus hominis et 1 colonie acinetobacter johnsonii & 6,20 & 4,07 & 99,991519 \\
\hline & $\mathrm{F} 4+$ & $<1$ & & & 6,27 & 7,27 & 100 \\
\hline & F4- & 1 & 1 & & 6,28 & 6,28 & 99,999947 \\
\hline \multirow{3}{*}{5} & T5+ & 12 & quelques colonies & 1 colonie Staphylococcus coagulase négative & 6,31 & 5,23 & 99,999409 \\
\hline & $\mathrm{F} 5+$ & $<1$ & & & 6,44 & 7,44 & 100 \\
\hline & F5- & $<1$ & & & 6,28 & 7,28 & 100 \\
\hline \multirow{3}{*}{6} & $\mathrm{~T} 1+$ & 84 & 83 & 1 colonie S.hominis & 6,20 & 4,27 & 99,994684 \\
\hline & F1+ & 3 & 3 & & 6,28 & 5,80 & 99,999841 \\
\hline & F1- & $<1$ & & & 6,28 & 7,28 & 100 \\
\hline \multirow{3}{*}{7} & $\mathrm{~T} 2+$ & 79 & 78 & 1 colonie S.epidermidis & 6,20 & 4,30 & 99,995000 \\
\hline & $\mathrm{F} 2+$ & $<1$ & & & 6,38 & 7,38 & 100 \\
\hline & F2- & 2 & 2 & & 6,27 & 5,96 & 99,999891 \\
\hline \multirow{3}{*}{8} & $\mathrm{~T} 3+$ & 75 & 73 & 1 colonie S.epidermidis et 1 colonie S.pasteuri & 6,31 & 4,43 & 99,996308 \\
\hline & $\mathrm{F} 3+$ & 2 & 1 & 1 colonie S.epidermidis & 6,43 & 6,13 & 99,999926 \\
\hline & F3- & $<1$ & & & 6,25 & 7,25 & 100 \\
\hline \multirow{3}{*}{9} & $\mathrm{~T} 4+$ & 11 & 9 & 2 colonies S.epidermidis & 6,20 & 5,16 & 99,999304 \\
\hline & $\mathrm{F} 4+$ & $<1$ & & & 6,27 & 7,27 & 100 \\
\hline & F4- & $<1$ & & & 6,28 & 7,28 & 100 \\
\hline \multirow{3}{*}{10} & $\mathrm{~T} 5+$ & 11 & 11 & & 6,31 & 5,27 & 99,999459 \\
\hline & $\mathrm{F} 5+$ & $<1$ & & & 6,44 & 7,44 & 100 \\
\hline & F5- & 1 & 1 & & 6,28 & 6,28 & 99,999947 \\
\hline \multirow{3}{*}{11} & $\mathrm{~T} 1+$ & 46 & 46 & & 6,20 & 4,54 & 99,997089 \\
\hline & F1+ & 4 & 4 & & 6,28 & 5,67 & 99,999788 \\
\hline & F1. & 6 & 4 & 1 colonie Staphylococcus wameri + 1 colonie non identifiable & 6,28 & 5,50 & 99,999681 \\
\hline \multirow{3}{*}{12} & $\mathrm{~T} 2+$ & 160 & 160 & & 6,20 & 3,99 & 99,989874 \\
\hline & $\mathrm{F} 2+$ & 13 & 13 & & 6,38 & 5,27 & 99,999460 \\
\hline & F2- & 1 & 1 & & 6,27 & 6,27 & 99,999946 \\
\hline \multirow{3}{*}{13} & $\mathrm{~T} 3+$ & 114 & 114 & & 6,31 & 4,25 & 99,994388 \\
\hline & $\mathrm{F} 3+$ & $<1$ & & & 6,43 & 7,43 & 100 \\
\hline & F3- & $<1$ & & & 6,25 & 7,25 & 100 \\
\hline \multirow{3}{*}{14} & $\mathrm{~T} 4+$ & 134 & 134 & & 6,20 & 4,07 & 99,991519 \\
\hline & $\mathrm{F} 4+$ & 4 & 4 & & 6,27 & 5,66 & 99,999783 \\
\hline & F4- & $<1$ & & & 6,28 & 7,28 & 100 \\
\hline \multirow{3}{*}{15} & T5+ & 46 & 46 & & 6,31 & 4,65 & 99,997736 \\
\hline & F5+ & $<1$ & & & 6,44 & 7,44 & 100 \\
\hline & F5- & $<1$ & & & 6,28 & 7,28 & 100 \\
\hline
\end{tabular}

$\mathrm{T}_{+}=$témoins positifs ; F+ = conteneurs positifs au test à l'eau ; F- = conteneurs négatifs au test à l'eau

Tableau XI : données des 15 séries à la pression de 75 mbar

Dans les figures 41,42 et 43 , les résultats des tableauX IX, X et XI sont classés en 4 groupes : < 1 UFC ; de 1 à 9 UFC; de 10 à 99 UFC et > 100 UFC.

Les résultats montrent que :

- quel que soit la pression appliquée, $100 \%$ des conteneurs ne disposant pas de filtres ( $T+)$ sont contaminés.

- A 25 mbar, 74\% des conteneurs présentant une fuite au test à l'eau laissent pénétrer les microorganismes malgré la présence barrière filtrante. $53 \%$ des mêmes containers sont contaminés à 50 mbar et $33 \%$ à 75 mbar. 

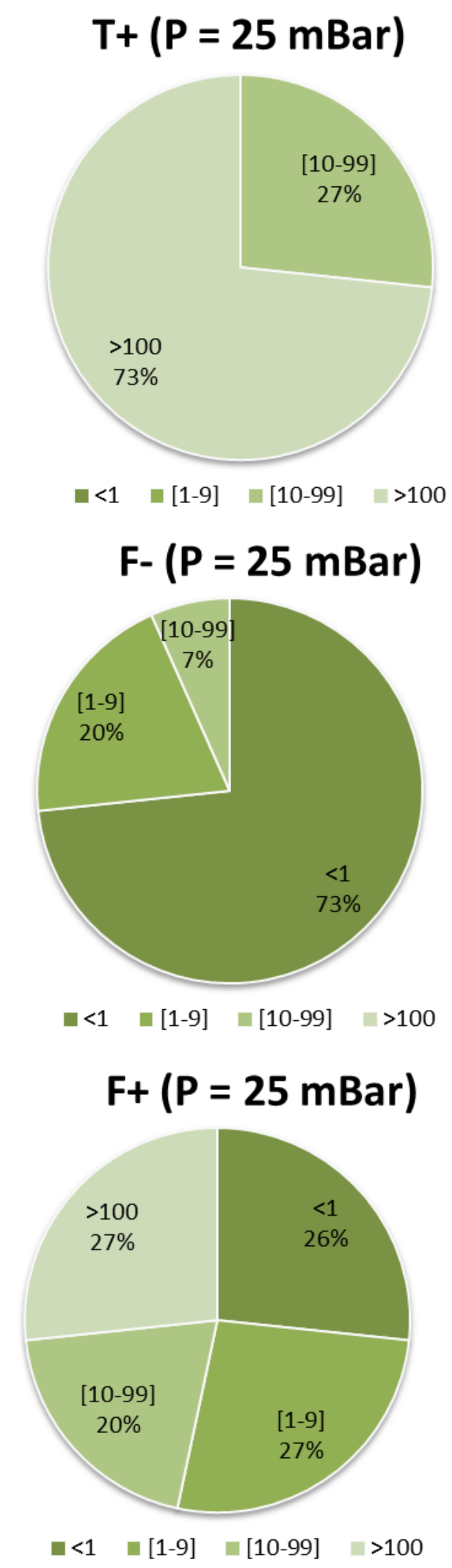

$\mathrm{T}_{+}=$témoins positifs $; \mathrm{F}+=$ conteneurs positifs au test à l'eau ; F- = conteneurs négatifs au test à l'eau Figure 41 : Répartition du nombre d'UFC par conteneur à une pression de 25 mbar 

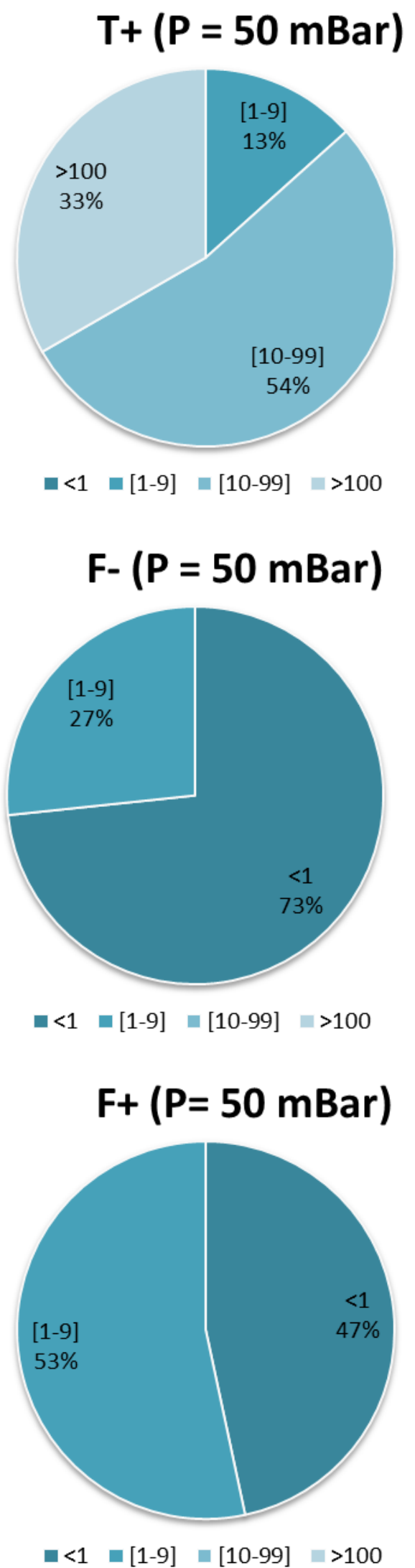

$\mathrm{T}_{+}=$témoins positifs ; $\mathrm{F}+=$ conteneurs positifs au test à l'eau ; F- = conteneurs négatifs au test à l'eau Figure 42 : Répartition du nombre d'UFC par conteneur à une pression de 50 mbar 


\section{$\mathrm{T}+(\mathrm{P}=75 \mathrm{mBar})$}
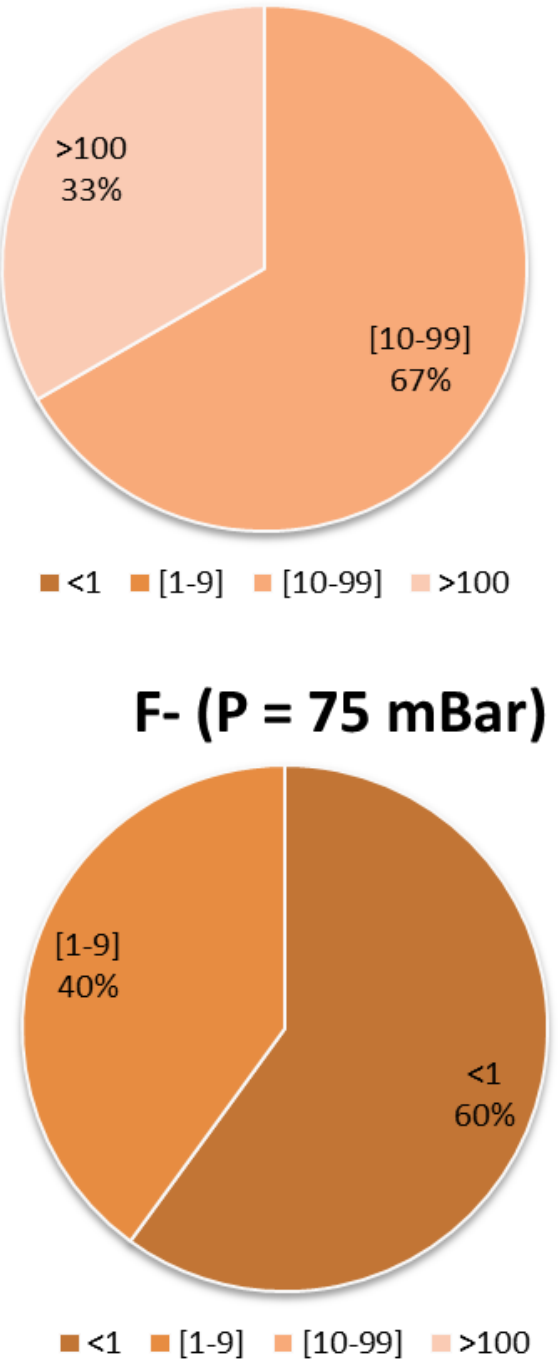

\section{$\mathrm{F}+(\mathrm{P}=75 \mathrm{mBar})$}

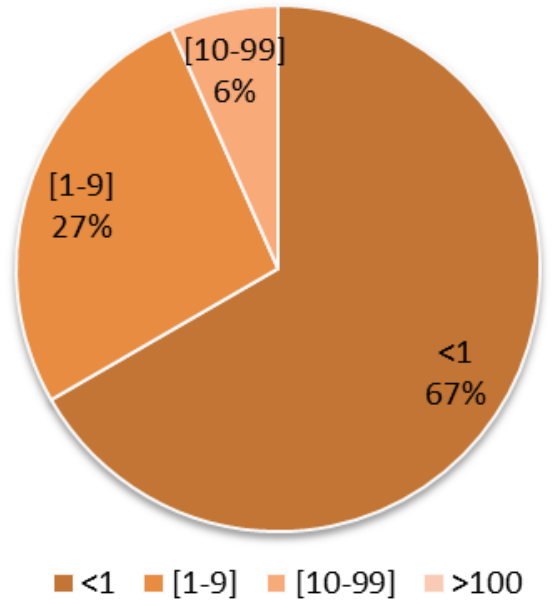

$\mathrm{T}_{+}=$témoins positifs ; $\mathrm{F}+=$ conteneurs positifs au test à l'eau ; F- = conteneurs négatifs au test à l'eau

Figure 43 : Répartition du nombre d'UFC par conteneur à une pression de 75 mbar 
Les données sélectionnées pour les tests statistiques ont été basées sur la pression et le LRV. La moyenne a été effectuée sur le nombre d'UFC retrouvées sur les plaques de géloses selon le type de conteneur ( 5 conteneurs témoins positifs, 5 conteneurs avec un test de fuite à l'eau positif et 5 conteneurs avec un test de fuite à l'eau négatif). Cette moyenne est réalisable étant donné que ce sont les mêmes conteneurs qui ont été utilisés pour les différentes séries. La méthode ANOVA (analyse de la variance) a été choisie pour cette analyse. Elle évalue l'importance d'un ou plusieurs facteurs en comparant les moyennes des variables de réponse du LRV pour les différents niveaux de facteurs (pression et type de conteneurs). 


\begin{tabular}{|c|c|c|c|}
\hline & Type conteneur & Pression (mBar) & $\mathrm{LRV}_{\text {moyenne }}$ \\
\hline T1+ & $T+$ & 25 & 3,39299769 \\
\hline F1+ & $\mathrm{F}+$ & 25 & 3,89573862 \\
\hline F1- & $\mathrm{F}-$ & 25 & 5,81830839 \\
\hline $\mathrm{T} 2+$ & $\mathrm{T}+$ & 25 & 3,39952207 \\
\hline $\mathrm{F} 2+$ & $\mathrm{F}+$ & 25 & 4,28467999 \\
\hline F2- & $\mathrm{F}-$ & 25 & 4,87054405 \\
\hline T3+ & $\mathrm{T}+$ & 25 & 3,52134567 \\
\hline F3+ & $\mathrm{F}+$ & 25 & 5,34152134 \\
\hline F3- & $\mathrm{F}-$ & 25 & 6,7934848 \\
\hline T4+ & $\mathrm{T}+$ & 25 & 3,39233701 \\
\hline F4+ & $\mathrm{F}+$ & 25 & 3,75675486 \\
\hline F4- & $\mathrm{F}-$ & 25 & 6,29979445 \\
\hline T5+ & $\mathrm{T}+$ & 25 & 3,37396797 \\
\hline F5+ & $\mathrm{F}+$ & 25 & 4,37900185 \\
\hline F5- & $\mathrm{F}-$ & 25 & 5,81830839 \\
\hline T1+ & $\mathrm{T}+$ & 50 & 4,10323955 \\
\hline F1+ & $\mathrm{F}+$ & 50 & 5,74166619 \\
\hline F1- & $\mathrm{F}-$ & 50 & 5,88630564 \\
\hline $\mathrm{T} 2+$ & $\mathrm{T}+$ & 50 & 3,88242412 \\
\hline $\mathrm{F} 2+$ & $\mathrm{F}+$ & 50 & 5,57898955 \\
\hline F2- & $\mathrm{F}-$ & 50 & 5,73192096 \\
\hline T3+ & $\mathrm{T}+$ & 50 & 4,15804139 \\
\hline $\mathrm{F} 3+$ & $\mathrm{F}+$ & 50 & 6,14487132 \\
\hline F3- & $\mathrm{F}-$ & 50 & 6,25812373 \\
\hline T4+ & $\mathrm{T}+$ & 50 & 4,28447045 \\
\hline F4+ & $\mathrm{F}+$ & 50 & 5,57683265 \\
\hline F4- & $\mathrm{F}-$ & 50 & 6,59050818 \\
\hline T5+ & $\mathrm{T}+$ & 50 & 4,45160687 \\
\hline F5+ & $\mathrm{F}+$ & 50 & 6,75682986 \\
\hline F5- & $\mathrm{F}-$ & 50 & 7,10902212 \\
\hline T1+ & $T+$ & 75 & 4,32170488 \\
\hline F1+ & $\mathrm{F}+$ & 75 & 5,90768056 \\
\hline F1- & $\mathrm{F}-$ & 75 & 5,90768056 \\
\hline $\mathrm{T} 2+$ & $\mathrm{T}+$ & 75 & 4,20448772 \\
\hline $\mathrm{F} 2+$ & $\mathrm{F}+$ & 75 & 5,74500392 \\
\hline F2- & $\mathrm{F}-$ & 75 & 6,26529125 \\
\hline T3+ & $\mathrm{T}+$ & 75 & 4,19387396 \\
\hline $\mathrm{F} 3+$ & $\mathrm{F}+$ & 75 & 6,60866252 \\
\hline F3- & $\mathrm{F}-$ & 75 & 7,2502129 \\
\hline T4+ & $\mathrm{T}+$ & 75 & 4,2301899 \\
\hline F4+ & $\mathrm{F}+$ & 75 & 6,14143961 \\
\hline F4- & $\mathrm{F}-$ & 75 & 6,75652254 \\
\hline T5+ & $\mathrm{T}+$ & 75 & 4,94608948 \\
\hline $\mathrm{F} 5+$ & $\mathrm{F}+$ & 75 & 7,44135817 \\
\hline F5- & $\mathrm{F}-$ & 75 & 6,75652254 \\
\hline
\end{tabular}

$\mathrm{T}_{+}=$témoins positifs ; F+ = conteneurs positifs au test à l'eau ; F- = conteneurs négatifs au test à l'eau

Tableau XII : données utilisées pour les tests statistiques 
Chaque LRV moyen est représenté par un point dans la figure ci-dessous selon la pression et le type de conteneurs. Les conteneurs négatifs au test à l'eau (contrôle négatif, F-) ont un LRV plus élevé que les témoins positifs ( $T+$ ).

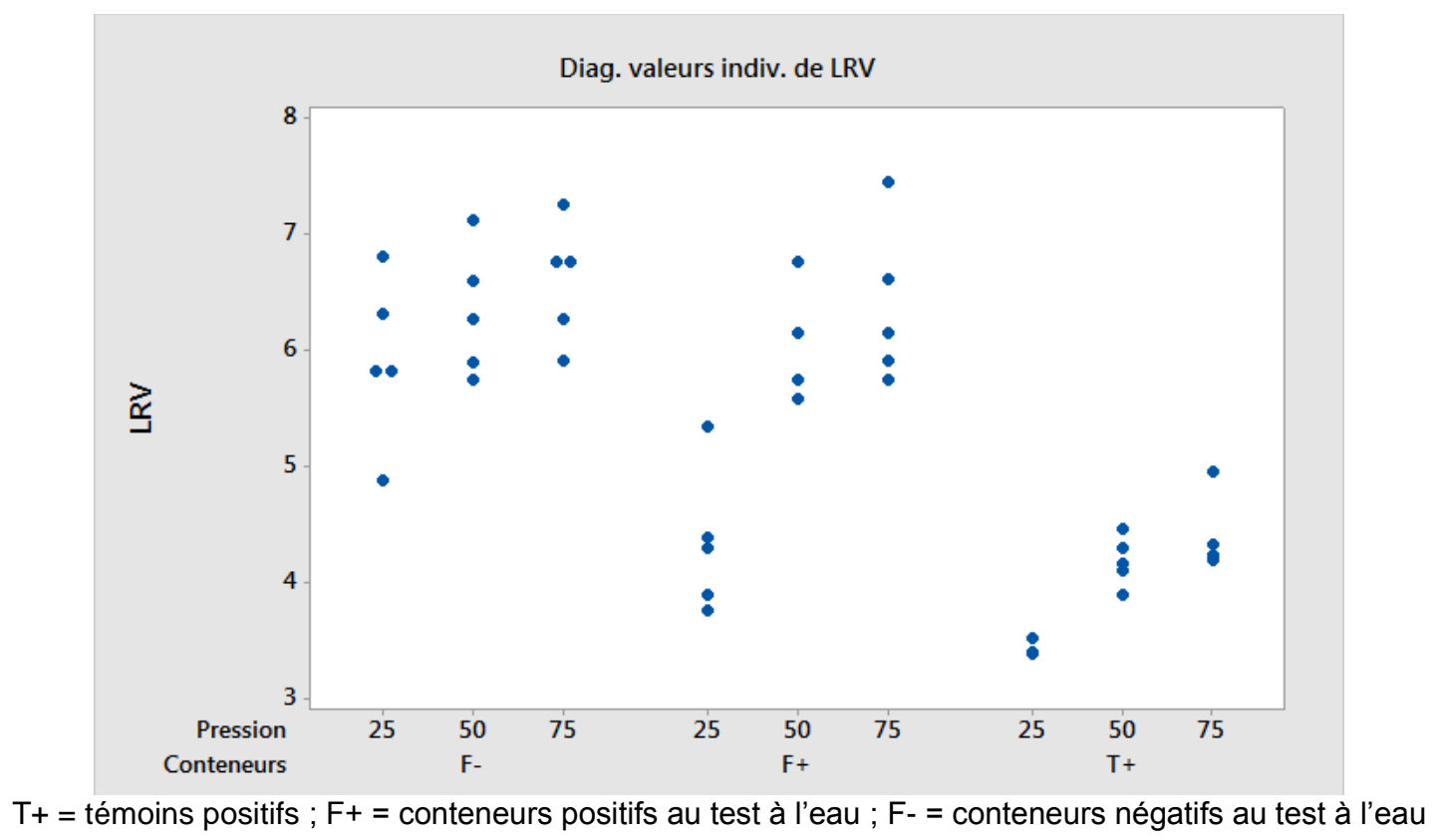

Figure 44 : Représentation graphique des données

Dans un second temps, plusieurs critères sont à tester selon la méthode ANOVA (analyse de la variance).

- Les comparaisons multiples permettent d'évaluer la différence entre des moyennes à l'aide d'un intervalle de confiance. Les intervalles de confiance (Figure 45) n'incluent pas la valeur zéro, l'hypothèse nulle est rejetée signifiant ainsi qu'il existe une différence significative entre les moyennes ( $p$-valeur $=0,020$ ).

- Le test de Levene teste l'homogénéité des variances. L'égalité des variances est une condition afin d'effectuer les tests paramétriques. Les variances sont homogènes au seuil alpha $=5 \%(p$-valeur $=0,067)$

- La méthode des comparaisons multiples est souvent plus puissante, ici p-valeur des comparaisons multiples est plus faible que le test de Levene. 


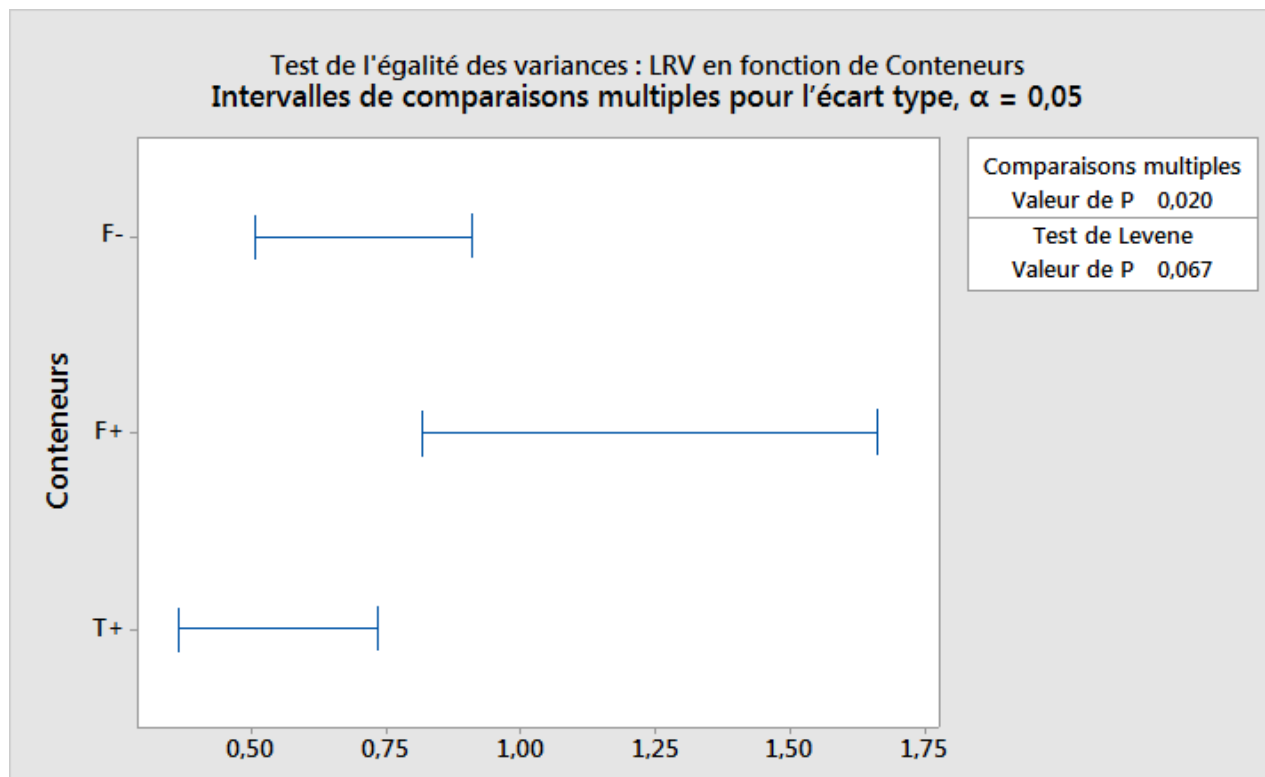

Si les intervalles ne se superposent pas, les écarts types correspondants sont significativement différents.

$\mathrm{T}+=$ témoins positifs ; F+ = conteneurs positifs au test à l'eau ; F- = conteneurs négatifs au test à l'eau

Figure 45 : Analyse de la variance entre les groupes (conteneurs)

Une carte multivariée a été réalisée dans la figure ci-dessous. Elle représente graphiquement les relations entre des facteurs (ici la pression et le type de conteneurs) et la réponse (LRV). Cela permet de comprendre les interactions. Nous pouvons observer dans l'analyse multivariée qu'en moyenne, la différence entre le témoin positif $(T+)$ et les conteneurs F- et F+ est assez importante pour chaque pression. Le graphique de l'analyse multivariée montre aussi que plus la pression est basse moins le LRV est important.

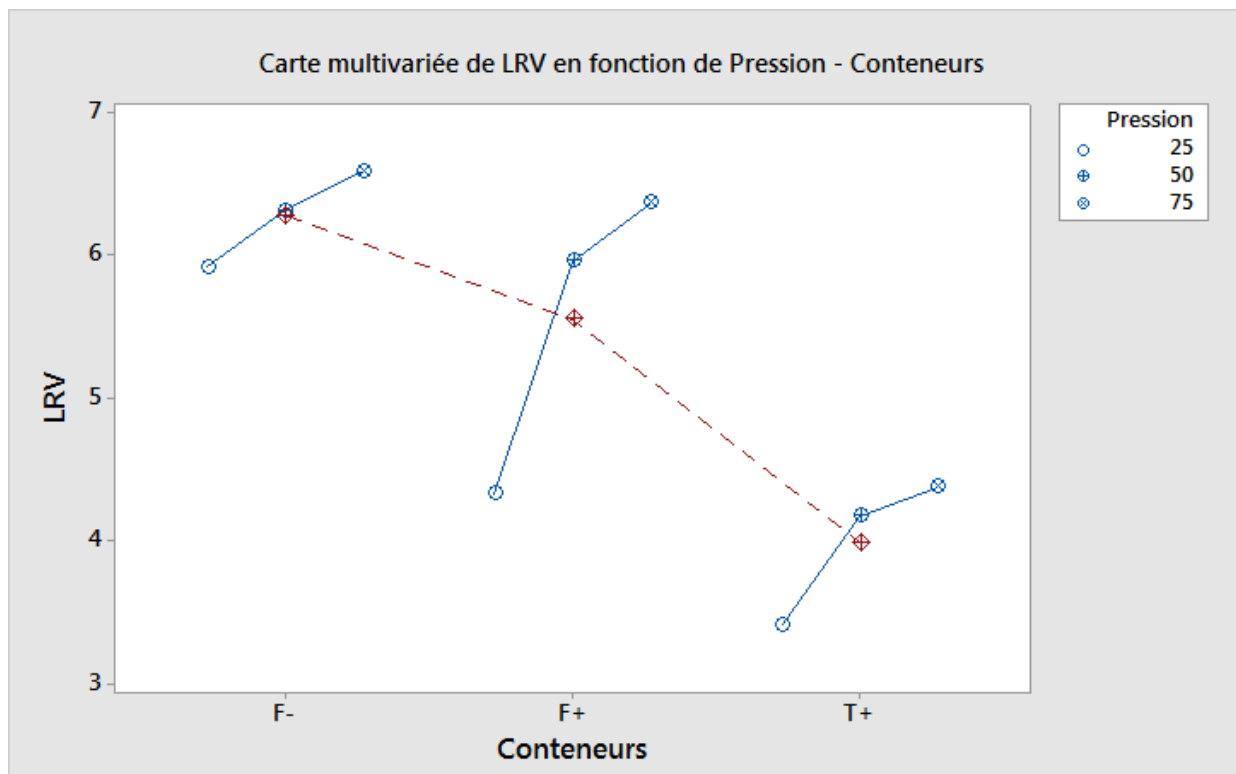

$\mathrm{T}_{+}=$témoins positifs $; \mathrm{F}+=$ conteneurs positifs au test à l'eau ; F- = conteneurs négatifs au test à l'eau

Figure 46 : Analyse multivariée 
Le diagramme des valeurs résiduelles examine l'ajustement adéquat dans les analyses ANOVA et de régression. Nous pouvons voir sur la figure ci-dessous que les valeurs sont normalement distribuées grâce à la droite de Henry. L'analyse des résidus est correcte et permet l'analyse des résultats de l'ANOVA.

Au seuil alpha $=5 \%$, il y a suffisamment de preuves statistiques pour dire qu'il y a un effet "conteneur" (ANOVA p-valeur $=0,000$ ) et un effet "pression" ( $p$-valeur $=0,012$ ) sur la valeur du LRV. Par contre, aucune interaction pression-conteneur n'est observée ( $p$ valeur $=0,08)$.

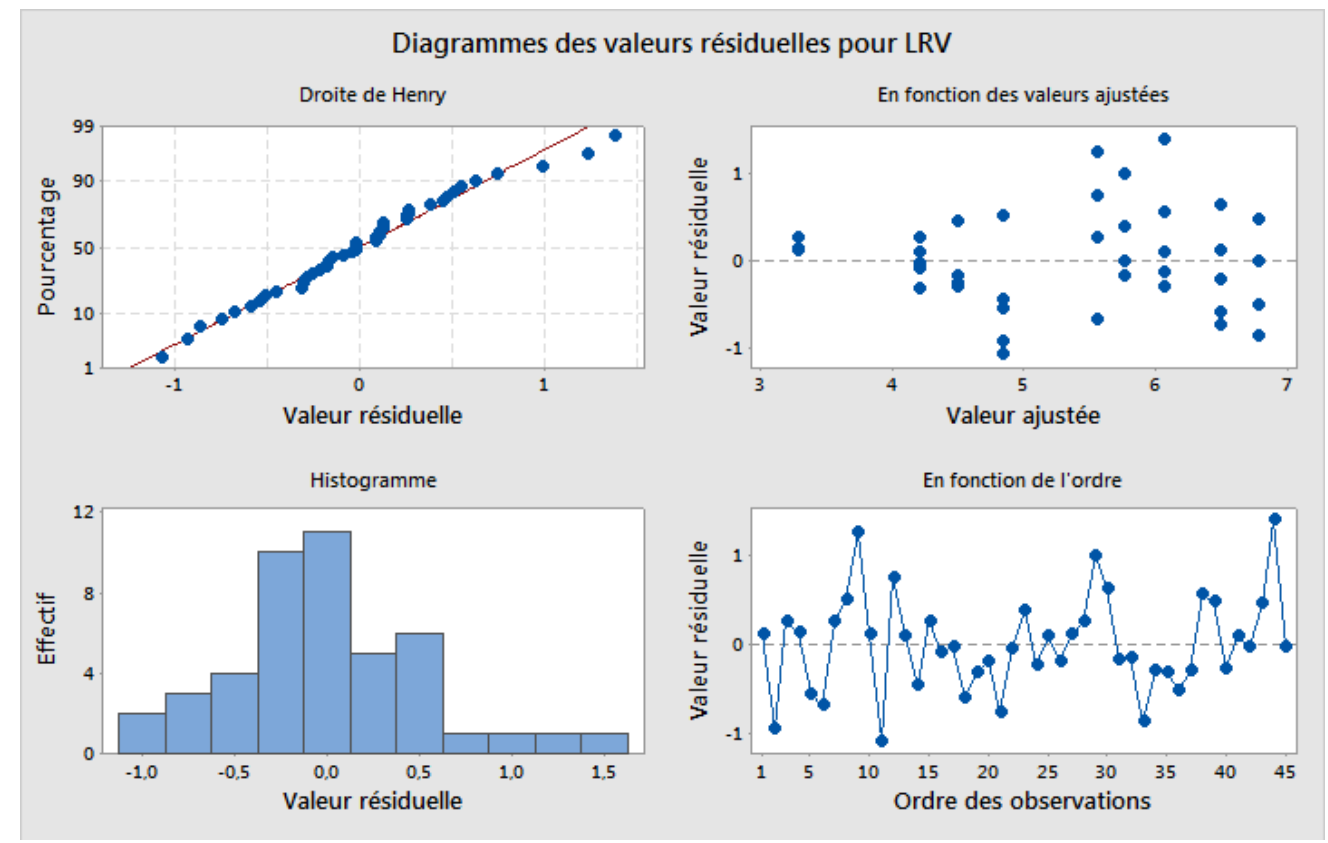

Figure 47 : Analyse de variance à deux facteurs - modèle linéaire général : LRV en fonction de Pression ; Conteneurs

La méthode de Dunnett a été utilisée dans la suite des résultats, elle permet la création d'intervalles de confiance pour les différences entre la moyenne de chaque niveau de facteur et la moyenne d'un groupe de contrôle, ici les conteneurs et le LRV.

Dans la figure 48 , au seuil alpha $=5 \%$, il y a une différence statistiquement significative entre les conteneurs négatifs au test à l'eau (contrôle négatif, F-) et les conteneurs positifs $(F+)(p$-valeur $=0,002)$. 


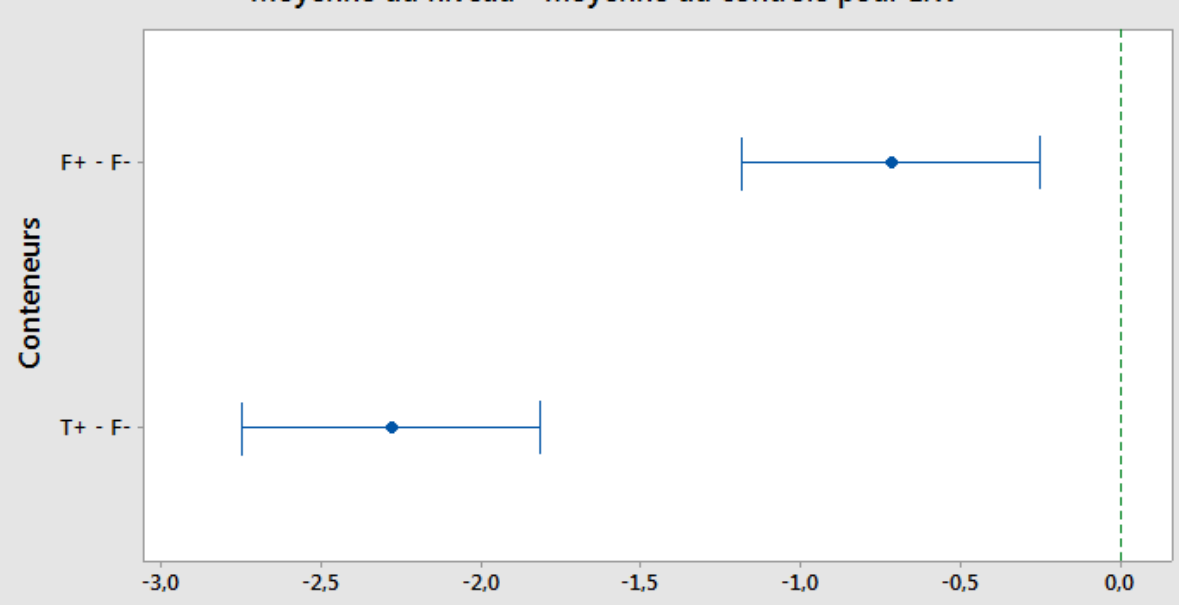

Projet : rapport Lucie Decarout.mpj; Feuille de travail : Feuille de travail 1; 24/02/2017 15:46:09

Si un intervalle ne contient pas la valeur zéro, la moyenne correspondante est

significativement différente de la moyenne du contrôle.

$\mathrm{T}_{+}=$témoins positifs $; \mathrm{F}+=$ conteneurs positifs au test à l'eau ; F- = conteneurs négatifs au test à l'eau

Figure 48 : Analyse Post-hoc des moyennes différentes - comparaisons multiples de Dunnett avec un contrôle $:$ réponse $=\mathrm{LRV}$, terme $=$ Conteneurs

De la même manière dans la figure 49 , au seuil alpha $=5 \%$, il y a une différence statistiquement significative entre le contrôle positif $T+$ et les conteneurs positifs au test à l'eau $(F+)(p$-valeur=0,002) ainsi qu'entre le contrôle positif $\mathbf{T +}$ et les conteneurs négatifs au test à l'eau ( $F-)$.

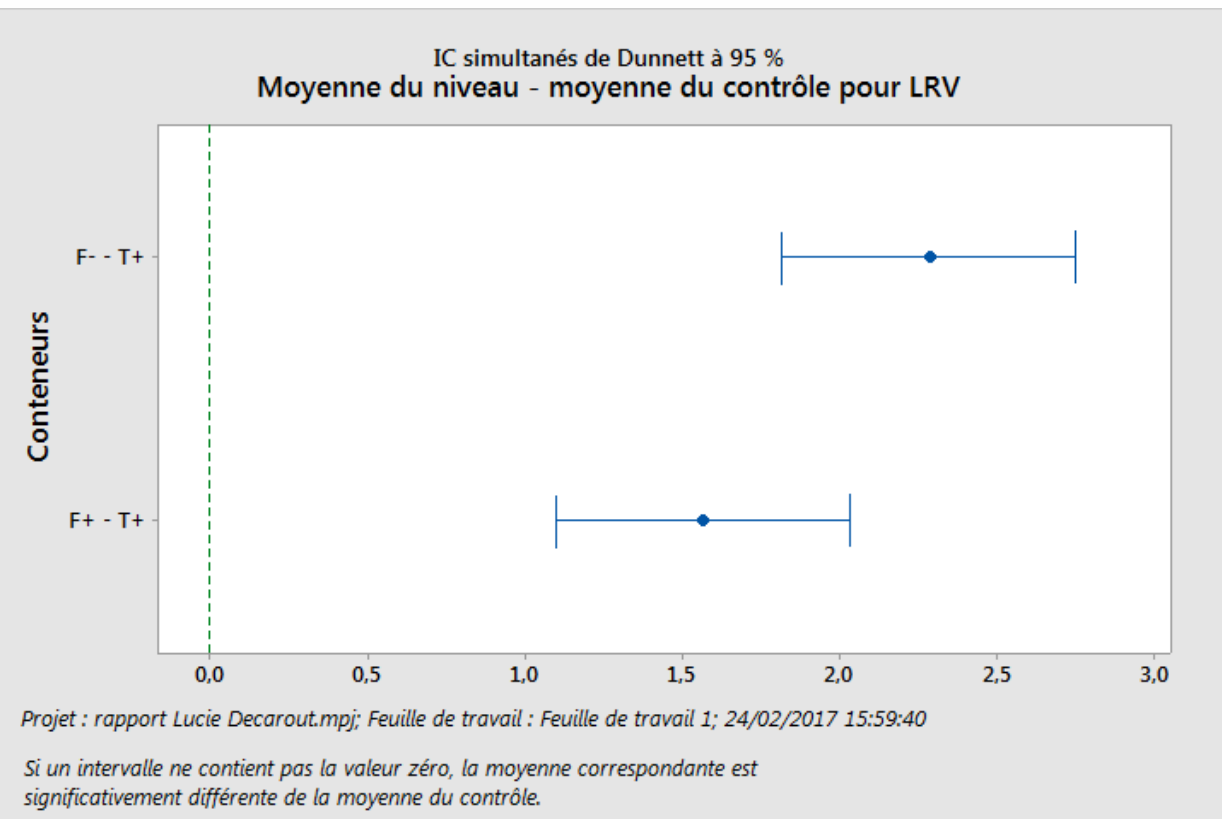

$\mathrm{T}_{+}=$témoins positifs ; F+ = conteneurs positifs au test à l'eau ; F- = conteneurs négatifs au test à l'eau

Figure 49 : Comparaisons multiples de Dunnett avec un contrôle : réponse $=\mathrm{LRV}$, terme $=$ Conteneurs 


\section{DISCUSSION}

Au cours de ce travail, nous avons souhaité vérifier l'intérêt et la pertinence du test de fuite à l'eau pour contrôler le maintien des performances des conteneurs de stérilisation. Pour répondre à ces questions, nous avons effectué plusieurs essais préliminaires avant d'élaborer le protocole d'étude final : détermination du volume d'air entrant dans les compositions stériles à la fin d'un cycle de stérilisation, observation des variations de pression à l'intérieur des emballages lors de leur transport et de leur stockage. Ces différents essais sont discutés et justifiés en première partie.

Détermination du volume d'air entrant dans les compositions à la fin d'un cycle de stérilisation

Afin d'apprécier les échanges gazeux s'effectuant au travers des systèmes de barrière stérile après stérilisation et au cours du refroidissement des compositions (Figure 33), nous avons mesuré, à l'aide de sondes de $T^{\circ} / P$ placées à l'intérieur de différents plateaux opératoire, le temps nécessaire pour revenir à la température ambiante. Après 120 minutes de refroidissement, la température à l'intérieur des plateaux est encore de $37^{\circ} \mathrm{C}$ et le retour à la température de $23^{\circ} \mathrm{C}$ ne s'effectue seulement qu'après $5 \mathrm{~h} 30$. Ces résultats, ainsi que l'ensemble des mesures associées, nous éclairent sur le délai de refroidissement nécessaire avant manipulation des articles lors du déchargement des stérilisateurs. Avec ces données, on comprend aisément que lors de la manipulation trop précoce des compositions stérilisées ou que lors de leur dépose sur une surface pleine, un risque d'endommagement ou de recondensation interne soit observé du fait de l'absence de refroidissement complet. Selon les BPPH «Le déchargement du stérilisateur est effectué après complet refroidissement ... et n'est pas source d'endommagement et de contamination ». Un délai minimum de 2 heures semble donc être un délai nécessaire avant toute manipulation des emballages stériles pour respecter cette recommandation. Ce résultat est proche de celui obtenu par Lefebvre et al (29) qui préconisait un temps minimum de $105 \mathrm{~min}$. comme délai standard de refroidissement des conteneurs. La différence retrouvée s'expliquant notamment par le site de relevé de température. Alors que nous considérons la $\mathrm{T}^{\circ}$ interne des paniers au contact des instruments, Lefebvre a mesuré la $\mathrm{T}^{\circ}$ de surface des conteneurs à l'aide d'un thermomètre infra-rouge.

Ce délai de refroidissement est justifié également lors d'une demande urgente par les utilisateurs de compositions directement issues du stérilisateur. Du fait de la température 
élevée des instruments en fin de cycle de stérilisation $\left(80^{\circ} \mathrm{C}\right)$, celle-ci ne permet par leur préhension par le chirurgien et pourrait également endommager les tissus du patient par brûlures. D'autre part, on observe d'après la figure 33, qu'il n'existe pas de différence de la vitesse de refroidissement selon le type d'emballage. Contrairement à toute attente, les conteneurs et leur contenu ne restituent pas plus vite que les paniers opératoires emballés sous non tissé, l'énergie calorifique accumulée au cours du cycle de stérilisation.

Les températures mesurées en sortie d'autoclave et après refroidissement nous ont permis de mesurer le volume théorique entrant dans nos compositions suite au phénomène de contraction des gaz lors de leur refroidissement. Après application de la loi des gaz parfaits, ce volume varie de 0,72 litres dans les paniers emballés et peut atteindre 2,45 litres dans les conteneurs (tableau VII). Selon les dimensions des conteneurs, certains auteurs décrivent un volume pouvant atteindre jusqu'à 6 litres (38). Dans les conditions normales, cet air entrant va traverser les systèmes de barrière stérile (SBS) empêchant ainsi la pénétration de micro-organismes à l'intérieur des emballages. Lors de l'utilisation de conteneurs présentant une atteinte de l'étanchéité de la jonction cuve/couvercle, une partie de cet air entrant pourrait pénétrer sans franchir ce SBS. Selon la qualité de l'air de la zone de déchargement, le nombre de poussières et de micro-organismes pourrait être relativement important. D'après Dunkelberg et al (30), l'efficacité de la barrière peut être influencée par différents facteurs et notamment la concentration de bactéries dans l'air ambiant. Actuellement, seules les zones de conditionnement des unités de stérilisation ont une exigence de maitrise de l'air définie selon les spécifications de la classe ISO 8 de la norme NF EN ISO 14644-1 (31). Dans son projet de révision des BPPH (32), la SF2S souhaite que cette exigence de classe ISO 8 soit également étendue à la zone de déchargement afin de prévenir la contamination des produits stérilisés lors de leur refroidissement.

Détermination des variations de pression en conditions réelles lors du stockage et du transport

Le transport joue un rôle important lors de la mise à disposition des compositions opératoires stériles d'autant que certains blocs opératoires ne se situent pas à proximité directe de l'unité de stérilisation. Dans certaines situations, il arrive même que les deux établissements se situent à des altitudes différentes donc à des pressions atmosphériques différentes. Lors du transport de nos compositions, II a été mesuré une variation de pression de 4 à 115 mbar (tableau VIII). D'après la loi de Mariotte, à température constante, la pression est inversement proportionnelle au volume. Cela entraine donc un appel d'air dirigé vers l'intérieur du conteneur lorsque la pression augmente, c'est-à-dire lorsque l'altitude 
diminue. Nous notons une variation du volume maximal mesuré de 2,4 litres dans ces conditions (tableau VIII). II est également intéressant de noter que la surpression d'une salle de bloc opératoire (+ $25 \mathrm{~Pa}$ ou + 0,25 mbar) n'a pas d'impact sur la variation de volume dans les paniers ou conteneurs stériles. De façon parallèle et contrairement aux hypothèses avancées par Dunkelberg (33), les variations de pression dues au transport en ascenseur n'ont qu'une faible incidence sur ces variations (Figure 37). Le transport en dehors de l'établissement est donc vraisemblablement la situation la plus à risque de contamination avec l'augmentation de pression atmosphérique. Les surpressions relatives présentes dans les arsenaux de stockage ou dans les salles de bloc opératoires ne semblent pas constituer des facteurs de contamination.

\section{Le protocole FD S98-053 comme test de performance}

Selon les BPPH, “Avant stérilisation, chaque conteneur réutilisable fait l'objet d'un contrôle visuel et son aptitude au fonctionnement est vérifiée selon les recommandations du fabricant ». D'après I'ISO 11607-1 paragraphe 5 «les critères d'acceptation doivent être établis pour l'inspection précédant chaque réutilisation". A ce jour, tous les établissements de santé équipés de conteneurs ne disposent pas d'une check-list de contrôles et seul, un fabricant de conteneurs, met à disposition des utilisateurs ce type de recommandations (24). Un autre document proposé par la SF2S est mis à disposition sur leur site web (32).

Si le contrôle visuel de fonctionnalité est à ce jour le principal test exécuté par les opérateurs en stérilisation, celui-ci est insuffisant pour détecter un défaut d'étanchéité de la jonction cuve/couvercle (3). Dans l'ISO 11607-1 " après formage du système de barrière stérile, les fermetures doivent constituer une barrière contre les micro-organismes » (7). Les fermetures sont définies comme "le moyen utilisé pour fermer un emballage lorsque aucun scellage n'est réalisé ", par exemple le joint du conteneur. Par conséquent, l'existence d'une fuite révélée par un test à l'eau positif ne pourrait-elle pas être à l'origine de pénétration de microorganismes dans les conteneurs ? Cette méthode de détection ne pourrait-elle compléter les contrôles visuels actuels?

Selon la même norme «l'intégrité $d u$ système barrière stérile doit être démontrée après la stérilisation et suivie d'essais de performances » (7). Concernant ces essais, la norme précise "les méthodes d'essais normalisées pour l'évaluation de l'intégrité du SBS sont préférées ". II est donc difficilement concevable que les contrôles de fonctionnalités par inspection visuelle correspondent aux essais de performance évoqués. Une question similaire se pose concernant le test à l'eau. Une réponse peut être apportée par d'autres éléments de la norme "en absence d'essais d'intégrités validés applicables au SBS, les 


\section{propriétés de performance de la barrière microbienne peuvent être établies en}

soumettant à essai les propriétés de barrière stérile des matériaux et l'intégrité des scellages et fermetures ". Le protocole FD S98-053(2) répond donc bien aux spécifications de la norme ISO 11607-1 et peut être considéré comme un essai de performance.

\section{Choix de la méthode}

Les essais préliminaires nous ont permis de démontrer que les variations de température et de pression sont des facteurs influençant le volume à l'intérieur des compositions stériles. Du fait de l'identification et l'existence de ces flux d'air, nous avons souhaité vérifier que l'impact d'une rupture d'étanchéité de la jonction cuve/couvercle n'avait aucune incidence sur le risque éventuel de pénétration de micro-organismes. En s'appuyant sur les exigences de la norme ISO 11607-1 "les essais de performance du SBS doivent être effectués dans les conditions les plus défavorables", nous avons élaboré, à partir d'une recherche bibliographique et des essais pratiques, les conditions d'un environnement conduisant au scénario le plus contraignant :

- Choix du micro-organisme: Microccocus luteus, Bacillus subtilis et Staphylococcus epidermidis sont les trois micro-organismes les plus fréquemment retrouvés dans la littérature (27) (28) (34) (33) (30). Micrococcus luteus, coccus Gram positif, de dimensions $<2 \mu \mathrm{m}$, non infectieux pour une personne en bonne santé et facile à obtenir auprès du laboratoire de microbiologie environnementale du CHMS a été retenu. D'autres auteurs préfèrent la méthode hollandaise du « test de l'emballage final » en utilisant des particules de latex de $1 \mu \mathrm{m}$ de diamètre. Cette méthode alternative nécessite un compteur de particules laser et la connexion de l'emballage sur une pompe à vide (35).

- Choix du mode et du milieu de culture : nous avions initialement employé des céramiques inertes (CeramTec Ceramic, laurens, SC, USA) comme support pour la fixation des contaminants environnementaux. Après exposition, ceux-ci étaient mis en culture dans un milieu TSA liquide. Cependant, du fait de l'impossibilité de comptabiliser le nombre d'UFC dans chaque tube positif, nous avons fait le choix d'utiliser des géloses solides. Un premier test a été effectué sur des boîtes de pétri conventionnelles mais celles-ci n'ont pas résisté à la température du cycle de stérilisation. Nous avons donc choisi de couler nos propres géloses dans des plaques de polypropylène résistantes à la température de stérilisation utilisée (cycle $125^{\circ} \mathrm{C}$, 20 min, 2.05 bar). La durée et température d'incubation ont été déterminées avec le service de microbiologie environnementale du CHMS. 
- Choix des pressions : 3 valeurs de pressions, 25, 50 et 75 mbar ont été choisies afin de provoquer une modification de la pression à l'intérieur des conteneurs. Ces valeurs de pressions ont été retenues car celles-ci étaient compatibles avec les variations observées lors du transport des compositions. La surpression était ajoutée dans une chambre étanche à l'aide d'une pompe à pied et après exposition, celle-ci était progressivement éliminée par ouverture la valve.

- Choix des conteneurs : à partir de conteneurs régulièrement maintenus et prélevés dans le circuit de retraitement, nous avons sélectionné des conteneurs présentant les caractéristiques souhaitées : 5 conteneurs satisfaisant l'ensemble des contrôles de fonctionnalité (visuel + test à l'eau négatif), 5 conteneurs présentant un test à l'eau positif (fuite), 5 conteneurs qui serviront de témoins positifs (sans filtre). Le facteur déterminant étant la réponse au test de fuite à l'eau.

Après sélection de tous ces paramètres, nous avons réalisé 15 séries de 3 conteneurs pour chacune des pressions.

Les résultats présentés dans les tableaux IX, X et XI révèlent parfois la présence de colonies autres que Micrococcus luteus. Ces autres espèces sont des staphylocoques, des bacilles ou encore des Acinetobacter. Ces bactéries absentes de l'aérosol ont pu s'introduire lors des différentes étapes du protocole: installation dans la chambre, réceptacle du nébuliseur, transfert vers le laboratoire de microbiologie, manipulation sous hotte ou encore scellage des emballages. La présence de ces nouveaux contaminants n'est pas surprenante si l'on considère nos témoins positifs, car ceux-ci pouvaient s'introduire à tout moment de la manipulation du fait de l'absence de filtres. Cependant, la révélation d'une contamination exogène pour au moins un témoin négatif $(\mathrm{F}-)$ de chaque série de pression, démontre la difficulté d'effectuer une manipulation de façon totalement aseptique. Cela est d'autant plus vrai que, bien que les sachets d'emballage finaux des plateaux aient été préalablement stérilisés, la réalisation de la soudure finale ne s'est pas effectuée avec une soudeuse ellemême stérile. Ces risques de contaminations lors de manipulation sont largement décrits dans la littérature (36) et constituent l'inconvénient principal de ces méthodes de test de stérilité. En tout état de cause, ces colonies exogènes sont relativement peu nombreuses dans notre étude et demeurent inférieures au seuil de 2 UFC/plateau.

Selon nos résultats, $100 \%$ des témoins positifs (sans filtres) sont contaminés et ceci quel que soit la pression exercée. Ce résultat tout à fait logique valide le principe de recueillement de Micrococcus luteus et la bonne tenue de nos géloses après stérilisation (absence de dessèchement). Plus surprenant concerne ceux obtenus avec les conteneurs 
considérés fonctionnels (F-). Pour chacune des pressions, un pourcentage relativement élevé de compositions contaminées est observé : $27 \%$ à 25 mbar, $27 \%$ à 50 mbar et $40 \%$ à 75 mbar. Ce résultat nous amène à plusieurs réflexions. Le niveau de $10^{8}$ bactéries est-il un seuil trop élevé pour la barrière filtrante d'un conteneur? Les pressions exercées, bien que compatibles avec des évènements susceptibles de survenir pendant le transport sont-elles trop élevées ? Les conteneurs représentent-ils un SBS satisfaisant ? Une réponse partielle est apportée par Harry et al (27) qui ont étudiés le comportement de 111 conteneurs vs 161 emballages souples lors de l'exposition à un aérosol de $10^{8}$ Micrococcus luteus. Les résultats de cette étude confirment la contamination de $87 \%$ des conteneurs avec un taux significativement plus élevés en fonction de leur âge. L'étude ne précise pas si ceux-ci étaient régulièrement maintenus. Un résultat similaire est obtenu dans une étude menée par Dunkelberg (33) qui démontre la contamination de $83 \%$ de containers soumis à l'exposition de contaminants à l'exception des conteneurs récents ( $<2$ ans) et disposant d'un filtre permanent. En conséquence, les résultats obtenus avec nos conteneurs ( $F-$ ) ne sont pas incompatibles avec les observations de la littérature.

Lors du traitement de nos résultats, nous avions initialement exprimé ceux-ci sous la forme d'un \% de barrière filtrante. Un pourcentage de 99,9964 \% de capacité de rétention des micro-organismes pouvait être obtenu et calculé (tableau IX série 2). En réalité ce mode d'expression des résultats, également utilisé par Junghann (15)(37) dans ses travaux est insuffisant pour démontrer les performances de la barrière filtrante des conteneurs. Ce taux de rétention de $99.9964 \%$ correspond en réalité à la pénétration de 23 UFC de Micrococcus dans l'emballage. Peut-on qualifier d'efficace une barrière laissant pénétrer 23 UFC de micro-organismes?

D'après Dunkelberg et al (33), l'expression des résultats en facteur de réduction logarithmique (LRV) serait plus adaptée pour démontrer et apprécier le rôle des barrières filtrantes. Si l'on considère un LRV $\geq 6$ comme le garant d'un produit stérile et du rôle de barrière filtrante, on constate effectivement que quel que soit la série considérée, le nombre de micro-organismes est inférieur ou égal à 1. Si l'on s'intéresse au LRV de chaque groupe de conteneurs, on observe : LRV $(F-)>\operatorname{LRV}(F+)>L R V(T+)$. Ce classement est logique du fait que les conteneurs exempts de fuite doivent présenter un LRV supérieur ou égal à 6 pour correspondre à la définition de l'état stérile alors que les témoins positifs, donc nécessairement non stériles, disposent d'un LRV faible.

D'autre part, l'analyse statistique révèle que plus la pression est basse et plus le LRV est faible (Figure 46). Ceci pourrait s'expliquer par le fait que l'action d'une pression élevée 
serait susceptible de masquer la fuite par compression du couvercle sur la cuve. Cependant dans le cas d'une fuite importante, cette pression n'est sans doute pas assez élevée pour comprimer l'orifice de la fuite. II n'a pas été décidé lors ce travail de quantifier la fuite mais seulement de la qualifier : absence ou présence. II serait sans doute intéressant de pouvoir le réaliser. Le test aux ultrasons serait une piste à explorer. Cette quantification nous permettrait de vérifier l'hypothèse de l'effet pression sur la fuite et le LRV.

Dans la figure 49, la comparaison multiple de Dunnett nous permet d'évaluer la signification statistique de différences entre des moyennes à l'aide des intervalles de confiance. Au seuil alpha $=5 \%$, il existe une différence statistiquement significative entre les conteneurs sans fuite $(F-)$ et les conteneurs positifs au test à l'eau $(F+)$ ( $p$-valeur=0,002). Ceci montre que l'existence d'un défaut d'étanchéité de la jonction cuve/couvercle influence la valeur du LRV et donc les performances de la barrière filtrante.

De même, la figure 48 montre une différence statistiquement significative entre le témoin positif $(T+)$ et les conteneurs $(F+)$ (alpha $=5 \%$, p-valeur $=0,002)$ Ce résultat démontre la différence de comportement entre ces 2 groupes de conteneurs bien qu'aucun des deux ne soit capable de garantir le maintien de la stérilité

Enfin, la répartition du nombre d'UFC en fonction du type de conteneur et de la pression exercée, nous montre une forte proportion d'UFC dans les témoins positifs $\left(T_{+}\right)$par rapport aux conteneurs ayant un test de fuite négatif ( $F-$-). A la pression de 25 mbar, nous obtenons $73 \%$ d'échantillons supérieures à 100 UFC pour les témoins positifs $(T+)$ et $73 \%<$ 1 colonie pour les conteneurs témoins négatif. Cette observation est confirmée par l'analyse multivariée de la figure 49 qui confirme qu'il existe une différence significative entre $(T+)$ et (F-).

Pour la réalisation de cette étude, nous avons fait le choix de ne pas utiliser d'instruments dans les conteneurs pendant les tests afin d'exposer totalement les plaques de géloses à l'aérosol de Micrococcus. La présence d'un plateau d'instrument sur le dessus des géloses, aurait probablement créé un obstacle physique. Il serait éventuellement intéressant de réaliser cette étude uniquement avec des instruments à l'intérieur des conteneurs car la présence de gélose favorise la révélation et la croissance des microorganismes. II est envisageable de considérer qu'en l'absence de géloses placées directement dans le fond des conteneurs, le nombre de colonies identifiées sur un support inerte serait nettement inférieur. En effet il n'est pas impossible que le comportement inerte des instruments limite le développement des colonies. 
A partir des résultats de cette étude nous pouvons conclure que les contrôles visuels de fonctionnalité des conteneurs sont insuffisants pour évaluer leurs performances avant chaque réutilisation. Contrairement à l'affirmation de certains fabricants soutenant que « l'efficacité de la barrière microbienne n'est pas liée à l'étanchéité des conteneurs », cette étude montre qu'une rupture d'étanchéité de la jonction cuve/couvercle ne permet pas de garantir le maintien de l'état stérile à l'intérieur de ces conteneurs. Le test à l'eau proposé dans le document FD S98-053 permet d'évaluer l'étanchéité de cette jonction et met donc en évidence la défectuosité de la barrière microbienne. Afin de prévenir ce défaut, une maintenance régulière des conteneurs réutilisables est indispensable. L'application de ce test pourrait également être effectuée par les sociétés en charge de ces prestations de maintenance afin de vérifier l'efficacité des travaux exécutés. A ce jour la fréquence de ce test n'est pas définie mais celui-ci est facilement réalisable et applicable pour les établissements de santé soucieux de la qualité des emballages utilisés. L'utilisation de conteneurs défectueux et présentant notamment un test à l'eau positif pourrait compromettre la sécurité des patients. 


\section{CONCLUSION}

Dans la pratique quotidienne, il n'est pas possible de vérifier l'état stérile de chaque composition opératoire avant son utilisation. Ainsi pour garantir la stérilité du produit final, les étapes du processus de stérilisation doivent être parfaitement maîtrisées et un contrôle final de l'intégrité des emballages doit être réalisé juste avant l'utilisation du produit stérile. Dans le cas des emballages souples, la recherche de déchirures ou de perforations compromettant la stérilité du dispositif emballé est relativement aisée. Inversement, dans le cas des conteneurs réutilisables, il n'existe pas de contrôles similaires pour identifier une rupture d'intégrité. Pour ces derniers, il est donc nécessaire d'effectuer, avant chaque recomposition, des contrôles de fonctionnalité afin de s'assurer du maintien de leurs performances. Le test de fuite à l'eau est l'un des tests proposé et appliqué par certains établissements de santé en France. A ce jour, ce test est très controversé par les fabricants d'emballages réutilisables. Ceux-ci prétendant le maintien de la stérilité de conteneurs présentant un test de fuite positif. Au cours de ce travail, nous avons souhaité vérifier l'intérêt et la pertinence du test de fuite à l'eau pour évaluer le maintien des performances des conteneurs de stérilisation avant réutilisation.

Dans un premier temps, afin de déterminer l'effet des principaux facteurs pouvant provoquer la pénétration d'air et de micro-organismes dans les emballages réutilisables, nous avons observé et analysé les variations de pression et de température pouvant survenir lors du stockage et du transport de compositions stériles. Dans un second temps, afin de vérifier l'aptitude de la barrière filtrante de conteneurs positifs au test de fuite à l'eau, nous avons placé ces emballages dans une chambre d'aérosolisation pour simuler leur exposition à un air contaminé. 5 séries de 3 conteneurs ont été exposées à un aérosol de Micrococcus luteus au cours de 3 variations de pressions différentes : 25, 50 et 75 mbar. Des plaques de gélose TSA à l'intérieur des emballages ont permis de révéler l'éventuelle présence de microorganismes après 5 jours de culture à $37^{\circ} \mathrm{C}$. Les résultats en UFC/ plateau sont convertis en facteur de réduction logarithmique (LRV) afin d'apprécier l'efficacité de la barrière filtrante.

Les résultats des premiers essais montrent que lors du refroidissement des compositions après stérilisation, un volume d'air pouvant atteindre 3 litres peut pénétrer à l'intérieur des conteneurs. Ce volume d'air entrant peut atteindre 2.4 litres lors du transport entre deux établissements situés à des altitudes différentes. Les surpressions habituellement présentes dans les salles de bloc opératoire (25 Pa) ne sont pas suffisantes pour provoquer de flux d'air vers l'intérieur des emballages. 
Concernant la pénétration de micro-organismes, les résultats de notre étude confirment que les conteneurs présentant un test de fuite à l'eau positif (fuite), sont significativement plus contaminés que des conteneurs négatifs au test ( $p$-valeur=0,002). D'autre part une même différence significative est observée entre des conteneurs ne disposant pas de barrière filtrante et ceux positifs au test de fuite ( $p$-valeur=0,002). Par ailleurs, l'application d'une surpression peut être retenue comme un facteur favorisant la pénétration de micro-organismes à l'intérieur des emballages stériles. D’après ces résultats, le test de fuite à l'eau peut être considéré comme discriminant pour apprécier le maintien des performances de la jonction cuve/couvercle des conteneurs réutilisables.

En conséquence, les conteneurs positifs au test devraient être retirés du circuit de retraitement et faire l'objet d'une maintenance curative avant toute réutilisation.

VU ET PERMIS D'IMPRIMER

Grenoble, le : 20103/297

LE DOYEN

LE PRESIDENT DE LA THESE

\section{Pr. Michel SEVE}

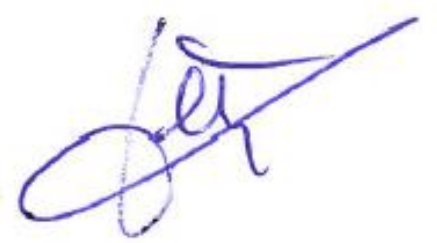

\section{Dr Raphaële GERMI}

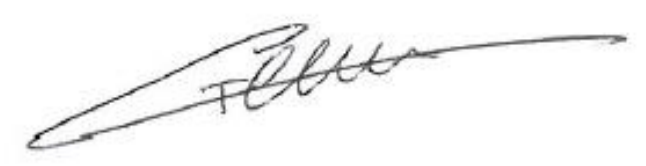




\section{BIBLIOGRAPHIE}

1. Arrêté du 22 juin 2001 relatif aux Bonnes Pratiques de Pharmacie Hospitalière.

2. AFNOR. FD S98-053 Protocole d'essais à effectuer sur les systèmes de barrière stérile réutilisables (conteneurs) afin d'évaluer l'étanchéité de la fermeture Cuve/Couvercle. 2014.

3. Lambert C. Contrôle de performance des conteneurs : intérêt du test à l'eau [Internet]. JIFS; 2014. Disponible sur: http://docplayer.fr/10997828-Controle-de-performance-desconteneurs-interet-du-test-a-l-eau.html

4. Décret $\mathrm{N}^{\circ}$ 2000-1316 du 26/12/00 relatif aux Pharmacies à Usage Intérieur.

5. Brischoux S, Maillan G, Cubertafond A. Les systèmes d'emballage des dispositifs médicaux en stérilisation. avril-juin 2010;Tome XXIX(2):128-32.

6. AFNOR. Norme NF EN 868-3. Matériaux et systèmes d'emballage pour les dispositifs médicaux stérilisés au stade terminal - Partie 3 : papier utilisé dans la fabrication des sacs en papier (spécifiés dans l'EN 868-4) et dans la fabrication de sachets et gaines (spécifiés dans I'EN 868-5). Octobre 2009.

7. Norme NF EN ISO 11607-1: Emballages des dispositifs médicaux stérilisés au stade terminal - Partie 1: Exigences relatives aux matériaux, aux systèmes de barrière stérile et aux systèmes d'emballage. La Plaine Saint-Denis; Août 2009.

8. Documentation technique. Emballage ONE STEP®. HALYARD KIMGUARD; 2017.

9. Thiveaud D. Emballages de stérilisation à usage unique. Hygiène en milieu hospitalier. Vol. 17. 1999. 17-24.

10. Goullet D, Deweerdt C, Valence B, Calop J. Fiches de stérilisation. HYGIENES. $1996 ; 41$.

11. AFNOR. Norme NF EN 868-5. Matériaux et systèmes d'emballage pour les dispositifs médicaux stérilisés au stade terminal - Partie 5: sachets et gaines thermoscellables constitués d'une face matière poreuse et d'une face film plastique. Septembre 2009.

12. Documentation technique. Système de Barrière Stérile «ULTRA ». AMCOR; 2013.

13. Documentation technique. Systèmes SteriSet ${ }^{\mathrm{TM}}$. LANDANGER; 2011.

14. Valence B. Application de la norme EN 11607 aux conteneurs. Journée AFS; 11 mars 2011.

15. JunghannB U. Résultats de l'évaluation des performances de stérilisation et de l'aptitude au stockage des conteenurs MicroStop(r). KLS Martin Group. 20 janv 2005;

16. Harald S, Eckehard W. Documentation technique conteneur de stérilisation MicroStop(r). KLS MARTIN GROUP; 2000.

17. http://www.materiel-sterilisation.com/permafiltr/1-1/permafilt-39r\%C2\%AE-gamme- 
classique-600×300×110-mm-p-1059.html consulté en février 2017

18. Documentation technique. Système de containers de stérilisation. Prospectus C40403 - 09/09 ; AESCULAP ; 2009.

19. Schlich, T. "Asepsis and Bacteriology: A Realignment of Surgery and Laboratory Science. Medical History. 2012;308-34.

20. Truax Charles. The Mechanics of Surgery. Norman Publishing. San Francisco; 1899. 157-158.

21. Guillot F. Appareils et instruments pour la médecine la chirurgie l'orthopédie. Impr. des Ets Hyperparaf. Paris; 1934. 21-24.

22. https://www.aesculapusa.com/assets/base/doc/DOC132_RevE-

SterilContainer_SystemCatalog.pdf consulté en janvier 2017.

23. https://www.bbraun.fr/content/dam/catalog/bbraun/bbraunProductCatalog/CW_FR/fr$\mathrm{fr} / \mathrm{b} 5 / g$ eneration-de-conteneurs.pdf.bb-.06308464/generation-de-conteneurs.pdf consulté en janvier 2017.

24. https://www.bbraun.fr/content/dam/catalog/bbraun/bbraunProductCatalog/CW_FR/fr$\mathrm{fr} / \mathrm{b} 5 /$ controle-de-fonctionnaliteconteneur.pdf.bb-.07174384/controle-de-

fonctionnaliteconteneur.pdf consulté en janvier 2017.

25. AFNOR. Norme NF EN 868-8. Matériaux et systèmes d'emballage pour les dispositifs médicaux stérilisés au stade terminal - Partie 8 : conteneurs réutilisables de stérilisation pour stérilisateurs à la vapeur d'eau conformes à l'EN 285. La Plaine Saint-Denis ; 2009.

26. Cavin F. Analyse de risque suite aux contrôles d'étanchéité des jointes des conteneurs dans plusieurs établissements suisses. 16èmes congrès WFHSS; 2015; Lille.

27. Harry L, Shaffer M, Delbert A, Harnish M, Michael McDonald M, Reid A. Vernon B, et al. Sterility maintenance study: Dynamic evaluation of sterilized rigid containers and wrapped instrument trays to prevent bacterial ingress. Am J Infect Control. dec 2015;43(12):1336-41.

28. Dunkelberg $\mathrm{H}$, Schmelz $\mathrm{U}$. Determination of the efficacy of sterile barrier systems against microbial challenges during transport and storage. Infect Control Hosp Epidemiol. févr 2009;30(2):179-83.

29. Lefebvre M, Combe L, Leclercq P-F, De Faria A, Cousin M-O, Demailly S. Détermination du délai nécessaire au refroidissement complet de l'instrumentation des containers avant leur libération. 36ème journée CEFH; 2014.

30. Dunkelberg $\mathrm{H}$, Wedekind $\mathrm{S}$. Preliminary results for a new final package test to assess the quality of sterile package systems. Infect Control Hosp Epidemiol. janv 2004;25(1):26-9.

31. Norme NF EN ISO 14644-1: Salles propres et environnements maîtrisés apparentés - Partie 1 : classification de la propreté particulaire de l'air. Décembre 2015.

32. Société Française des Sciences de la Stérilisation http://www.sf2s-sterilisation.fr/ 
consulté en mars 2017.

33. Dunkelberg H, Fleitmann-Glende F. Measurement of the microbial barrier effectiveness of sterilization containers in terms of the log reduction value for prevention of nosocomial infections. Am J Infect Control. juin 2006;34(5):285-9.

34. Moriya GA de A, Graziano KU. Sterility maintenance assessment of moist/wet material after steam sterilization and 30-day storage. Rev Lat Am Enfermagem. août 2010;18(4):786-91.

35. Kastelein J, Vossen V. Influence of prion cycle on the bacterial barrier performance of sterilisation wrap according to the final pack test. Cent Serv. 2013;4:281-4.

36. Butt W, Bradley D, Mayhew R. Evaluation of the shelf life of sterile instrument packs. Oral Surgery, Oral Medicine, Oral Pathology, Oral Radiology, and Endodontics. $72^{\mathrm{e}}$ éd. 1991;

37. JunghannB U, Winterfield S, Gabele L, Kulow U. Hygienic-Microbiological and Technical Testing of Sterilizer Container Systems. Zentr Steril. 1999;(7):154-62. 


\section{Faculté de Pharmacie, \\ Université Joseph Fourier Grenoble I.}

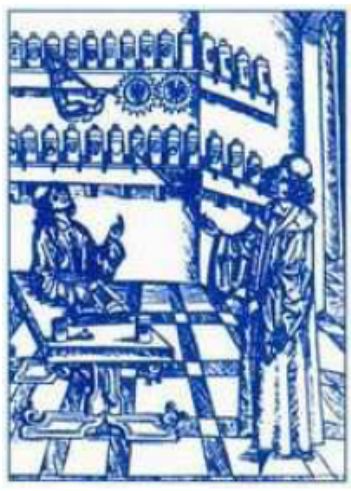

\section{Serment \\ de \\ Galien}

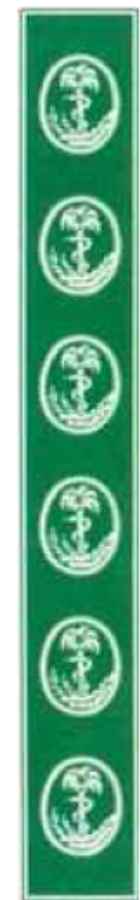

« Je jure en présence des Maîtres de la Faculté, des Conseillers de l'Ordre des Pharmaciens et de mes condisciples:

D'honorer ceux qui m'ont instruit(e) dans les préceptes de mon art et de leur témoigner ma reconnaissance en restant fidèle à leur enseignement.

D'exercer, dans l'intérêt de la santé publique, ma profession avec conscience et de respecter non seulement la législation en vigueur, mais aussi les règles de l'honneur, de la probité et du désintéressement.

De ne jamais oublier ma responsabilité et mes devoirs envers le malade et sa dignité humaine ; en aucun cas, je ne consentirai à utiliser mes connaissances et mon état pour corrompre les mœurs et favoriser des actes criminels.

Que les hommes m'accordent leur estime si je suis fidèle à mes promesses. Que je sois couvert(e) d'opprobre et méprisé(e) de mes confrères si j'y manque ". 
EVALUATION DE L'INTERET DU TEST DE FUITE A L'EAU POUR LE CONTROLE DE FONCTIONNALITE DES CONTENEURS DE STERILISATION

\section{RESUME :}

Le conteneur est un emballage réutilisable qui doit permettre d'assurer le maintien de la stérilité jusqu'au point d'utilisation. Afin de vérifier la préservation des performances de ces emballages, certaines unités de stérilisation utilisent le test de fuite à l'eau. A ce jour, ce contrôle de fonctionnalité n'est ni retenu, ni reconnu par les fabricants. L'objectif de ce travail est de vérifier le maintien de la stérilité à l'intérieur des conteneurs lorsque le test de fuite est positif (rupture d'étanchéité cuve/couvercle). Afin d'identifier les conditions pouvant modifier l'efficacité de la barrière microbienne, les variations de pression et de température ont été relevées lors du stockage et transport. Au total, 5 séries de 3 conteneurs (témoin positif sans barrière filtrante, conteneur avec test de fuite à l'eau négatif et positif) ont été exposées, après stérilisation, à un aérosol de Micrococcus luteus dans une chambre étanche à différentes pressions : 25, 50 et 75 mbar. Préalablement, des plaques de gélose étaient disposées au fond des conteneurs puis mises en culture après exposition pendant 5 jours à $37^{\circ} \mathrm{C}$. Les résultats en UFC ont été convertis en facteur de réduction logarithmique (LRV) afin d'apprécier l'efficacité de la barrière filtrante. Les résultats confirment que la surpression est un facteur favorisant de la pénétration de micro-organismes dans les conteneurs. D'autre part, les conteneurs présentant un test positif sont significativement plus contaminés que des conteneurs disposant d'une étanchéité parfaite ( $p$-valeur=0,002). Le test de fuite à l'eau peut donc être considéré comme discriminant pour évaluer le maintien des performances des conteneurs.

MOTS CLES: stérilisation, système de barrière stérile, test de fuite à l'eau, contamination, conteneurs

ADRESSE : [Données à caractère personnel]

FILIERE : PHARMACIE HOSPITALIERE PRATIQUE ET RECHERCHE 